BNL- - 52326

DE92 016755

\title{
ENHANCED CONVECTIVE AND FILM BOILING HEAT TRANSFER BY SURFACE GAS INJECTION
}

\author{
*M.R. Duignan, G.A. Greene, and **T.F. Irvine, Jr.
}

April 1992

*EXPERIMENTAL. HEAT TRANSFER AND FLUID DYNAMICS GROUIP DEPARTMENT OF NUCLEAR ENERGY BROOKHAVEN NATIONAL LABORATORY, ASSOCIATED UNIVERSITIES, INC. UPTON, LONG ISLAND, NEW YORK 11973

*"DEPARTMENT OF MECHANICAL ENGINEERING STATE UNIVERSITY OF NEW YORK STONY BROOK. LONG ISLAND, NEW YORK 11794

UNDER CONTRACT NO. DE-ACO2-76CHODO16 WITH THE UNITED STATES DEPARTMENT OF ENERGY 


\section{DISCLAIMER}

This report was prepared as an account of work sponsored by an agency of the United States Government. Neither the United States Government nor any agency thereof. nor any of their employees, nor any of their contractors, subcontractors, or their employees, makes any warranty, express or implied, or assumes any legal liability or responsibility for the accuracy, completeness, or usefulness of any information, apparatus, product, or process disclosed, or represents that its use would not infringe privately owned rights. Reference herein to any specific commercial product, process, or service by trade name, trademark, manufacturer, or otherwise, does not necessarily constitute or imply its endorsement, recommendation, or favoring by the United States Government or any agency, contractor or subcontractor thereof. The views and opinions of authors expressed herein do not necessarily state or reflect those of the United States Government or any agency, contractor or subcontractor thereof.

Printed in the United States of America

$$
\text { Available from }
$$

National Technical Information Service

U.S. Depertment of Commerce

5285 Port Royal Road

Springfield, VA 22161

NTIS price codes:

Printed Copy: A06; Microfiche Copy: A01 


\section{ABSTRACT}

Heat transfer measurements were made for stable film boiling of water over a horizontal, flat stainless steel plate from the minimum film boiling point temperature, $T_{\text {SUAFACE }} \sim 500 \mathrm{~K}$, to $T_{\text {SUAFACE }} \sim 950 \mathrm{~K}$. The pressure at the plate was approxinately 1 atmosphere and the temperature of the water pool was maintained at saturation. The data were compared to the Berenson film-boiling model. which was developed for minimum film-boiling-point conditions. The model accurately represented the data near the minimum filin-boiling point and at the highest temperatures measured, as long it was corrected for the heat transferred by radiation. On the average, the experinental data lay within $\pm 7 \%$ of the model.

Measurements of heat transfer were made without film boiling for nitrogen jetting into an overlying pool of water from nine 1-imm-diameter holes, drilled in the heat transfer plate. The heat flux was maintained constant at approximately $26.4 \mathrm{~kW} / \mathrm{m}^{2}$. For water-pool heights of less than $6 \mathrm{~cm}$ the heat transfer coefficient decreased linearly with a decrease in height. Alove $6 \mathrm{cIII}$ the heat transfer coefficient was unaffected. For the entire range of gas velocities measured $[0$ to $8.5 \mathrm{~cm} / \mathrm{s}]$, the magnitude of the heat transfer coefficient only changed by approximately $20 \%$. The heat transfer data bound the Konsetov model for turbulent pool heat transfer which was developed for vertical heat transfer surfaces. This agreement suggests that surface orientation may not be important when the gas jets do not locally affect the surface heat transfer.

Finally, a database was developed for heat transfer from the plate with both film boiling and gas jetting occurring simultaneously, in a pool of water maintained at its saturation temperature. The effect of passing nitrogen through established film boiling is to increase the heat transfer from that surface. At the highest superficial gas velocity measured, approxillately 8.5 $\mathrm{cm} / \mathrm{s}$, and for a constant surface temperature, the heat transfer increases by a factor of two over the heat transfer with no enhancement by gas flux. Further, as the superficial gas velocity approaches zero, the data approach the stable filin boiling data. A semi-empirical model was developed and correlated to the database representing better than $90 \%$ of all the measured data within $\pm 15 \%$ bounds. 


\section{EXECUTIVE SUMMARY}

An experimental apparatus was constructed so that film boiling could be sustaired over a heated horizontal, flat surface with a non-condensihle gas flux from the surface. The heat transfer surface was a polished stainless-steel plate with nine jet holes whose locations conform to the observed (Duignan et a1., 1989) Taylor instability theory. On the plate sat a $10.16 \mathrm{~cm}$ inside diameter quartz tube to contain the water. The primary measurements made were: the plate-to-water heat fluxes by conduction and condensation, the plate surface temperatures by extrapolation from embedded thermocouples in the plate, and the superficial gas velocities from the jet holes in the plate.

For the stable film boiling asymptote, there were no gas jet holes in the heat transfer surface; both visual observations of the boiling and heat transfer measurements were made. The boiling pool was maintained at the saturation temperature and the pressure was atmospheric. The observations included measurements of the diameter, release period, and the interspacing of the bubbles. From these observations the film boiling heat flux could be determined. Heat transfer measurements were made at surface superheats of 143 to $567 \mathrm{~K}$ and surface heat fluxes of 27 to $116 \mathrm{~kW} / \mathrm{m}^{2}$. A comparison was made to the stable film boiling model of Berenson (1961).

For the pool bubbling asymptote, the plate-to-water heat flux was held constant at approximately $26 \mathrm{~kW} / \mathrm{m}^{2}$ while heat transfer measurements were made. The superficial gas velocity range was from 0.6 to $10 \mathrm{~cm} / \mathrm{s}$ while the pool height was varied from 2 to 15 cin of water. The effect of the water pool height on the heat transfer was observed.

Finally, measurements were made of film boiling heat transfer with a gas flux from the heated surface. The pool was maintained at saturation and at atmospheric pressure. The heat fluxes ranged from 48 to $215 \mathrm{~kW} / \mathrm{m}^{2}$ and the surface superheats from 166 to $552 \mathrm{~K}$. The superficial gas velocities were varied from 0.6 to $10 \mathrm{~cm} / \mathrm{s}$. On the basis of this database, a semi-empirical inodel was developed.

From this investigation the following conclusions were made and are broken down into three separate categories, i.e., stable film boiling, pool bubbling, and film boiling with gas-flux-enhancenent.

\section{Stable Film Boiling}

1.) From visual observations of stable film boiling over a large horizontal flat surface, bubbles are released in an orderly pattern which conforms to a square grid with a cell dimension of the most dangerous wavelength, $\lambda_{d}$. 
2.) The heat flux in film boiling over a large horizontal flat surface at a single superheat can be estimated within $25 \%$ of the actual heat flux by measurements of: the most dangerous wavelength, $\lambda_{d}$, the bubble release diameter, $D$, and the bubble release period, $\tau$, assuming that two bubbles are released from an area equal to $\lambda_{d}{ }^{2}$ per period.

3.) On the average, the Berenson film boiling model (1961) represents the heat flux from a large horizontal flat surface, over which film boiling of water occurs, within $7 \%$. Further, the model is applicable near the minimum film boiling point and up to surface temperatures of, at least, $950 \mathrm{~K}$, as long as the radiation contribution to the heat flux is included.

\section{Pool Bubbling}

1.) For the chosen pattern of gas jet holes in the heat-transfer surface and a pool diameter of $10.16 \mathrm{~cm}$, it was found that, at a constant superficial gas velocity, the heat traisfer coefficient decreased when the pool height fell below $6 \mathrm{~cm}$. Above pool heights of $6 \mathrm{~cm}$ the heat transfer coefficient remained relatively constant. The bubbling pool was visually turbulent at all heights but was less so at its lowest, $2.5 \mathrm{~cm}$. The reduction in the measured heat transfer coefficient was probably caused by a reduction in the turbulent eddy movement or a reduction in the turbulent eddy size itself. However, direct measurements of the eddies were not made.

2.) For pool heights greater than $6 \mathrm{~cm}$, the heat transfer coefficient was found to be a weak function of the superficial gas velocity. It appears that the main effect of the "sparsely" located jets was to maintain the pool turbulent and well mixed, since no perceivable change in the surface heat transfer occurred when the gas stopped exiting the gas holes as bubbles and became a jet. Over the range measured, changes in the jet velocity did little to change the general level of agitation in the pool.

\section{Film Boiling with Gas-Flux-Enhancement}

1.) Over the range of superficial gas velocities investigated, the effect of the gas jetting on the filin boiling was to increase the surface heat transfer, at a constant surface superheat. The increase is approximately two-fold over heat. transfer without gas jetting at a superficial gas velocity of apprnximately 8.5 $\mathrm{cm} / \mathrm{s}$.

2.) The heat transfer is increased by gas jetting at all the surface superheats investigated.

3.) When the surface superheat is close to the minimum film-boiling point, the introduction of the gas jets tends to cause the film to collapse to nucleate 
boiling, unless the surface temperature is increased. This finding suggests that the required minimum film boiling superheat may increase with an increase in the superficial gas velocity.

4.) A semi-empirical model developed for gas-flux-enhanced film boiling is,

$$
N u_{f}\left(j_{g}\right) / N u_{f}\left(j_{g}=0\right)=\left(1+\beta_{1} j_{g} / \beta_{11}\right)^{1 / 4}
$$

and represents all the experimental data for water with an uncertainty of $\pm 15 \%$. The dimensionless coefficient $\beta_{11}=(.425)^{4}$ is from Berenson (1961) and $\beta_{1}=0.068(\mathrm{~cm} / \mathrm{s})^{-1}$ was determined by correlation with the experimental data. 


\section{ACKMOWLEDGMENTS}

The authors wish to thank the technical staff, James H. Klein, Charles C. Finfrock, John R. Klages and Carl E. Schwarz for their assistance in the construction of the experimental apparatus.

The authors acknowledge the support of Dr. S. B. Burson during the course of the investigation. 
Page

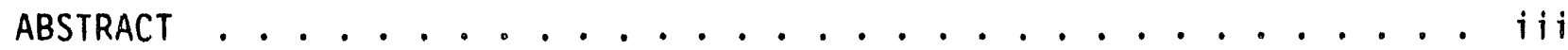

EXECUTIVE SUMMARY . . . . . . . . . . . . . . . . . . . V ACKNOWLEDGEMENTS . . . . . . . . . . . . . . . . . . viii

LIST OF FIGURES . . . . . . . . . . . . . . . . . . . . . xi

LIST OF TABLES . . . . . . . . . . . . . . . . . . . xii

NOMENCLATURE ............................................. xii

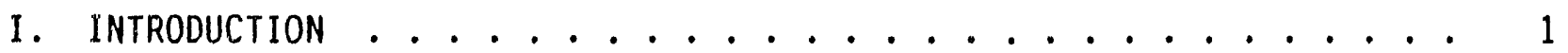

II. REVIEW OF THE Literature . . . . . . . . . . . . . . . 3

Filill Boiling ........................ 3

Pool Bubbling . . . . . . . . . . . . . . . . 10

III. ANALYTICAL MODEL . . . . . . . . . . . . . . . . 13

The Problem ...................... 13

The Assumptions..................... . . 17

A Solution .................... . . . 18

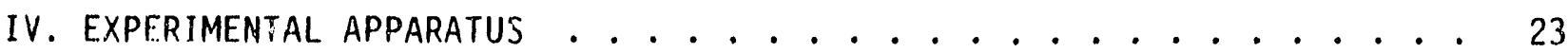

Overview ..................... . . . . . . . . . . . . . .

Test Pool . . . . . . . . . . . . . . . . . . 23

Heat Transfer Surface ................... . 26

Condensing Systern . . . . . . . . . . . . . . . . 31

fas Flow System....................... 33

Data Acquisition Systenn................ . . . 33

V. PRESENTATION OF nESULTS . . . . . . . . . . . . . . . . . 34

Filın Boiling Over a Horizontal Flat Surface . . . . . . . 34

a. Visual Observations of Filin Boiling ......... 34

b. Film Boiling with No Gas injection.......... 38

Gas Jetting into an Overlying Liquid Pool . . . . . . . . . . 41

Filın Boiling and Gas Jetting Combined . . . . . . . . . . . 45

a. Database Dn Gas-Flux-Enhanced Filin Boiling. . . . . . . 46

b. Correlation of Experimental Data to the Semi-Empirical

Model................... 48 
VI. SUMMARY AND CONCLUSIONS ................... 51

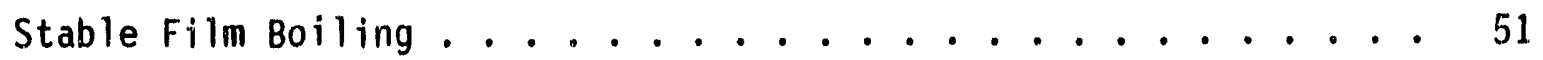

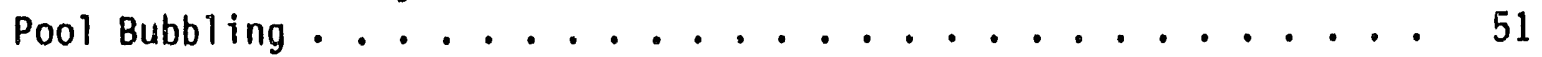

Film Boiling with Gas Flux Enhancement .......... 52

VII.REFERENCES ......................... 54

APPENDIX A1: ANALYTICAL MODEL TO STABLE FILM BOILING . . . . . . 59

APPENDIX A2: CALIBRATION OF THE HEAT TRANSFER PLATE

THERMOCOUPLES .............. 63

APPENDIX A3: LIST OF MEASURING DEVICES USED AND TIIEIR

UNCERTAINTY . . . . . . . . . . . . 67

APPENDIX A4: ERROR ANALYSIS .............. 68

Estimate of the Measurement Uncertainty ......... 68

General outline .................. . . 68

Specific Measurement Uncertainties . . . . . . . . . 69

a. Heat Transfer Plate Thermocouple Temperature ..... . 69

b. Heat Flux ............... . . 69

c. Heat Transfer Surface Temperature . . . . . . . 70

d. Heat Transfer Coefficient .......... 70

e. Superficial Gas Velocity.......... 70

APPENDIX A5: TABULAR DATA .............. 73

APPENDIX AG: PHYSICAL PROPERTIES OF IMPORTANCE . . . . . . . . 88

Properties of $\mathrm{H}_{2} \mathrm{O} \ldots \ldots \ldots . \ldots . \ldots 88$

Properties of Stainless Steel............. 89

Data Sources for the Properties............. 90

APPENDIX A7: FILM BOILING WITH AND WITHOUT GAS FLUX ENHANCEMENT . . . . 91 


\section{LIST OF FIGURES}

Figure

Page

II.1 Features of film boiling development ...........4

III.1 Idealization of the bubble and jet dynamics . . . . . 13

III.2 Mapping of Equation III.1.............. 15

IV.1 Experimental apparatus . . . . . . . . . . . 24

IV.2 Pool and heat transfer plate . . . . . . . . . 25

IV.3 Top surface of the lieat transfer plate . . . . . . . 27

IV.4 Heat transfer plate and heater assembly . . . . . . 28

IV.5 Idealized temperature across the top of the heat transfer surface .............. . 29

IV.6 Magnification of the inside of a typical thermocouple ............... 32

IV.7 Mapping of a thermocouple within its well . . . . . . 32

V.1 Single frame from the high-speed filin of

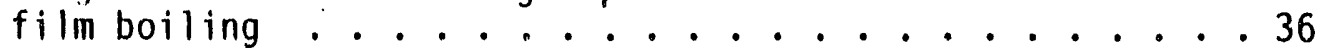

V.2 Still photograph of film boiling ........... 36

V.3 Filin boiling of water over a horizontal

flat surface ................ 40

V.7 Film boiling of water over a horizontal flat surface .................. 42

V.5 Heat transfer in a bubbly water pool with

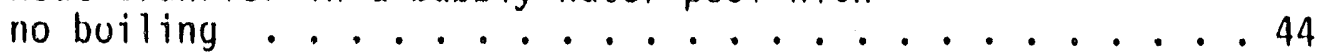

V.6 Gas flux enllanced film boiling data for water . . . . . 47

V.7 Correlation of experimental data . . . . . . . . . 49 


\section{LIST OF TABLES}

Table

Page

IV. 1

Thermocouple locations . . . . . . . . . . . . 27

A2.1

Thermocsiple calibration for heat transfer plate without gas holes... . . . . . . . . . . 64

A2.2 Thermocouple calibration for heat transfer plate with gas holes ................ 66

A4. 1 Measurement uncertainties . . . . . . . . . . 68

A4. 2

Film boiling data to determine errors . . . . . . . . 72

A5.1

Filın boiling with no gas injection . . . . . . . . . 74

A5.2a

Bubbling data, no filin boiling: constant pool height... . . . . . . . . . . . . . 76

$A 5.2 b$

Bubbling data, no film boiling: constant $j_{g}$. . . . . 79

A5.3 Film boiling with gas injection database . . . . . . . 82 


\section{MOMENCLATURE}

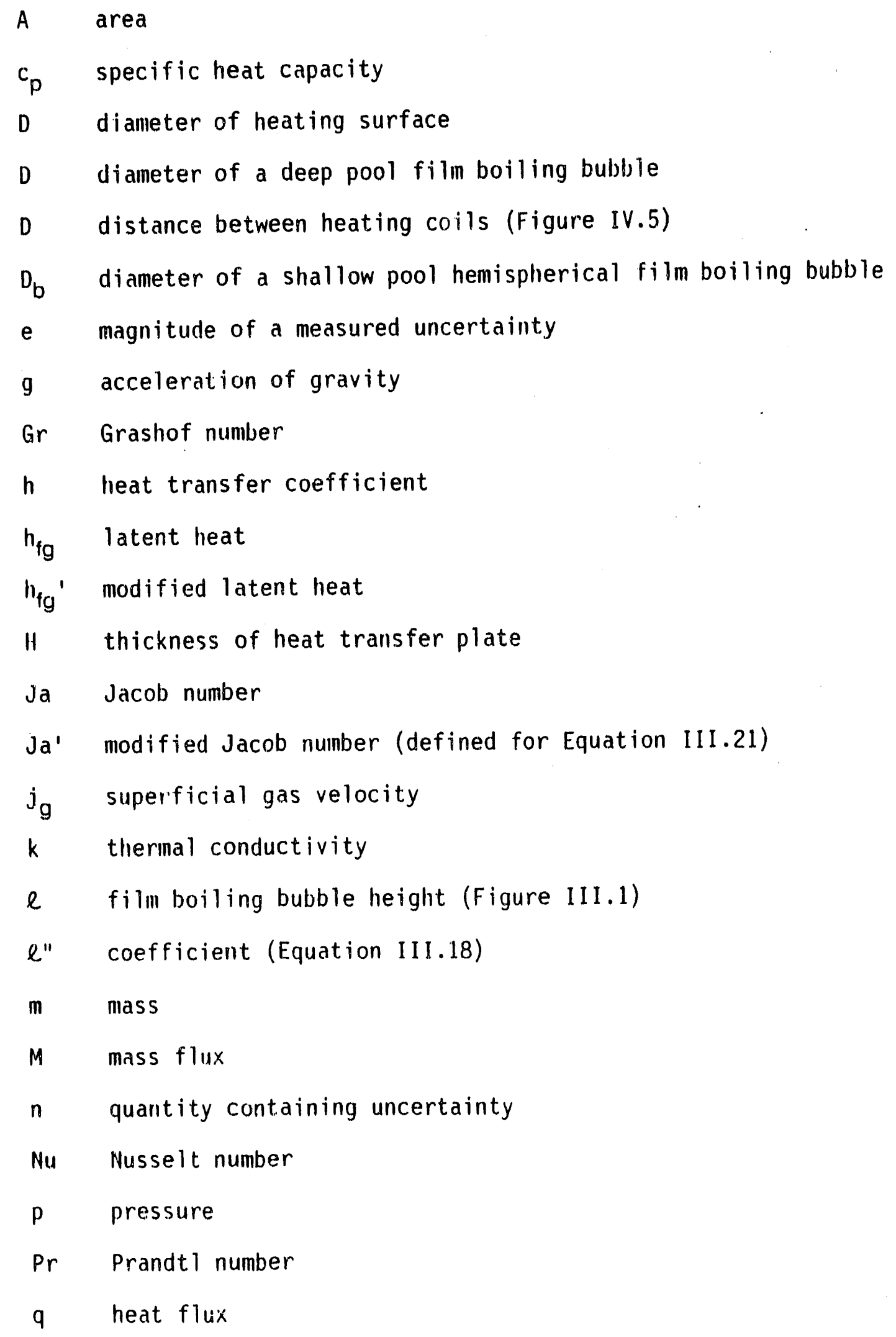


Q heat

$r, x, y$ directional variables

$R$ radius of the heat transfer plate

$R$ gas flowmeter reading

$t$ time

$T$ temperature

$\Delta T_{\text {SAT }}$ superheat, $\left(T-T_{\text {SAT }}\right)$

$\checkmark, \bar{v} \quad$ local and a erarge velocity, respectively

\section{GREEK SYMBOLS}

a liquid void fraction (Equation II.9)

$\beta_{1} \beta^{\prime}, \beta_{1}, \beta_{n}$ coefficients used in Section III

$\delta$ vapor film thickness

$\epsilon \quad$ surface enittance

$\theta \quad$ directional variable

$\lambda$ Taylor wavelength

$\mu \quad$ dynamic viscosity

$\nu \quad$ kinematic viscosity

$\rho$ density

$\sigma \quad$ surface tension

$\sigma_{\mathrm{SB}} \quad$ Stefan-Boltzmann constant

$\tau$ period of the Taylor wave 


\section{SUBSCRIPTS}

$0,1,2$ specific reference locations

b bubble

BER Berenson

COND conduction

CRIT critical

d most dangerous 2 dimensional theoretical wavelength

E experiment

$\delta$ vapor fijm thickness

f film

FB film boiling

g gas

e liquid

\& Laplace

M gas flowmeter

$r$ radial

RAD radiation

SAT saturation

SURF surface

ss stainless steel

STD standard

w wall 


\section{INTRODUCTION}

Assessments of severe core danage accidents in light water reactors are necessary to quantify the public risk under such circumstances. A major contributor to risk under accident conditions is the ex-vessel behavior of the moiten core debris. It is postulated that under severe accident conditions, the failure of the reactor's pressure vessel would lead to the deposition of molten core debris into the reactor cavity. Because the cavity of the reactor is made of concrete, it would inmediately be attacked by the molten core debris, releasing non-condensible gases into the molten pool. This stage of a reactor accident is termed the molten core-concrete interaction.

Heat transfer to a gas-evolving surface from an overlying molten pool was initially modeled as if there were a stable gas film between the surface and the pool. Benjamin (1979) showed that this situation is similar to film boiling. In film boiling on a horizontal flat plate or heat transfer through a stable gas film, such as in the suislination of dry ice under a pool of water (Dhir et al., 1977; Reimann and Alsmeyer, 1982), gas is released in a fixed geometrical pattern (Duignan et al., 1989) where the relative locations of bubbles are governed by the Taylor instability theory (Taylor, 1950). More recently, Bradley (1988) suggested that heat transfer from an overlying pool to an outgassing concrete suriace is distinctly different from simple models of gas films. He stated that the gas release from the concrete surface "...is usually far less than that required to form a stable [gas] $\mathrm{film}_{\mathrm{m}}$ and [as a result] interinittent debris concrete contact occurs." If this is the case, the heat transfer is strongly dependent upon the liquid-solid contacts and the increased movement of liquid past the heat transfer surface caused by the bubbling action, as in pool bubbling.

During a severe accident in a light water reactor, water may be introduced into the reactor cavity onto the molten core debris. This increases the transfer of heat from the molten core debris, possibly reducing the core temperature.

Blose, et al. (1987) carried out an experiment in which they poured water onto a inolten stainless-steel pool, contained in a concrete vessel. They observed the heat transfer environment as the molten steel attacked a concrete basemat while being cooled by an overlying pool of water. At that time the effects of non-condensible gases, released from the concrete, on the heat transfer [from the molten pool to the water pool] were not known. In fact, Blose et al. (1987) stated that, "...no consistent pattern for modelling water pools overlying core debris has developed within the reactor safety community." Not knowing how the gas would affect the core-to-ivater heat transfer the investigators neglected that effect when analyzing their results, and concluded that only nucleate boiling could have occurred on the core-water interface. To 
have concluded otherwise meant that film boiling was the heat transfer mechanism on the interface. Assuming that stable film boiling had occurred during the experiment meant that the core interface temperature had to be above the melting point of the stainless steel [calculated by the investigators and confirmed in Appendix A7]. Since the upper surface of the molten steel core was determined to have been a solid porous crust during the experiment, the crust temperature had to be lower than the melting temperature of stainless steel: therefore, stable film boiling was not possible.

As illustrated in Appendix A7, if Blose et a7. (1987) had been able to include the effect of the non-condensible gas on the core-water interface heat transfer [using the results of this present study] they may have concluded that film boiling was a possibility. The effect of the gas is to increase the filin boiling heat transfer so that the stainless steel surface temperature would have been calculated to be below its solidification temperature.

The primary reason for this investigation was to develop a database on lieat transfer due to gas-flux-enhanced film boiling. The steps taken to develop an experimental apparatus instigated two asymptotic studies, i.e., stable film boiling and pool bubbling [no film boiling].

Visual observations and heat transfer measureme. ts were made of stable film boiling of water, at 1 atmosphere and the saturation temperature, on a horizontal, flat stainless-steel plate. From visual observations, several aspects of the bubble dynamics were measured, i.e., the inter-bubble distance, the bubble release period, and the bubble diameter. The measurements of heat transfer were compared to the Berenson (1961) film-boiling model.

Measurements of convective heat transfer from the steel plate without filin boiling [pool bubbling] were made by drilling nine 1-mm-dianeter holes in that plate. The nine gas holes conform with the expected fixed geometrical pattern of bubble release in film boiling. When placing the geometrical pattern on the circular heat-transfer surface [diameter of $10.16 \mathrm{~cm}$ ] only nine gas holes could be made, giving a bubble site density of 0.11 sites $/ \mathrm{cm}^{2}$. The convective heat transier results were compared to the Konsetov (1961) model for turbulent pool bubbling.

Finally, the two effects, film boiling and pool bubbling, were combined and heat transfer measurements made to develop a database. To facilitate use of this database on gas-flux-enhanced filın boiling a semi-empirical model was developed and correlated with the data. Suggestions are given on how the simple model developed may be inproved and what further investigations may be necessary to better understand the combined effects of film boiling and pool bubbling on the overall heat transfer from a surface. 


\section{REVIEW OF THE LITERATURE}

There is no literature on film boiling over a horizontal flat plate with a non-rondensible gas emerging from the plate. What can be given is an outline on the two components which make up the phenomenon under study, i.e., filı boiling and pool bubbling from a horizontal flat surface. It is hoped that understanding the parts will lead to an understanding of the whole.

The following is neither an exhaustive nor a definitive review of the literature on film boiling and pool bubbling, for the list is very long. The studies referred to bring out the salient points of the subjects they treat, so that the reader will have an introductory knowledge of the information available at the time this work was done.

\section{Film Boiling}

Nukiyama (1934) clearly put this form of boiling into perspective with the other two forms, nucleate and transition, for the first time in his experimental study of an electrically heated wire in water, Figure II.la. Moreover, both still and motion photographic evidence of all three boiling regions were shown by Westwater and Santangelo (1955) from a steam-heated circular tube immersed in methanol. Visual observations of film boiling on horizontal flat surfaces are much more difficult; however, there are sone studies (Borishansky, 1953: Hosler and Westwater, 1962; Lao, 1969; Duignan et al., 1989). Nukiyana (1934) wanted to observe experimentally all the boiling phenomena together including the film boiling region which he called the "spheroidal state" [first coined by Boutigny in 1843, as pointed out by Gottfried et al. (1966)]. Before 1934, fillil boiling was not directly related to nucleate boiling, but was thought to be an isolated phenomenon seen when a liquid was placed on a surface whose temperature was equal to or greater than the Leidenfrost temperature (McAdalls, 1954; Gottfried et al., 1966). As is common in science, most phenomena are usually experimentally observed before getting a comprehensive theoretical treatment; film boiling is no exception.

While the first successful theoretical treatment of filin boiling was shown by Bromley (1948), the foundations for that theory were laid much earlier. Nusselt (1916) investigated the heat transfer from flat surfaces and tubes inclined at various angles when subjected to condensation [figure [I.16]. He developed several theoretical relations for the heat transfer coefficient; one was:

$$
h=0.725\left[k_{f}^{3} \rho_{f}^{2} g h_{f g} /\left(D \mu_{f} \Delta T\right)\right]^{1 / 4}
$$


(a)

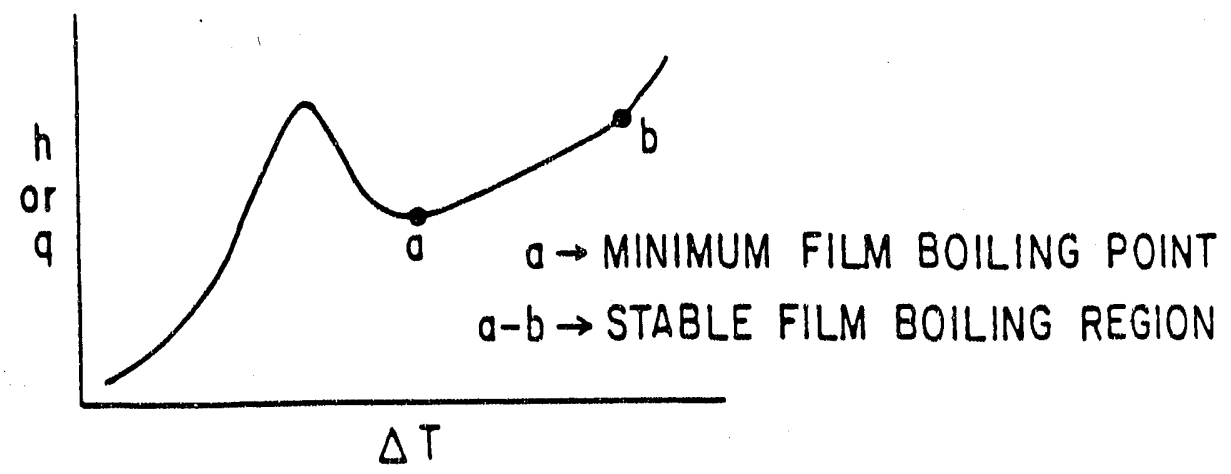

(b)
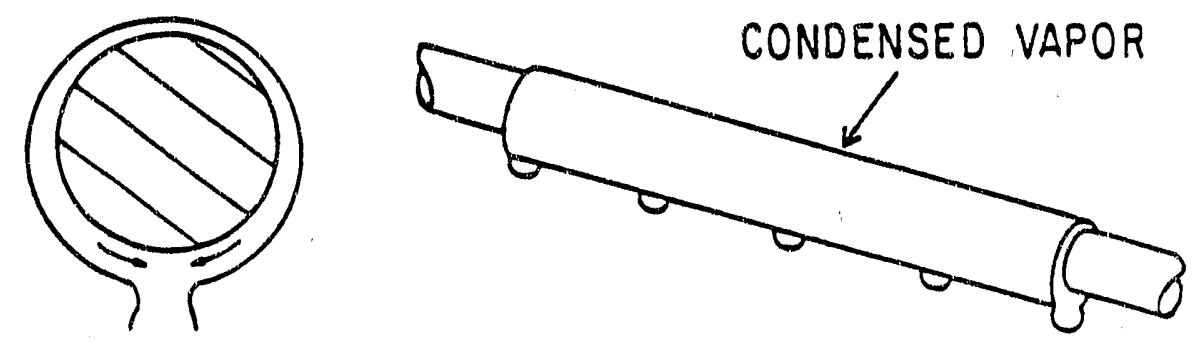

(c)
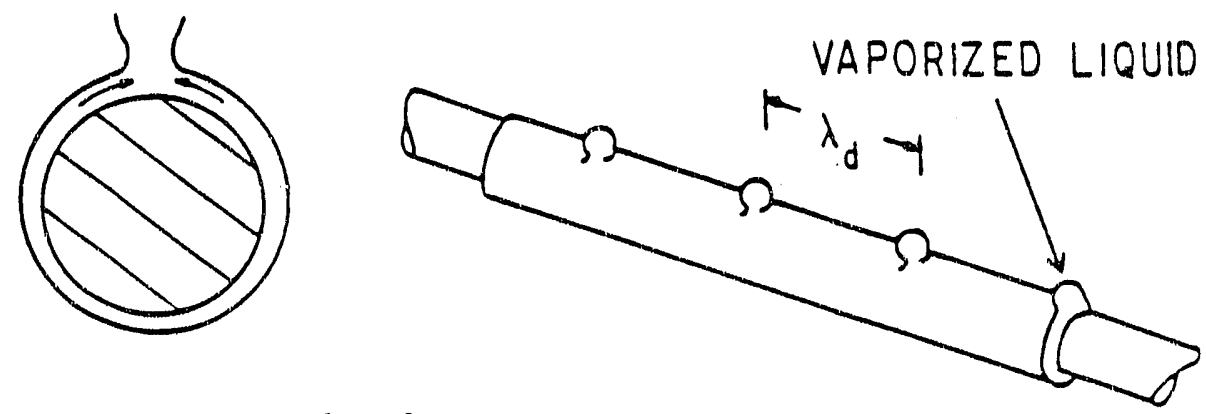

AREA PER BUBBLE $\pi r_{2}^{2}=\lambda_{d}^{2} / 2$
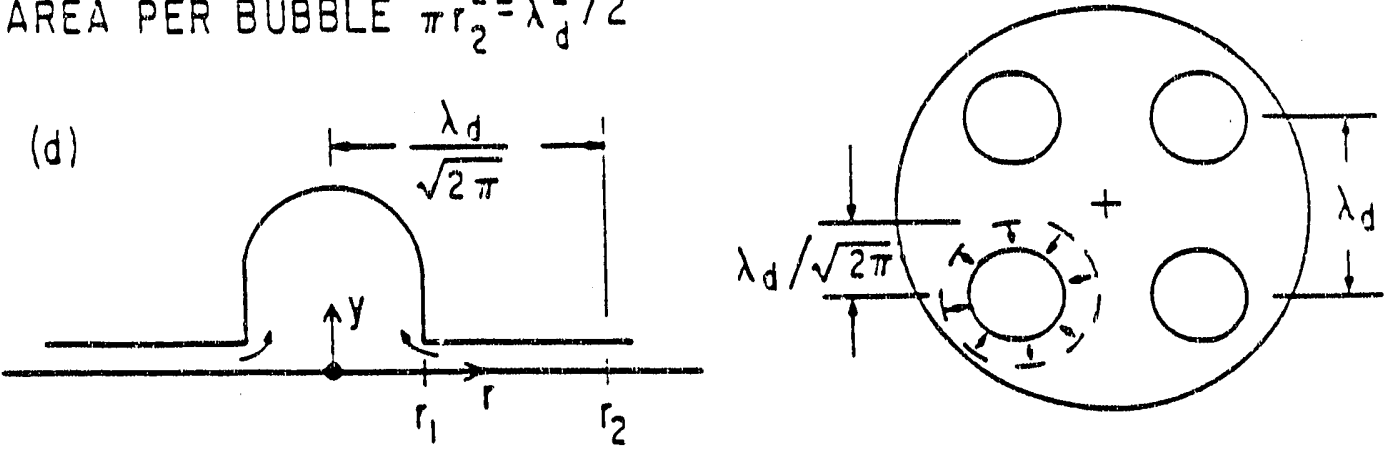

Figure II.1 Features of film boiling development 
Dhir and Lienhard (1971) also derived Equation 11.1 and determined the coefficient to be 0.729 , which they believed to be more accurate.

Equation II.1, representing a horizontal round tube, was derived by simplifying the governing equations with the following assumptions:

1.) The film of condensation is so thin that the temperature gradient through it is a straight line.

2.) The heat is all carried to the metal surface by pure conduction in the direction perpendicular to the surface.

3.) Physical properties of the condensate may be taken at the mean film temperature.

4.) The [heat transfer] surface is relatively smooth and clean.

5.) The film of condensate always moves in viscous motion.

6.) The curvature of the film may be neglected.

7.) The temperature of the solid surface is constant.

Note, the above assumptions were taken from Monrad and Badger (1930) who sumilarized Nusselt's analysis in English.

With the above assumptions, Nusselt (1916) included two boundary conditions.

b.c. 1: The condensate velocity at the tube wall is zero.

b.c. 2: If the condensing vapor is stationary above the condensed film, there is no force tending to shear at the vapor-liquid interface.

Lao (1969) pointed out that in 1941 Colburn suggested using Nusselt's laminar film condensation theory to describe filll boiling theoretically. Even though, it was not until 1948 that Bromley developed a comprehensive model, based primarily on the Nusselt film-condensation approach. The Bromley model is:

$$
h_{\text {COND }}=0.724\left[k_{f}^{3} \rho_{f}\left(\rho_{l}-\rho_{f}\right) g h_{f g}^{\prime} /\left(D \mu_{f} \Delta T\right)\right]^{1 / 4}
$$

Equation II.2 was developed for film boiling around a horizontal circular tube surrounded by liquid, Figure II.1C. Besides the change in the density terms, because the film in film boiling is the less dense medium, Equation II.2 differs from Equation II.I in that, with the higher temperatures experienced in 
film boiling, the amount of heat absorbed by the vapor film itself may be significant. Therefore, this was compensated for in the latent heat term:

$$
h_{f g}{ }^{\prime}=h_{f g}\left(1+0.5 c_{p} \Delta T / h_{f g}\right)
$$

Equation II.1 neglects this sensible heat term since the temperature differences in the condensate film are small and, if ignored, only cause a maximum error of $3 \%$ at the highest temperature (Monrad and Badger, 1930). Also, note the subscript on the heat transfer coefficient, COND = conduction. When the surface temperature of the tube is high enough, radiation contributes significantly to the overall heat transfer; Bromley (1948) showed that temperature to be above approximately $500 \mathrm{~K}$. Equation II.2 is only the conduction contribution through the vapor film. To Nusselt's assumption Bromley added:

8.) The tube is completely surrounded by a continuous vapor film.

9.) Vapor rises under the action of buoyant forces.

10.) Boiling liquid is at its boiling point at the vapor-liquid interface.

11.) The heat is transferred through the film by radiation as well as by conduction.

Bromley (1948) recognized that Nusselt's second boundary condition, of zero shear at the vapor-liquid interface, may not hold for film boiling. Not knowing whether the liquid interface acted as a fixed or free boundary to the flowing vapor film, he let the coefficient 0.724 be redetermined by a correlation with his experimental data. He obtained a coefficient of $0.62 \pm 0.04$, which meant that the interface presents some drag to the flowing vapor in the film [a fixed boundary makes the coefficient 0.512]. The success of Bromley's application of the Nusselt model of laminar film conclensation to film boiling made it the standard on which future developments were based.

Chang (1959) suggested that a study of the wave stability of the vaporliquid interface could give a model to describe film boiling. His model deviated substantially from experimental data (Hosler and Westwater, 1962), but it led Zuber (1959) to suggest that Taylor's wave-instability study (Taylor, 1950) may be used to model boiling phenomena. This wave-instability study was most successfully used by Berenson (1961) to develop a model for film boiling on a horizontal flat surface, Figure II.1d. His relation is:

$$
h_{\text {COND }}=0.531\left[k_{f}{ }^{3} \rho_{f}\left(\rho_{\ell}-\rho_{f}\right) g h_{f g}{ }^{\prime} /\left(D_{\ell} \mu_{f} \Delta T\right)\right]^{1 / 4}
$$


where $D_{l}$ is from the direct influence of the wave instability theory. $D_{\ell}=$ $\left[\sigma / g\left(\rho_{\ell}-\rho_{f}\right)\right]^{1 / 2}$ is also referred to as the Laplace reference length. Note that the coefficient 0.531 was obtained by applying Nusselt's second boundary condition, i.e., there are no shear forces exerted on the vapor-liquid interface. Berenson, like Bromley, correlated his experimental data to his equation to obtain a more accurate coefficient since the actual shear forces at the vapor-liquid interface were not known. Berenson obtained a coefficient of 0.425 .

Both Equation II.2 and Equation II.4 have the same general form except for the change in the characteristic reference length $D \rightarrow D_{l}$. This similarity is not surprising, even though Equation II.2 represents a horizontal tube and Equation II.4 a horizontal flat plate, in light of Nusselt's sixth assumption of neglecting the film curvature. In fact, Lienhard and Wong (1964) showed that if a tube diameter is greater than $20 \%$ of what is known as the "most dangerous wavelength", $\lambda_{d}=2 \pi(3)^{1 / 2} D_{\ell}$, which comes from the instability theory, the heatreleasing mechanisms [e.g. the distance between releasing bubbles] are within $5 \%$ percent of those of a horizontal flat surface. This is basically a criterion to judge when the thickness of the vapor film around the tube is small compared to the diameter of the tube: Bromley's (1948) experiment met that criterion.

For the first time, bubble dynamics, through the Taylor (1950) instability theory, were linked to film boiling through the Laplace length and were shown by Bellman and Pennington (1954) to be directly related to wave geometry in the instability theory. For a two-dimensional case, they showed that waves had a minimum length of $\lambda=2 \pi\left[\sigma / g\left(\rho_{\ell}-\rho_{f}\right)\right]^{1 / 2}$ and a maximum of $\lambda_{d}=2 \pi\left[3 \sigma / g\left(\rho_{\ell}-\rho_{f}\right)\right]^{1 / 2}$ [for a three-dimensional presentation see, Sernas (1969)]. They called this maximum length, $\lambda_{d}$, the "most dangerous wavelength" because at this wavelength the amplitude of the disturbance grows most rapidly. Further discussion of bubble dynamics can be found in Duignan et al. (1989). What follows is a brief summary of some of the approaches taken by other investigators to improve the theory on which Equation II.4 was based.

Hamill and Baumeister (1967) tried a theoretical approach that did not depend on the bubble hydrodynamics but was based on the maximization of the rate of entropy production. They obtained the same form as Equation II.4 except the coefficient was 0.41 instead of 0.425 , and the coefficient of the sensible heat contribution shown in Equation II.3 was $19 / 20$ instead of $1 / 2$. Ruckenstein (1967) attempted to improve Berenson's equation by determining the coefficient in Equation II.4 as a function of the initial and final radii of the buoyant bubbles leaving the vapor-liquid interface, plus some undetermined constants. The complexity of Ruckenstein's coefficient to Berenson's equation makes it undeterminable and, therefore, unusable.

More recently, Klimenko (1981) used a model developed by Frederking et al. 
(1966) which eliminated the dependence upon any length scale. He was concerned that the contribution of latent heat to the heat transfer was in considerable error when simply using Equation II.3. Bromley (1948) directly looked at the heat cransfer dependence on the sensible heat in the form of the Jacob number, $\mathrm{Ja}=c_{p} \Delta T / h_{f g}$, shown in Equation II.3. He found an insignificant dependence which could not be quantified since it lay within the uncertainty of the data. Klimenko [with some important corrections to his first paper, Klimenko and Shelepen (1982)] developed the following equation:

$$
h=0.169\left[k_{f}^{2} \rho_{f}\left(\rho_{l}-\rho_{f}\right) g h_{f g} /\left(\mu_{f} \Delta T\right)\right]^{1 / 3}
$$

which he stated describes laminar flow in the vapor film layer [by his own criteria] and for Ja< 0.5 , which is the case in the present study of water in film boiling. Since Klimenko did not disassociate components of heat transfer by either conduction, convection, or radiation, Equation IJ.5 includes all tirose contributions, therefore $h$ was used instead of $h_{\text {COND. Ramilison and Lienhard }}$ (1987) found that Equation II.5 terts to model stable film boiling slightly better than Berenson's Equation II.4 when the surface superheat [surface temperature minus the working fluid's saturation temperature] becomes such that the radiation from the surface is an important factor. Bramiey (1948) showed that radiation is significant at surface superheats of approximately. $500 \mathrm{~K}$ and above. Moreover, Ramilison and Lienhard (1987) stated "...the physical inechanisms upon which [Berenson's equation] is based to be more convincing," but that "... while the details of Klimenko's formulation are probably not perfect, it nevertheless provides us with a very nearly perfect basis for fitting the existing data." Correlating this study's data of stable film boiling with a least-squares fit to equation 11.5 gave a coefficient of 0.214 instead of 0.169 , a difference of about $27 \%$ which is close to Klimenko's stated uncertainty of $\pm 25 \%$.

An explanation is necessary to clarify the term "stable film boiling" which might seem to conflict with the fact that several film boiling models are based on an "instability" theory. The term "stable" is clear and the condition of being "stable" in film boiling is also clear, meaning that film boiling is occurring without the denser medium, the liquid, penetrating the vapor filin sufficiently to touch the heat transfer surface. What is not clear is: 1) the point where transition boiling ["a combination of unstable film boiling and unstable nucleate boiling alternately existing at any given location on the heating surface" (Berenson, 1962)] ends and filin boiling begins, and 2) whether this point marks the beginning of stable film boiling. That point is commonly called the minimum film boiling point (MFB). There are many studies on that 
topic: to summarize, the exact superheat where MFB occurs depends on the liquid, the surface roughness of the heat traisfer surface, and the pressure, among other factors. It does not necessarily mean that no liquid touches the heat transfer surface, only that the percentage touching is low enough that as the superheat increases so does the heat flux, albeit slowly. One quantitative criterion (Poniewski, 1987) states that "tongues" of liquid can no longer penetrate the vapor filn to touch the heat transfer surface when the surface temperature exceeds the critical temperature of the liquid, i.e., $T_{\text {WALL }}>T_{\text {CRIT }}$, thu's, stable film boiling is assured.

Finally, the component of radiation in film boiling has only been indirectly mentioned and needs to be put into perspective. Because this review began with the laminar condensation model of Nusselt (1916), where radiation in the $\mathrm{film}$ is insignificant, this aspect of the heat transfer mechanism was not immediately relevant. As was shown by Bromley (1948), even when the heat transfer surface temperature reaches $500 \mathrm{~K}$, the contribution to the overall heat transfer is less than approximately $10 \%$. When radiation becomes important, he showed that its contribution can be superimposed on $h_{\text {COND }}$ in the form:

$$
h=h_{\text {COND }}\left(h_{\text {COND }} / h\right)^{1 / 3}+h_{\text {RAD }}
$$

and can be simplified to a first-order linearized form of,

$$
h=h_{\text {COND }}+3 / 4 h_{\text {RAD }}
$$

Equation 11.7 accurately represents Equation 11.6 for the temperatures of concern in this investigation [i.e., to surface temperatures of approximately $1000 \mathrm{k}$. Bromley (1948) assumed that the heat transfer surface and the vaporliquid interface could be equated to parallel plates so that the classical radiation model could be used, i.e.,

$$
h_{\text {RAD }}=\sigma_{S B}\left[1 / \epsilon_{S S}+1 / \epsilon_{\ell}-1\right]^{-1}\left(T_{S U A F}{ }^{4}-T_{S A T}{ }^{4}\right) / \Delta T_{S A T}
$$

where $\sigma_{S B}$ is the Stefan-Boltzmann constant. 


\section{Pool Bubbling}

In studying the phenomena of pool bubbling from porous and drilled holed surfaces or pool boiling, it is important to know if they transfer heat in the same manner. If the contribution of latent heat, as discussed by Rallis and Jawurek (1964), is a large portion of the heat transfer, there would be little similarity. Even when the contribution of latent heat car be neglected, the bubbling and boiling may not be similar.

Sims and Duffield (1971) attempted to correlate porous- and drilledsurface bubbling heat transfer with nucleate boiling so that they could explain the hydrodynamic aspects of the heat transfer mechanisms in nucleate boiling. They found that when the latent heat transport is small, porous surfaces initate nucleate boiling, but all their data on drilled surfaces poorly modeled nucleate boiling, since "...the number of bubble generating sites does not vary with the amount of gas leaving the heat transfer surface." Using several drilled heat transfer surfaces with varying hole densities, 4 to 400 sites $/ \mathrm{cm}^{2}$, Kutateladze and Malenkov (1976) showed that as the number of holes increased, the heat transfer coefficient of a drilled plate approached that of a porous surface which, in turn, could be equated to nucleate boiling under a limited range of superficial gas velocities.

In trying to understand the heat transfer mechanism in bubbling or boiling, a complicating factor is the effect that one bubble has on another as they form and leave the surface. When the bubbling sites are far apart, the inter-bubble interactions can be neglected and only the effect of the bubbles jetting into the overlying pool on the surface heat transfer needs to be studied. An important question is how far apart the bubbling sites have to be in order to neglect inter-bubble effects.

Bard and Leonard (1967) showed that the effect of bubbling from a single orifice on the local heat transfer decreases inversely with the distance from the orifice. For distances along the surface greater than $10 \mathrm{~mm}$ from the center of an orifice $1 \mathrm{~mm}$ or less in diameter, heat transfer was not affected by the presence of the bubble. This finding was confirmed by several nucleate boiling studies dealing with nucleation site densities on horizontal surfaces (Tien, 1962; Lienhard, 1963; Kurihara and Myers, 1960). Lienhard (1963) stated that when the nucleation site density is less than approximately $032 \mathrm{sites} / \mathrm{cm}^{2}$, the "...sites will cease to influence one another." This site density generates an area of bubble influence on the heat transfer surface which, if assumed circular, has a radius of $10 \mathrm{~mm}$, corroborating the observations of Bard and Leonard (1967). Therefore, if the bubbling sites are located far enough away from each other, the main contribution to the surface heat transfer is due to the movement of the fluid on that surface by natural convection and by the stirring action caused by the bubbles. 
Konsetov (1966) proposed that heat transfer from a surface in a bubbling pool is due primarily to liquid turbulent eddies. He stated that approximately one-third of the heat was removed by flow normal to the surface, and the remaining two-thirds by the parallel movement of those turbulent eddies. Interestingly, Konsetov (1966) made no mention about the orientation of the heat transfer surface in the pool, whether the bubbles were emanating from the lieat transfer surface or from another source, or about the specific shape of the surface. He developed a heat transfer relationship using the data from two bubbling pool studies, Fair et al. (1962) and Kölbel et al. (1958). Both studies measured the heat transfer from vertical cylinders in "deep" pools whell the bubbling came from a source lower in the pool ["deep" means that the pool height is equal to or greater than its width]. Using their data, Konsetov (1966) developed a model which accounted for the void fraction in the bubbling pool as a function of the superficial gas velocity, and a range of sizes for the turbulent eddies. He developed the following relationship,

$$
h / k\left(\nu^{2} / g\right)^{1 / 3} \operatorname{Pr}^{-1 / 3}\left(\mu_{w} / \mu\right)^{0.14}=0.25 \alpha^{1 / 3}
$$

where $\alpha$ is the void fraction. The void fraction was empirically determined by Kutateladze, as shown in Konsetor (1966), to be:

$$
\alpha=0.4\left[j_{g}^{2 / 3}\left(g \sigma /\left[\rho_{\ell}-\rho_{g}\right]\right)^{-1 / 6}\left(\rho_{g} / \rho_{\ell}\right)^{0.15}\right]
$$

Konsetor evaluated Equation II.10 for an unspecified gas-liquid system (presumably air-water) and, upon substitution into Equation II.9, arrived at the following relationship for the bubbling heat transfer coefficient:

$$
h\left(W / m^{2} K\right)=0.19\left[k j_{g}^{0.22} \operatorname{Pr}^{1 / 3}\left(\mu / \mu_{w}\right)^{0.14}\left(g / \nu^{2}\right)^{1 / 3}\right]
$$

This formula is insensitive to variations in the properties in Equation II.10 and is applicable to a wide range of fluids. The coefficient in Fquation 11.11 is not dimensionless; it has units of $(\mathrm{m} / \mathrm{s})^{-0.22}$ and requires the other variables to have consistent units. The magnitude of this coefficient will change if the 
units are changed. In this correlation, all properties are calculated at the pool temperature unless indicated otherwise.

In the following section a model will be developed to explain how heat is transferred from a surface where there is both film boiling and pool bubbling. Several aspects of the present section will be incorporated into the model, after which the model and the experimental database will be compared. 


\section{ANALYTICAL MODEL}

\section{The Problem}

Consider a horizontal flat heat transfer surface, at a temperature $T_{\text {SuAf, }}$, over which stable film boiling is occurring in a pool of liquid at its saturation temperature, Figure III.1a. After some time a non-condensible gas at the same temperature as the heat transfer surface begins to jet through the surface from discreet locations. These jets traverse the vapor-liquid boundary; a single jet is shown in Figure III.Ib.

Berenson (1961) stated that "the difficulty which arose when attempting to analyze [film boiling heat transfer from a horizontal surface] was the fact that the vapor flow geometry was not clear." Unfortunately, almost thirty years later, the complication of a jet traversing the vapor-liquid interface makes Berenson's statement still valid although the vapor flow geometry in stable film boiling is better understood today (Duignan et al., 1989; Sernas et al., 1973). While the two phenomena, jetting and film boiling, coexisted, to facilitate model development for this analysis it was assumed that they occur independently. Where these two phenomena are thought to connect is through the increased agitation created in the liquid pool by the presence of the jet. This

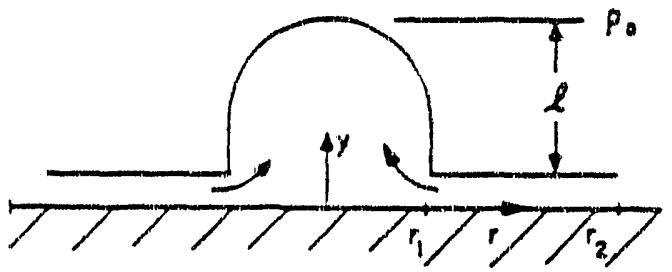

(a)

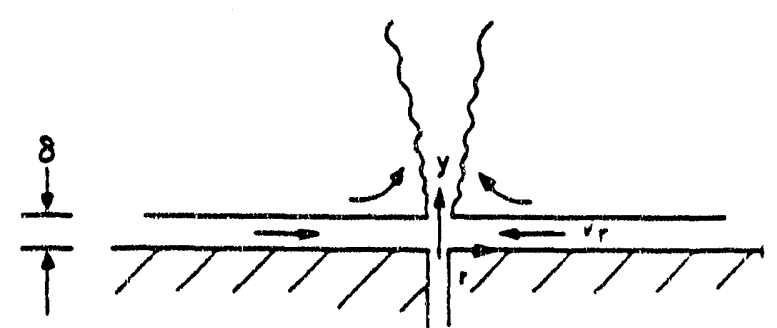

(b)

Figure III.I Idealization of the bubble and jet dynamics

increased agitation may increase the movement of the vapor-liquid interface while film boiling occurs, and, in turn, the increased movement of the interface might affect the vapor flow in the film. Moreover, if the vapor flow increases, more liquid would be transforined to vapor; as a consequence, more heat is transferred. 
Two methods of increasing the vapor movement seem equally possible:

1) Konsetor (1966) postulated that the movement of turbulent eddies near a heat transfer surface in a bubbly pool is both perpendicular and parallel. Eddies move past the heat transfer surface and increase in energy, which then is carried away from that surface. In film boiling, eddies cannot reach the heat transfer surface because of the vapor $f i l m$, but somehow they interact with the vapor-liquid boundary. The eddies may mechanically agitate that boundary and thus increase the flow of vapor in the film. That increased vapor flow may be the result of the agitated boundary decreasing the drag forces on the flowing vapor or forcing the boundary closer to the heat transfer surface, which would result in a reduced therial resistance of the vapor film.

2) The second method of increasing the vapor movement may be from the increased movement of the vapor-liquid interface by the viscous dragging of liquid immediately above the interface towards the jet. That is, as the jet enters the pool it entrains the liquid near its boundaries as seen in Figure III.1b. Moreover, vapor is also entrained from the vapor film which, in turn, reduces the film's thickness, leading to an increase in heat transfer.

This second method, increasing the mass flux of vapor away from the film, can be applied directly to Berenson's analytical solution (1961); therefore, it will be used in the modeling for this study. To begin model development, it is necessary to have some insight in the relationship between the jet velocity and the vapor velocity in the film near the jet. In turn, this relationship will be used to determine the mass flux of vapor leaving the film with the jet, to obtain the overall vapor flux from both the jet and the film boiling.

Analytical and experimental work of a turbulent circular free jet into an infinite pool is shown by Schlichting (1979) [an analysis of a turbulent jet was chosen since the included criterion ( $p .183$, Schlichting, 1979) for the onset of a turbulent jet is: $\operatorname{Re}=U_{\text {JET }} d_{J E T} / \nu>30$ and for this work $\left.\operatorname{Re}>60\right]$. The velocity component of interest from the theoretical analysis is in the radial direction, perpendicular to and towards the jet. He showed that:

$$
v_{\text {RADIAL, LIQUID }}=v_{r_{\ell}}(r, y)=1 / 4(3 K / \pi)^{1 / 2} / y\left[\left(\eta-1 / 4 \eta^{3}\right) /\left(1+1 / 4 \eta^{2}\right)^{2}\right]
$$

where

$$
\begin{aligned}
& \eta=1 / 4(3 K / \pi)^{1 / 2} / \epsilon_{0} r / y \quad \infty \\
& K=\text { constant kinematic momentum }=2 \pi \int_{0}^{\infty} u^{2} r d r \\
& \epsilon_{0}=\text { eddy viscosity }
\end{aligned}
$$


Schlichting (1979) also gave the supporting experimental results:

$$
\epsilon_{0} /(K)^{1 / 2}=0.0161 \quad \text { and } \quad(K)^{1 / 2}=1.59(0.0848 y) U_{\text {JET }}
$$

therefore, Equation III.1 takes the form,

$$
v_{r \ell}(r, \delta) / U_{\text {JET }}=37.77\left[\left(15.17(r / \delta)-873.45(r / \delta)^{3}\right) /\left(1+57.56(r / \delta)^{2}\right)^{2}\right]
$$

Figure III.lb shows the coordinates of the jet. Note that the radial velocity in Equation III.1 has been evaluated at $y=\delta$, which is the plane coinciding with the vapor-liquid interface.

Equation III.1 shows two pertinent characteristics which will be highlighted in the discussion. The radial component of the liquid velocity, $v_{\text {re' }}$ is directly proportional to the jet velocity, $U_{\text {JET }}$, and at "large" distances away from the jet, $r \gg 5 \delta$, velocity drops by more than an order of magnitude to a

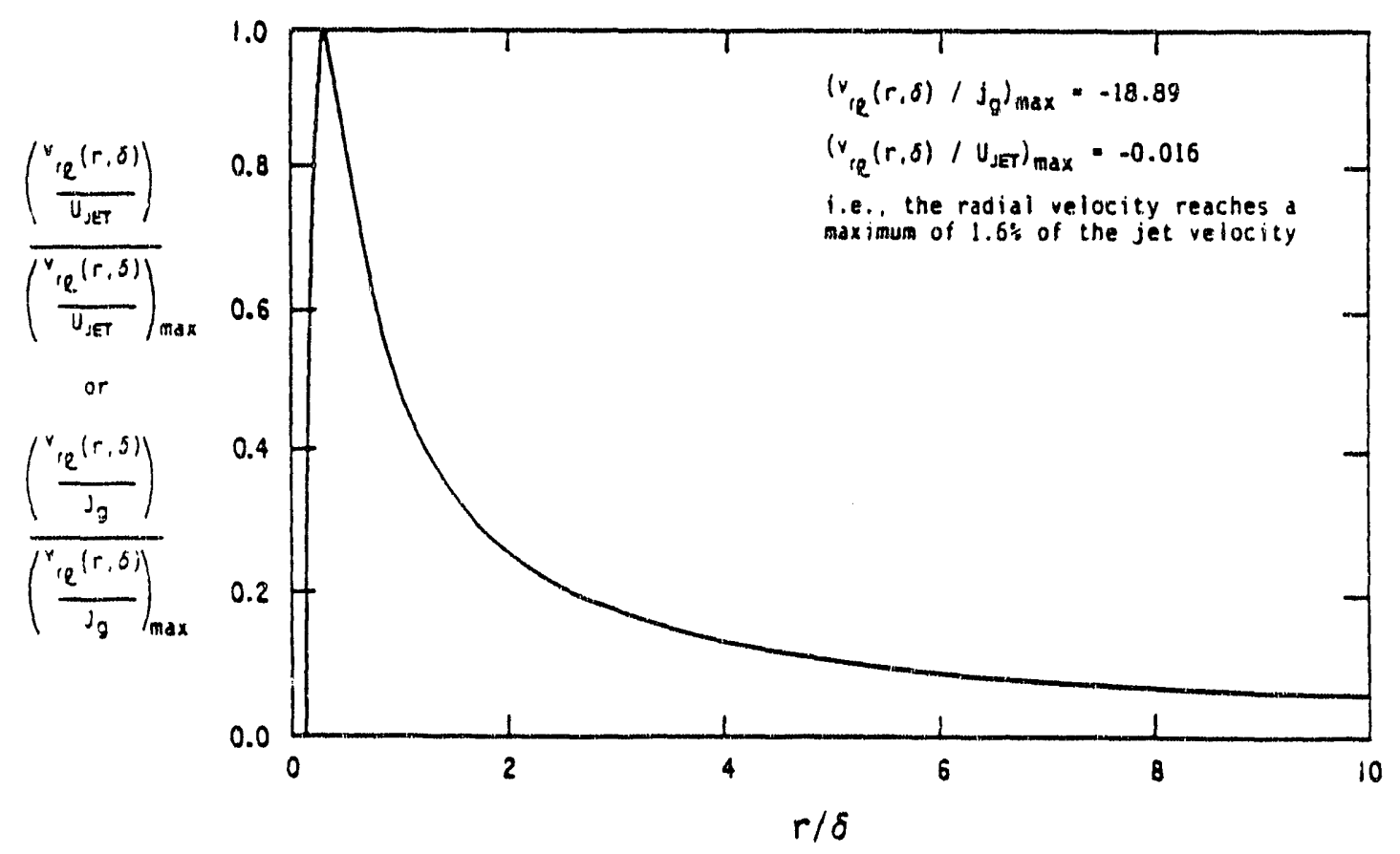

Figure III.2 Mapping of Equation III.1 
relatively constant value, Figure III.2. Since the superficial gas velocity, $j_{g}$, differs from $U_{\text {JET }}$ by only the ratio of the heat transfer surface area and the jet hole areas (there are nine jets), the normalized ordinate in Figure III.2 may be equally expressed by either expression.

Two other facts about Equation III.1 should be pointed out:

1) Rankin et al. (1983) stated that exact solutions of the Navier-Stokes equation exist describing axisymmetric submerged jets but "...due to its simplicity and proven accuracy...schlichting's solution is the one most applied." These authors were referring to the laminar form of Schlichting's solution, but the turbulerit form, of which Equation III.1 is a part, has exactly the same form except for the substitution of $\epsilon_{0}$, the eddy viscosity, by $\nu$ and its solution has been equally tested (Schlichting, 1979).

2) Equation III.1 was developed for zero density difference between the jet and the liquid.

Therefore Equation III.1 cannot be directly applied to the present problem since it involves a jet of considerably less density, $\mathrm{N}_{2}$ gas, than the medium into which it is entering, $\mathrm{H}_{2} \mathrm{O}$ liquid. Albeit, it is hoped that the characteristics of the radial velocity of the liquid caused by the jet can be used qualitatively to develop an upper convective boundary condition for the vapor film, i.e.,

$$
v_{r \ell}(r, \delta)=v_{r \delta} \propto U_{J E T} \propto j_{g} \quad \text { for } r \gg \delta
$$

For this study $r$ varies from $r_{1}$ to $r_{2}$, Figure III.1a; therefore, assuming $r_{1}=$ $\lambda_{d} / 4$ (Zuber and Tribus, 1958) with $\lambda_{d}=27.2 \mathrm{~mm}$ (Duignan et al., 1989), then $r_{1}$ $\sim 6.8 \mathrm{~mm}$, making the statement $r \gg \delta$ true since $\delta \sim 0.03 \mathrm{~mm}$ (Berenson, 1961).

The assumption that the vapor-liquid interface is moved by the viscous movement of the liquid just above that interface may be an oversimplification, but with the existing complexity of the velocity field, it may be a good starting point. The inadequacies of the following analysis should be overcome by correlating the resulting semi-empirical solution to the experimental data. The analysis to be presented follows closely the analyses from Nusselt (1916), Bromley (1948) and Berenson (1961); their analyses will be augmented to conform to the current problem. 


\section{The Assumptions}

1) The change in height of the vapor-liquid boundary between bubbles is negligible compared to the average height of the bubble above the interface, i.e., $\Delta \delta / \ell \ll 1$.

2) The mass flux of vapor leaves the film by two independent phenomena, i.e., from viscous entrainment by the non-condensible jets, and from the film boiling action.

3) The kinetic energy of the vapor is negligible compared to the enthalpy change from evaporation.

4) The physical properties of the vapor film can be determined at the average temperature of the heat transfer surface and the vapor liquid interface.

5) The temperature at the vapor-liquid interface is assumed to be at the saturation temperature of the liquid.

6) The heat is transferred through the vapor film by conduction and radiation only.

7) Two bubbles grow from an area of $\lambda_{d}{ }^{2}$ at any one time, where $\lambda_{d}=2 \pi\left[3 \sigma / g\left(\rho_{\ell} \rho_{f}\right)\right]^{1 / 2}$, Sernas et al. (1973).

8) The vapor rises under the action of buoyant forces.

9) The temperature of the heat transfer surface is constant with time.

These assumptions apply to both the following analysis and to the part of the Nusselt-Bromley-Berenson analytical model shown in Appendix A1. Equation A1.7 was the ending point in Appendix $A 1$ and is the starting point here, i.e.,

$$
\bar{v}_{r}=\left[1 /\left(\beta \mu_{f}\right)\right] d p / d r \delta^{2}
$$

$\beta$ is the constant to be determined. 


\section{A Solution}

It is proposed that the mass flux of the vapor leaves the film by two separate mechanisms: 1) The vapor is carried away from the film by buoyant forces in the form of bubbles, and 2) The vapor is entrained with the jet by viscous drag. It is further proposed that both of these phenomena are independent. Finally, the two mass fluxes are then added together to obtain the total mass flux of the vapor. Knowing the total mass flux from the vapor film, we can determine the film thickness and, therefore, obtain the heat transfer across that film by conduction.

The mass flux from the film can be determined from continuity:

for film boiling.

$$
M_{F B}=\left(\rho_{f} \bar{v}_{r} \text { Area }\right)_{\text {FILM BOILING }}
$$

for the jet,

$$
M_{\text {JET }}=\left(\rho_{f} \bar{v}_{r} \text { Area }\right)_{\text {JET }}
$$

It is assumed that the two phenomena experience the same temperature gradient across the $\mathrm{film}$ and have the same area of influence, therefore:

$$
M=M_{F B}+M_{J E T}=\rho_{f} \text { Area }\left(\bar{v}_{r_{F B}}+\bar{v}_{r_{J E T}}\right)
$$

The analysis in Appendix A1, which led to Equation A1.7 is assumed to be the same for both the vapor velocity in the film due to 1) film boiling; Figure III.1a, and 2) the jet; Figure III.Ib. Substituting the appropriate form of Equation $\mathrm{Al} .7$ in Equation 111.6 then,

$$
M=\left[(1 / \beta d p / d r)_{F B}+(1 / \beta d p / d r)_{J E T}\right] \rho_{f} \text { Area } \delta^{2} / \mu_{f}
$$


To repeat from Equation III.3, the radial component of the vapor velocity is proportional to the superficial gas velocity of the jet. Equation Al.7 shows that the radial pressure gradient is directly proportional to the vapor velocity. It is now assumed that the radial pressure gradients for the film boiling and the jet phenomena are proportional so that:

then let,

$$
(1 / \beta d p / d r)_{\text {JET }}=\bar{v}_{r_{\text {JET }}} \propto j_{g} \propto j_{g}(d p / d r)_{F B}
$$

$$
(1 / \beta d p / d r)_{J E T}=1 / \beta^{\prime} j_{g}(d p / d r)_{F B}=1 / \beta^{\prime} j_{g} d p / d r
$$

Substituting Equation III.9 into Equation III.7 results in,

$$
M=\left[\left(1 / \beta+j_{g} / \beta^{\prime}\right) \rho_{f} \text { Area } \delta^{2} / \mu_{f}\right] d p / d r
$$

The assumption of proportional pressure gradients may be questionable, since the pressure gradient in the vapor film for film boiling is the driving force behind the vapor's movement but for the jet it is the viscous drag that causes the vapor in the film to move. The purpose of this modeling is to obtain a simple and convenient relationship among the important contributors to the vapor mass transfer. This relationship will ultimately result in a heat transfer model to be correlated to the experimental data. The correlation coefficients $1 / \beta$ and $1 / \beta^{\prime}$ should mitigate inadequacies the above analys is may contain.

The area of influence for the bubbling in film boiling is $2 \pi r \delta$ and, therefore, Equation III.10 becomes:

$$
M=\left[\left(1 / \beta+j_{g} / \beta^{\prime}\right) \rho_{f} 2 \pi r \delta^{3} / \mu_{f}\right] d p / d r
$$

The total mass flow of vapor in the film may also be obtained by assuming that all the heat goes into transforming the liquid to vapor and to heat up the vapor itself, i.e.,

$$
Q=M h_{f g}{ }^{\prime}
$$

where $h_{f g}{ }^{\prime}=h_{f g}\left(1+.5 J a_{f}\right), \quad($ Bromley, 1948) 
and

$J a_{f}=J a c o b$ Number $=c_{p_{f}} \Delta T / h_{f g}$

Assuming that $T(y)$ is linear across the vapor film, and using Fourier's law, the heat conducted across the film can be expressed by,

$$
Q=k_{f} \text { Area } \Delta T / \Delta y=k_{f}\left(\pi r_{2}^{2}-\pi r^{2}\right) \Delta T / \delta
$$

Combining Equations III.11, 12, 14 and solving for the film boiling pressure gradient gives,

$$
d p / d r=\left(1 / \beta+j_{g} / \beta^{\prime}\right)^{-1}\left[\mu_{f} k_{f} \Delta T /\left(\rho_{f} \delta^{4} h_{f g}^{\prime}\right)\right]\left(\pi r_{2}^{2}-\pi r^{2}\right) / 2 \pi r
$$

Equation III.15 is now integrated radially across the film, i.e., from $r_{1}$ to $r_{2}$, where $p\left(r_{1}, \delta\right)=p_{1}$ and $p\left(r_{2}, \delta\right)=p_{2}$. Using $\pi r_{2}{ }^{2}=\lambda_{d}{ }^{2} / 2$ from assumption seven the result is,

$$
p_{2}-p_{1}=\left(j_{g} / \beta^{\prime}+1 / \beta\right)^{-1}\left[\mu_{f} k_{f} \Delta T / 1\left(\delta^{4} \rho_{f} h_{f g}{ }^{\prime}\right)\right]\left[\lambda_{d}{ }^{2} / 8 \pi\right]\left[2 \ln \left(r_{2} / r_{1}\right)+r_{1}{ }^{2} / r_{2}{ }^{2}-1\right]
$$

The LHS of Equation III.16 can also be equated to the static force balance e.t $r=r_{1}$ and $r=r_{2}$, Figure III.la, i.e.,

resulting in,

$$
\begin{array}{cl}
p_{2}-p_{0}=\rho_{l} g l & \text { at } r=r_{1} \\
p_{1}-p_{0}=\rho_{f} g \ell+2 \sigma / r_{b} & \text { at } r=r_{2}
\end{array}
$$

$$
p_{2}-p_{1}=\ell\left(\rho_{l}-\rho_{f}\right) g-2 \sigma / r_{b}
$$

Zuber and Tribus (1958) assumed at the minimum film boiling point, $r_{b}=\lambda_{d} / 4$ and as previously stated $\lambda_{d}=2 \pi\left[3 \sigma /\left(g\left(\rho_{\ell}-\rho_{f}\right)\right)\right]^{1 / 2}$ which gives Equation III.17 the form of:

$$
p_{2}-p_{1}=\ell^{\prime \prime}\left(\rho_{\ell}-\rho_{f}\right) g \lambda_{d}
$$


Implicit in Equation III.18 is that the average bubble height, $l$, shown in Equation III.17 and Figure III.1a is proportional to the diameter of the bubble, $d_{b}$. Berenson (1961) gave $\ell=0.68 d_{b}$ from experimental observations made by Borishansky (1953). Since Borishansky was measuring "the thickness of a bubbly spheroid", which was the height a bubbly "pancake" of fluid floating on a larger horizontal surface and not the height of the bubbles themselves, the 0.68 constant may be incorrect. Even so, the experiments of Lewis (1950) in verifying the wave instability theory of Taylor (1950) concluded that "an exponential increase in [wave] amplitude... [occurs] until the amplitude is about 0.4 [times the wavelength]." As a result, at approximately $\ell=0.4 \lambda_{d}$ the wavecrest begins to form into a bubble that will subsequently break off from the vapor $f i l m$. Since $\lambda_{d} \propto d_{b}$ [Duignan et al., (1989) measured $d_{b}=\lambda_{d} / 1.28$ ] then $\ell \alpha \lambda_{d}$ and, therefore, the height of a bubble above the vapor film will be taken as $\ell=$ constant $\times d_{b}=$ constant $\times \lambda_{d}$. The constant in Equation III.18, $l$ ", which contains coefficient, constant', will subsequently be absorbed in an overall constant to be determined by correlation with the experimental data.

Equating Equation III.18 to III.16 and solving for the film thickness gives,

$$
\delta^{4}=\left(\beta_{1} j_{g}+\beta_{\| 1}\right)^{-1}\left[\mu_{f} k_{f} \Delta T D_{\ell} /\left(g \rho_{f}\left(\rho_{\ell}-\rho_{f}\right) h_{f g}{ }^{\prime}\right)\right]
$$

where $D_{l}=\lambda_{d} /\left(2 \pi(3)^{1 / 2}\right)=\left[\sigma /\left(g\left(\rho_{l}-\rho_{f}\right)\right)\right]^{1 / 2}=$ Laplace-reference length and if the heat transfer is by conduction only then:

$$
h_{\text {COND }}=k_{f} / \delta=\left(\beta_{1} j_{g}+\beta_{11}\right)^{1 / 4}\left[k_{f}^{3} g \rho_{f}\left(\rho_{l}-\rho_{f}\right) h_{f g}{ }^{\prime} / \mu_{f} \Delta T D_{l}\right]^{1 / 4}
$$

When $j_{g}=0$ in Equation III.20, the equation reverts to the stable film boiling model developed by Berenson (1961); therefore, the coefficient $\beta_{\| 1}$ is taken to be the value that Berenson obtained from correlating experimental data to his model, i.e., $\beta_{\| 1}^{1 / 4}=0.425$.

The total heat transfer is,

$$
h=h_{\text {COND }}+3 / 4 h_{\text {RAD }}
$$

from Equation II.7 and $h_{\text {RAD }}$ is Equation II.8. 
Note, the coefficient of Equation III.20 is non-dimensional since the terms in the brackets together form the dimensions of $h^{4}$. This fact can be seen directly by grouping the non-dimensional terms, i.e.,

$$
N u_{f}=\left(\beta_{1} j_{g}+\beta_{11}\right)^{1 / 4}\left[\mathrm{Gr} \operatorname{Pr} / \mathrm{Ja}^{\prime}\right]_{f}^{1 / 4}
$$

where, $\quad \mathrm{Nu}=\mathrm{h}_{\mathrm{COND}} \mathrm{D}_{\ell} / \mathrm{k}_{f}=$ Nusselt Number

$$
\begin{aligned}
& \mathrm{Gr}=D_{\ell^{3} g} g\left(\rho_{l} / \rho_{f}-1\right) / \nu_{f}^{2}=\text { Grashof Number } \\
& \operatorname{Pr}=\mu_{f} c_{p_{f}} / k_{f}=\text { Prandt } 1 \text { Number } \\
& J^{\prime}=c_{p_{f}} \Delta T / h_{f g}{ }^{\prime}=\text { Modified Jacob Number }
\end{aligned}
$$

That is, while $\beta_{11}$ is dimensionless so is the group $\beta_{1} j_{\mathrm{g}}$ with $\beta_{1}$ taking on the reciprocal dimensions of $j_{g}$. Normalizing Equation lil.20 to the Berenson Equation, $j_{x}=0$, at the same superheat gives a convenient form for correlation:

$$
\begin{gathered}
N u_{f}\left(j_{g}\right) / N u_{f}\left(j_{g}=0\right)= \\
h_{\text {COND }} / h_{C O N D}\left(j_{g}=0\right)=q_{C O N D} / q_{C O N D}\left(j_{g}=0\right)=\left(1+\beta_{1} j_{g} / \beta_{\| 1}\right)^{1 / 4}
\end{gathered}
$$




\section{EXPERIMENTAL APPARATUS}

\section{Overview}

In general, the purpose of the experiment was to determine the effect on film boiling heat transfer from a horizontal, flat cylindrical disk when a noncondensible gas was passed through the vapor film. One apparatus was used, which was periodically modified to conform to the investigation at hand. The study had three basic phases, each of which demanded a slightly different experimental configuration. The overall schematic of the experimental apparatus in shown in Figure IV.1.

For the first phase, there were no holes in the heat transfer plate and, therefore, no gas flow system. The secorid phase involved gas injection into the overlying pool of water, but without film boiling. The last phase combined both phenomena, film boiling with a non-condensible gas injection through the heat transfer surface. The non-condensible gas used was $99.996 \%$ pure nitrogen.

Heat was sent through the heat transfer surface into the overlying pool of water by means of a flexible electric heater. The pool of water was contained in a cylindrical quartz tube which sat directly above the stainless-steel heat transfer surface. The heat flux to the pool was measured by thermocouples embedded in the heat transfer plate ard by measuring the mass flux of liquid water as it condensed in the condensing system. Note, in the experiment with bubbling but no film boiling the condensing system was not used because a large percentage of the heat transfer occurred through sensible heat. The liquid in the bubbling pool phase was not kept at its saturation temperature; an assessment of the effect of the bubbling action on heat transfer was desired, and not of nucleate boiling.

Finally, the pertinent data were read by a data acquisition system to facilitate precise and accurate information. An explanation of the various aspects of the experiment apparatus follows.

\section{Test Pool}

The experimental test pool had to be made from a material that would stand up to the highest temperature that the heat transfer plate would experience, approximately $1000 \mathrm{~K}$, and also allow visual observation of the phenomena. The first of these characteristics could have been met by many materials, but the second was very limiting. The material chosen was quartz which met both requirements. Furthermore, quartz has a small coefficient of linear expansion, so that the volumetric expansion of the pool, which occurred from room temperature to the maximum operating temperature, did not cause the seals at the 


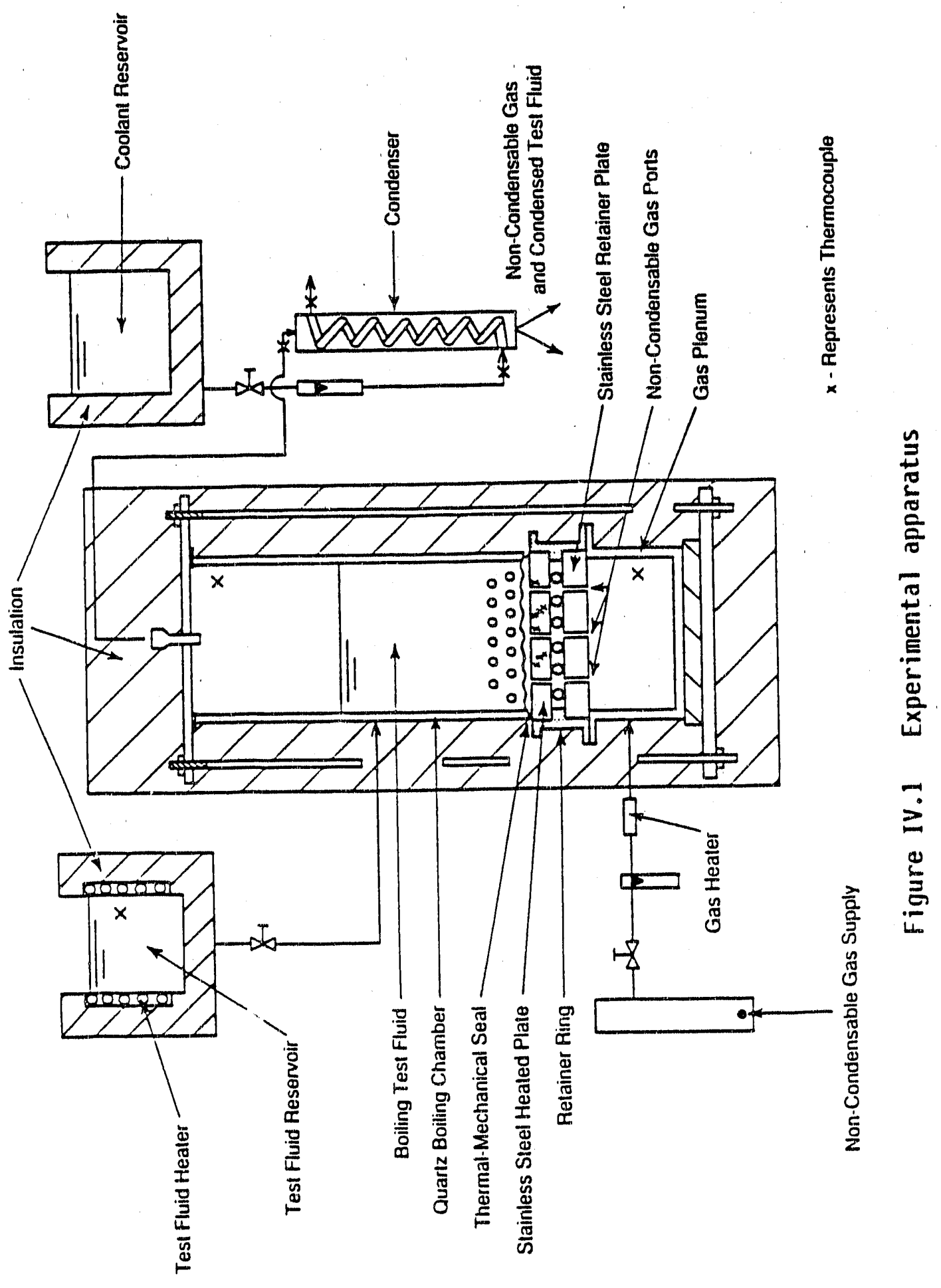


top and the bottom of the pool to leak (Figure IV.2). Moreover, the pool wall had to withstand the thermal shocks that took place each time the experiment was started.

The cylindrical test pool stood approximately $25 \mathrm{~cm} \mathrm{high} \mathrm{and} \mathrm{had} \mathrm{an} \mathrm{inside}$ diameter of $10.16 \mathrm{~cm}$, with a wall thickness of $0.3 \mathrm{~cm}$. At a height of $8 \mathrm{~cm}$ from the bottoin of the pool there was an entrance port for the entry of makeup fluid. A stainless-steel tube was fitted through the port which directed the incoming test fluid to a height of about $2 \mathrm{~cm}$ above the heat transfer plate.

The quartz container was sealed at its top by a stainlessusteel plate and a Teflon gasket. The plate was fitted with an exit tube which led to the condensing system. The top plate secured the quartz tube to the heat transfer plate by means of four bolts. The bottom of the pool was sealed by a Durabla heat-resistant gasket, which had a thickness of approximately $0.04 \mathrm{~cm}$ and an inside diameter of $10.55 \mathrm{~cm}$. This thickness is about ten times larger then the expected thickness of the vapor film previously observed in film boiling (Berenson, 1961). It was hoped that after film boiling started, the vapor-

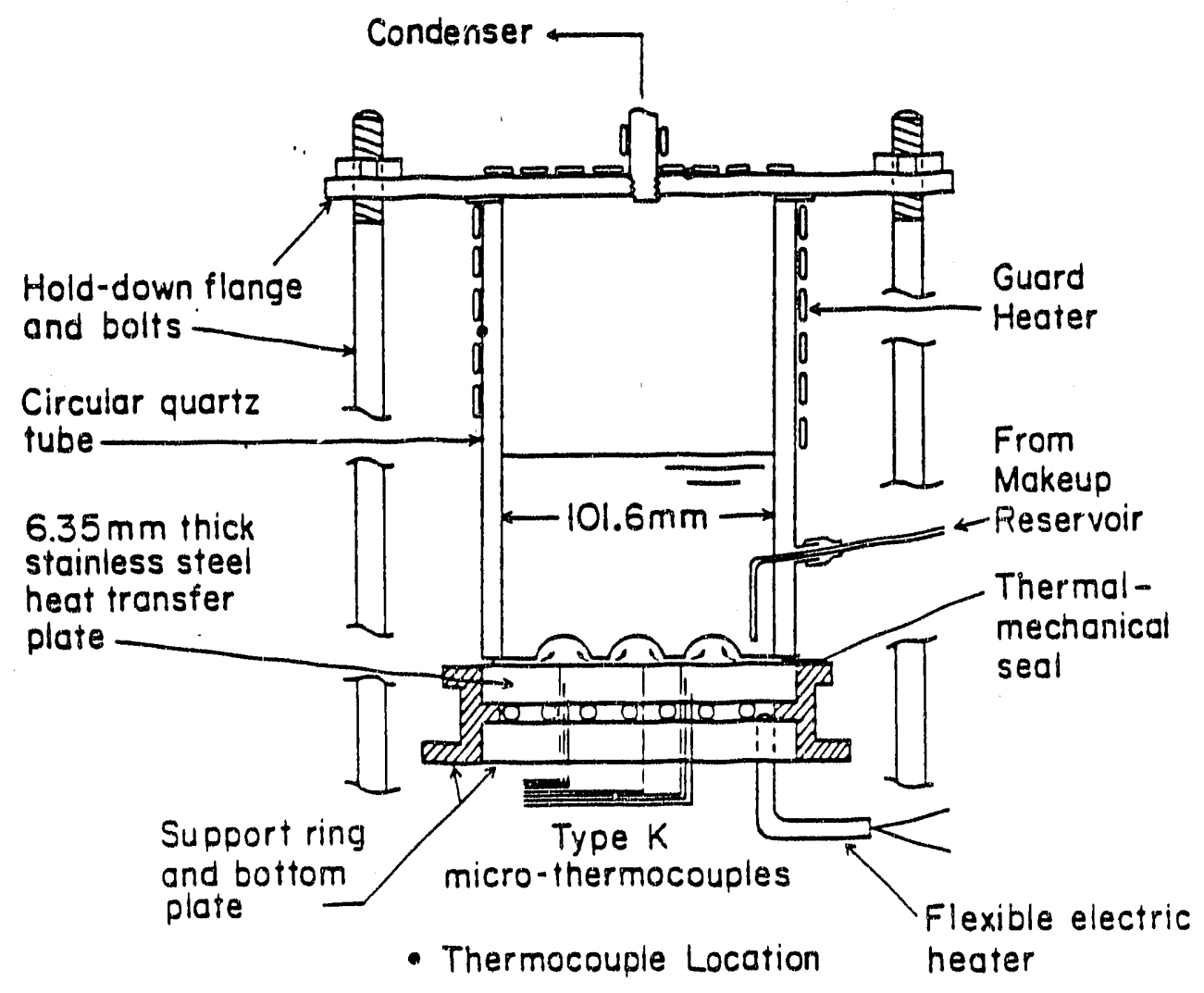

Figure IV.2 Pool and heat transfer plate 
liquid boundary would be as close as physically possible to the inside bottom edge of the quartz pool wall. Being on the bottom edge of the wall would assure a minimum surface area for the boundary, so that the more efficient mechanism of heat release, nucleate boiling, could be minimized. Furthermore, the inside diameter of the gasket was made to be approximately $0.04 \mathrm{~cm}$ larger than the inside diameter of the pool wall so that it would be recessed back from the wall, thus eliminating a surface area over which nucleate boiling could oscur. To clarify, a small gap was created between the bottom of the quartz pool wall and the heat transfer surface so that when film boiling started the vaporliquid boundary coincided with the bottom edge of the quartz wall, thereby minimizing the surface upon which nucleate boiling could occur.

Finally, the side wall and the top of the test pool were covered with guard heaters to assure that there would be no subcooling between the wall and the pool. This precaution was taken so that measurements of the heat flux, during film boiling by the condensing system, would be as accurate as possible. The temperature of the pool wall was maintained close to the saturation temperature of water by monitoring the thermocouples placed between the pool wall and guard heaters.

\section{Heat Transfer Surface}

Figure IV.3 shows the top view of the heat transfer plate. Figure IV.3a highlights the layout of the thermocouples for the heat transfer plate without gas injection holes, while Figure IV.3b shows the gas holes and the placement of thermocouples specific for that plate. Table IV.1 contains the actual locations of the thermocouples in their respective heat transfer plates. Also, Figure IV. 4 shows a schematic of an inside slice of the heat transfer plate with some material descriptions and pertinent dimensions. This schematic view shows how the thermocouple, gas orifices and heating coil were arranged within the plate.

The first phase of this study was conducted to develop a database for film boiling without a non-condensible gas passing through the heat transfer plate. This was the logical starting point, since the information could be compared with existing film boiling studies, but also it could be done before physically drilling holes in the heat transfer plate for the gas to enter the vapor film. Drilling holes in the heat transfer surface caused several problems which had to be addressed before further experimentation could continue.

The second part of the experiment involved constructing a new heat transfer plate since the removal of the old heat transfer plate from the apparatus destroyed the implanted micro-thermocouples. The new heat-transfer plate with gas holes was used in both the bubbling [without boiling] phase and the film boiling [with gas injection] phase of this study. Apart from the gas flow 


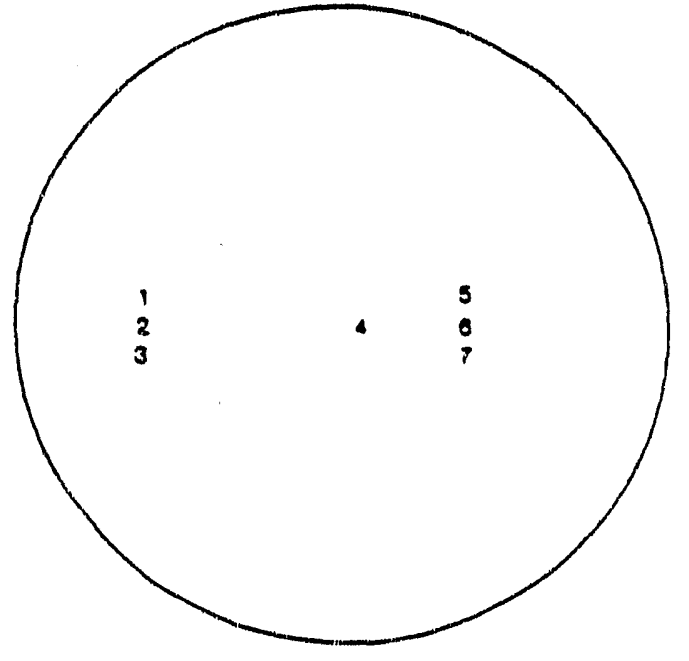

(a)

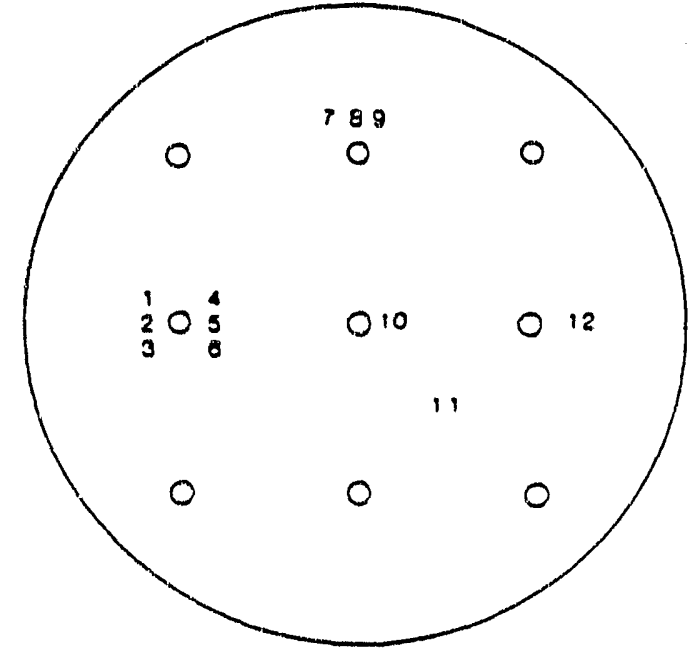

(b)

Figure IV.3 Top surface of the heat transfer plate

Table IV.1 Thermocouple locations

Plate without holes

Radial Distance Depth*from Top

TC\# from Center (mm) Surface (mm)
Plate with holes

\begin{tabular}{rcc}
\hline & $\begin{array}{c}\text { Radial Distance } \\
\text { from Center(mm) }\end{array}$ & $\begin{array}{c}\text { Depth from Top } \\
\text { Surface(imm) }\end{array}$ \\
\hline 1 & 35.3 & 5.34 \\
2 & 35.3 & 0.80 \\
3 & 35.3 & 3.09 \\
4 & 20.2 & 3.08 \\
5 & 20.2 & 0.81 \\
6 & 20.2 & 5.31 \\
7 & 36.5 & 0.79 \\
8 & 36.5 & 3.07 \\
9 & 36.5 & 5.26 \\
10 & 2.4 & 0.72 \\
11 & 20.2 & 0.79 \\
12 & 36.1 & 0.82
\end{tabular}

\section{3}

35.3

35.3

3.9

21.1

21.1

21.1

\subsection{2}

2.95

4. 9?

0.74

0.76

2.94

5.05

Uncertainty in depth measurement is 0.02 imm and the surface-to-thermocounle location includes the distarice from the top of the thermocouple well to the midpoint of the thermocouple bead, which averaged $0.25 \mathrm{~mm}$ for all thermocouples. 


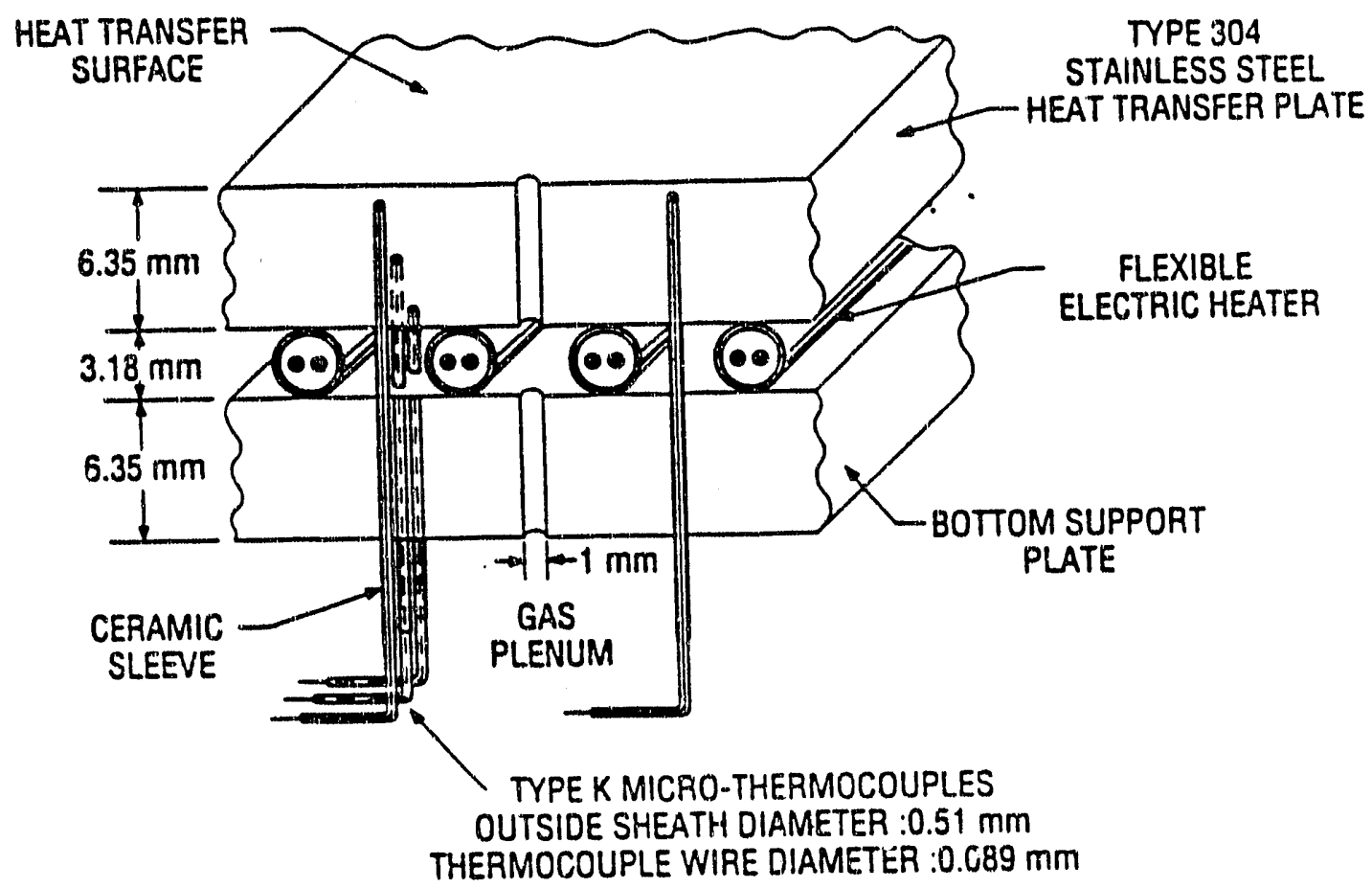

Figure IV.4 Heat transfer plate and heater assembly

system which supplied the non-condensible gas to the holes in the heat transfer plate, the experimental apparatus was basically identical for all phases of this study.

In making the heat transfer plate two very important problems had to be addressed: 1) Would the flexible coil, used to heat the plate, create the necessary uniform temperature on the upper surface of the plate since the coil was only in contact with the bottom of the plate in discrete locations, see Figure IV.4. 2) Would the thermocouples, implanted in the plate to measure the upper-surface temperature and the heat flux through that plate, give accurate readings? Both questions were answered analytically before constructing the experimental apparatus.

Figure IV.5 is the result of an analytical study which idealized a coil heater to be a series of point-heat sources below the heat transfer surface as a boundary condition. This analytical analysis is similar to that by Eckert and Orake (1972); a step-by-step procedure can be found in Duignan (1989). From this analysis the distance between successive contacts of the coil on the plate was chosen to be approximately equal to the thickness of the heat transfer plate, i.e., $H / O=1$ in Figure IV.5. This intercoil distance would give the 
upper heat-transfer surface a uniform temperature from one contact to the next as long as the same amount of heat was released at each point of contact. Since the filament of the heating coil had a diameter of approximately $3.2 \mathrm{~mm}$ and the heat transfer plate had a thickness of $6.35 \mathrm{~mm}$, the chosen separation between coils left a gap of approximately a one coil diameter between successive coils. This gap was enough for the thermocouples and gas holes in the plate assembly to pass through. The analytical study was considered conservative, since it assumed that all the heat enters the plate through an infinitesimal contact point between the heating coil and heat transfer plate. In reality, this point has a finite surface and also the sides of the coil heat the plate, through radiation. These two factors ensure a more uniform surface temperature than the analysis shows, because the heat from coil actually enters the plate over a wider area than the point contact.

To obtain accurate temperature measurements, it was important to consider how and where the thermocouples were to be located in the heat transfer plate. Since a thermocouple only measures its own temperature, it was necessary to place it where its temperature would closely correspond to that of the plate at the same location, as if the thermocouple were not present at all. Because of the physical linitations in making very long, thin thermocouple wells through the stainless-steel heat transfer plate, the thermocouple leads, which extend

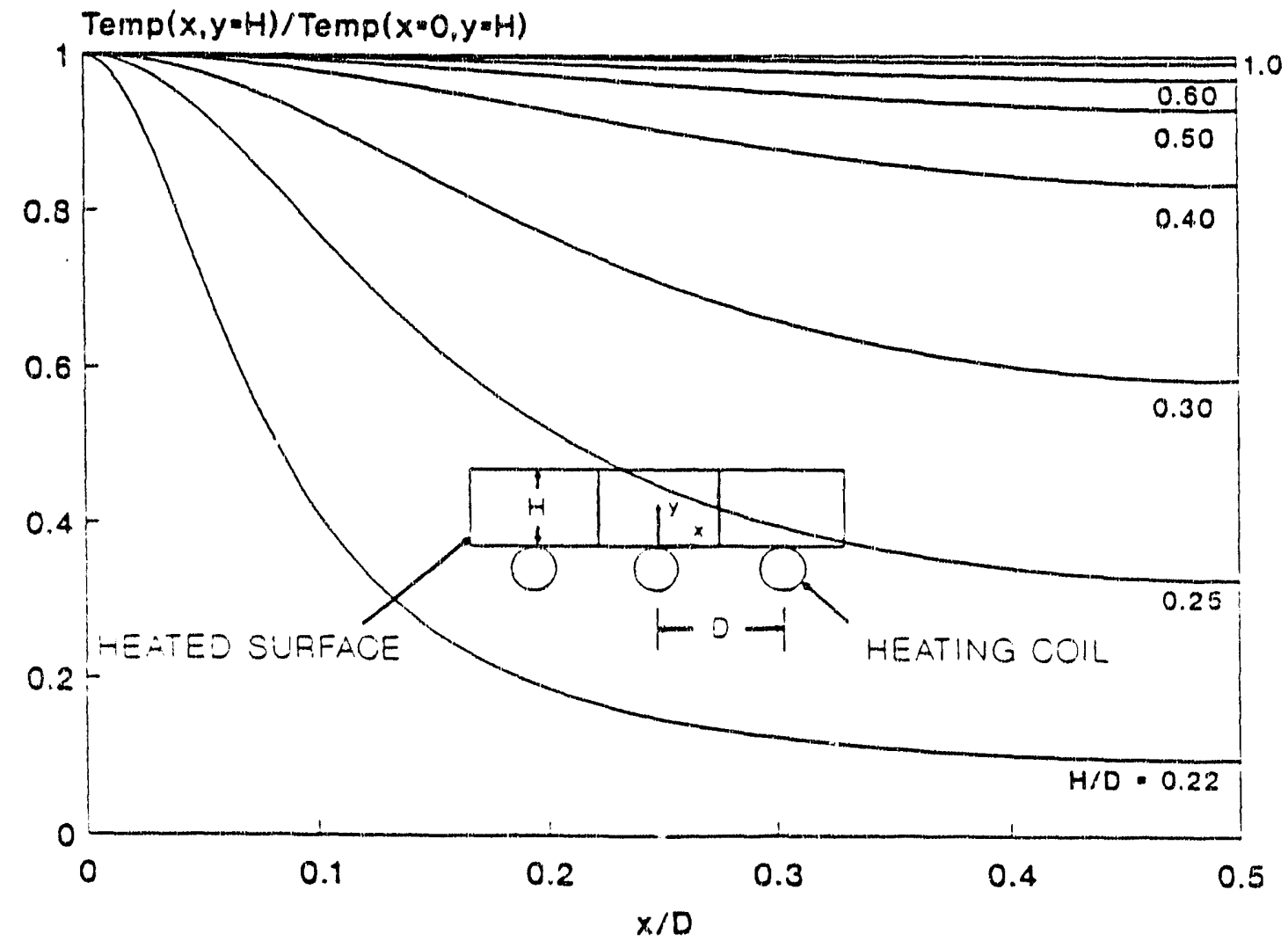

Figure IV.5 Idealized temperature across the top of the heat-transfer surface 
immediately from the thermocouple bead, could not be placed radially though the heat transfer plate. Orientation of the leads along the radii would have been preferred as then they would closely follow the isotherms in the plate. A less desirable alternate orientation was chosen to have the leads exit the plate along a vertical axis (Figure IV.4). Placed vertically through the plate, the leads were exposed to the temperature gradient in the plate, and, as such, could be an avenue for a differing heat flow than the one in the heat transfer plate. If the resistance to heat flow in the thermocouple wires and the accompanying probe, in which they were encased, differed from that of the heat transfer plate, the thermocouple bead would experience a temperature different from what would exist if the thermocouple were not present. Knowing this possible error in reading a plate temperature, an idealized model was developed to try to quantify how much the thermocouple temperature would differ from the true temperature. Assuming that the thermocouple was a fin, following an analysis by Sparrow (1976) as a guide, it was found (Duignan, 1989) that the thermocouple reading would differ by approximately $0.65 \mathrm{~K}$ from the true local temperature. This temperature difference is relatively insignificant since the absolute temperatures used in this experiment were greater by three orders of magnitude. Therefore, the orientation of the thermocouples shown in Figure IV.4 was deemed acceptable for the experiment.

The last important concern about the thermocouples in the heat transfer plate is an accurate knowledge of their location. The top plate surface-tothermocouple distances listed in Table IV.1 is a sumnation of the distance from the top of the plate to the bottom of thermocouple well, from the well bottom to the top of the thermocouple bead, and, finally, the radius of the bead itself. The first distance was easily measured with a depth micrometer. Measuring the last two dimensions presented more difficulty. They were determined from measurements of similar thermocouples embedded in test blocks which were machined to expose the thermocouple bead and the distance between the top of the bead to the well bottom. Figure IV.6 shows two views of the thermocouple beads, their respective lead wires, and the thermocouple probe sheath with its $\mathrm{MgO}$ insulation removed. These pictures show that the bead height is approximately $80 \%$ of the outside diameter of the thermocouple probe, which was approximately $0.51 \mathrm{~mm}$. Figure IV.7 is a graph of actual dimensions of a thermocouple in its well, which was measured with a microscope on a traversing table, accurate to $1 \mu \mathrm{m}$.

With the knowledge of the thermocouples' locations and how much their readings differed from the true plate temperatures both the surface temperature of plate and the heat flow through the plate could be measured once the implanted thermocouples were calibrated. [The calibration can be found in Appendix A2.] The calibration showed that the "true" thermocouple temperature differed from those obtained from tabulated EMF values, published by the National Bureau of Standards(NBS), by not more than $1.5 \mathrm{~K}$ over the range of experimental temperatures. Note, "true" means a reading obtained from a 
platinum resistance thermometer which had an accuracy of better than $0.01 \mathrm{~K}$. Because of the high plate temperatures used, above $500 \mathrm{~K}$, this $1.5 \mathrm{~K}$ maximum temperature difference was considered insignificant and therefore the NBS tabular values were applied directly to determine the thermocouple temperature from its voltage output.

From the thermocouple readings both the surface temperature of the plate [by extrapolation], and the heat flux through the plate [by conduction] were determined. An example of how those two quantities were determined is shown in Duignan (1989).

\section{Condensing System}

Besides calculating the heat conduction through the heat transfer plate, another means used to obtain the heat flux was by measuring the mass of water vapor leaving the boiling chamber. This was done by condensing the vapor and measuring the rate at which water left the system. After eliminating the sources of superheating and subcooling water in the test pool, this mass flux measurement became the most accurate and primary means of measuring heat flux. Moreover, the assessment of heat flux based on the collected condensate was inherently more stable than the method of heat conduction. Small changes in the temperature of the heat transfer plate led to large changes in the axial temperature gradient through the plate, and hence, large fluctuations in the inferred heat flux by conduction.

Figure IV.1 shows how the condensing system was setup. Care was taken to make sure that the condensers used completely condensed all the water vapor, while not significantly increasing the pressure in the boiling chamber, which would have changed the saturation temperature of the water. The pressure in the test pool was periodically checked and found to be approximately $5 \mathrm{~cm}$ of $\mathrm{H}_{2} \mathrm{O}$ above atmospheric pressure, not enough to change significantly the saturation temperature from the value at atmospheric pressure. Total condensation was checked by measuring the temperature of the exiting mixture of nitrogen, water vapor, and water.

The only other concern in the measurement of mass flux was the loss of water which left the condensing system with the nitrogen. To this end, the water vapor contained in the saturated nitrogen gas leaving the condenser, was taken into account. Furthermore, the escaping nitrogen was checked to see if it was transporting water droplets. It was found that no perceptible water, in the form of liquid, left with the gas below superficial gas velocities of approximately $10 \mathrm{~cm} / \mathrm{s}$. As seen in Appendix A5, most of the data were for gas velocities relow this value. 

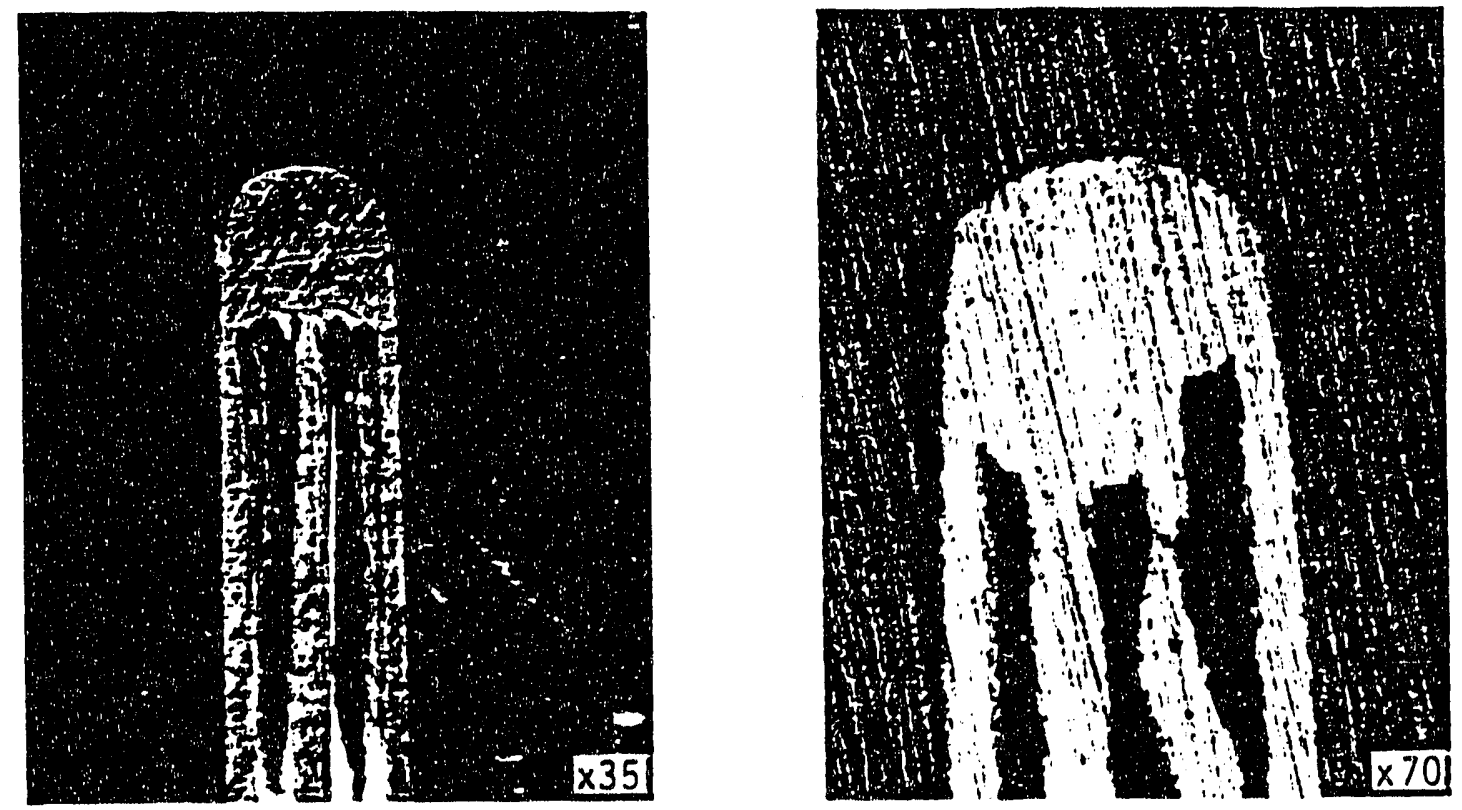

Figure IV.6 Magnification of the inside of a typical thermocouple

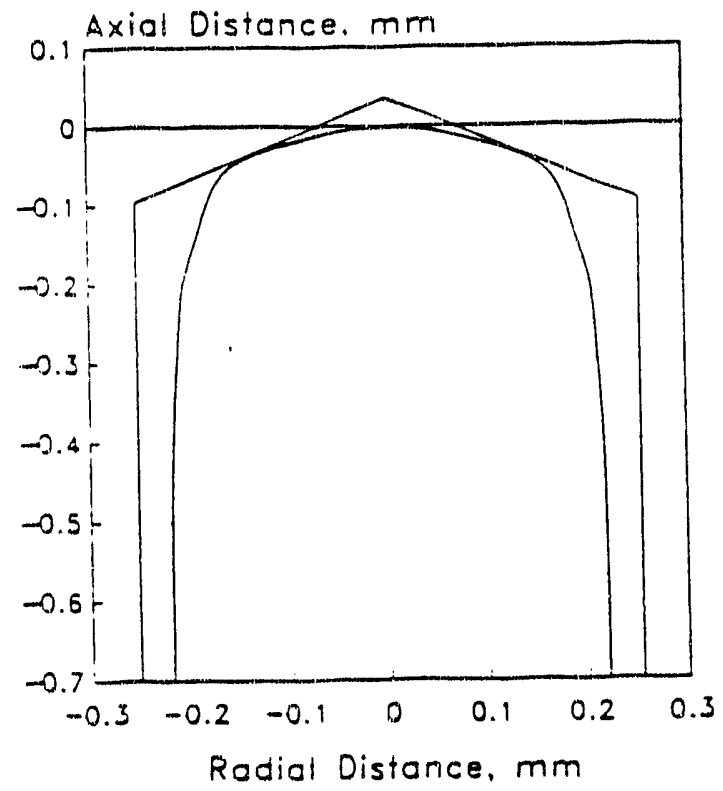

Figure IV.7 Mapping of a thermocouple within its well 


\section{Gas Flow System}

The non-condensible gas-flow system shown in Figure IV.I consisted of a gas supply reservoir, a pressurized metering system, and an in-line gas heater. The in-line gas heater ensured that gas entering the experimental apparatus was approximately at the temperature of the heat transfer plate. Even though the heat capacity of the nitrogen is insignificant with respect to the stainlesssteel apparatus or the water in the bubbling pool, its entering the system at the temperature of the plate ensured that no local cooling would occur around the jet holes, which might have created instabilities.

The gas flow rate was measured by a rotameter which was metered at $0.276 \mathrm{MPa}$ above atmospheric pressure to insure a smooth flow through the meter. To maintain approximately the same pressure drop across all the jet holes in the heat transfer plate a gas plenum was used, which also included a thermocouple to monitor the temperature of the incoming gas.

\section{Data Acquisition System}

The centralized data acquisition and analysis system was constructed around a HP 9640 system, which consisted of a 21 MX mini-computer with 112 kilobytes of random access memory, and a 7.5 megabyte cartridge disk. The system was controlled by interactive software, which received transfer parameters from the experimenter and scanned data channels upon command.

The twelve thermocouples of the heat transfer plate were read sequentially at 0.1 second intervals during one minute. A one-minute interval gave fifty temperature values for each thermocouple, which were averaged to give a resulting temperature. Further, all thermocouple outputs were measured by a programmable digital voltmeter with a resolution of 1 microvolt, and the thermocouple scanning time was 1 millisecond per channel. 


\section{PRESENTATION OF RESULTS}

The mechanisms of heat transfer from a surface over which film boiling occurs and through which non-condensible gas jets emerge at discreet locations are complex. In developing a heat-transfer database, attempts were made to better understand the complex heat-transfer environinent by observing film boiling and jetting separately. The following section has been broken down into three parts: film boiling from a horizontal flat surface, gas jetting into an overlying liquid pool, and film boiling and gas jetting combined.

\section{Film Boiling Over a Horizontal Flat Surface}

This section describes the result of two experinents, the first to observe film boiling occurring over a "large" horizontal surface, and second to obtain heat transfer data to compare to the Berenson (1961) film boiling model. Note, the term "large" applies to a surface which meets the criterion: $0>2 \lambda_{d}$ (Kesselring et al., 1967). Since the dianeter of the heat transfer plate used was $D=101.6 \mathrm{~mm}$ and for water $2 \lambda_{d} \sim 54.4 \mathrm{~mm}$, then the surface is considered large.

\section{a. Visual Observations of Film Boiling}

This subsection is an excerpt from a more detailed paper (Duignan, et al., 1989) and is only summarized here.

A photographic study of film boiling on a flat surface was performed to measure the hydrodynamic parameters in the Berenson (1961) model. Specific considerations were given to the geometric pattern of the bubbles, the interbubble spacing, and the release period of the bubbles at one specific surface superheat. The temperature of the plate surface chosen for the high-speed films was $735 \mathrm{~K}$, thought to be well into the stable film-boiling region (Poniewski, 1987). The measured point on the boiling curve corresponding to the conditions chosen for this study was.

$$
q=67 \mathrm{~kW} / \mathrm{m}^{2}, \quad \Delta T_{\text {SAT }}=362 \mathrm{~K}
$$

where $q$ is the average value of the boiling heat flux determined by conduction through the heat transfer plate $\left[69 \mathrm{~kW} / \mathrm{m}^{2}\right]$ and by condensing the water vapor leaving the boiling chamber $\left[65 \mathrm{~kW} / \mathrm{m}^{2}\right]$. At this superheat, the Berenson (1961) 
model predicts the heat flux to be $70 \mathrm{~kW} / \mathrm{m}^{2}$, including a $3 \%$ radiation correction (Bromley, 1948). The radiation estimate assumes a water emittance of 0.96 and 0.10 for the polished stainless-steel plate.

To determine the optimum pool depth for observing the geometric pattern of bubble release, a video movie was taken as the pool boiled down. Although patterns were discernible at a depth of $20 \mathrm{~mm}$, lower depths were visually better. It was decided to take two high-speed filins, one at about a 15-minliquid depth, and another at about $5 \mathrm{~mm}$. Using a bubble release period of 0.20 seconds as a guide (Hosler and Westwater, 1962), a speed of 400 frames per second for 10 seconds was. chosen. This speed should catch a large number of complete bubble cycles. On both high-speed films a geometric bubble pattern was discernible, but at the 15-mm-liquid depth the pool obscured the geometry. Therefore data to be discussed were obtained on the 5-mm-deep pool. Still photographs were also taken to obtain sharper inages of the bubble pattern.

To demonstrate the spatial regularity of bubble formation, a typical frame from a high-speed film is shown Figure V.la and a more detailed still photograph in Figure V.2a. Figures $V .1 b$ and $V .2 b$ are tracings of their respective pictures, to highlight the locations of the bubbles. Superimposed on the tracings is a square grid lattice with a cell dimension of the most dangerous wavelength $\lambda_{d}$ (bollman and Pennington, 1954). In general, the large circles in the lattice, representing mature bubbles, match the bubbles most prominent in the photographs. The circular dots, which represent the beginning of bubble formation or the void from which a bubble had recently departed, lie in the inter-bubble locations. Thus, the observed pattern corresponds to the idealized pattern of bubble release proposed by Sernas (1973).

In Figures V.1 and V.2, the superimposed square grid lattice does not fit perfectly on the bubble structure. Lienhard and Schrock (1963) report that the underlying geometric pattern of the bubbles becomes distorted by drift in the distance between release sites and by the horizontal movement of bubbles as they rise in a turbulent pool. Ideally, the heat transfer plate should be isothermal. However, there was a temperature difference of a approximately 35 $K$ from the centerline to the outer edge of the plate. Lao (1969) showed that this thermal gradient has a negligible effect on the inter-bubble spacing, but it can have a noticeable effect on the requency of the Taylor wave. The vertical boundaries of the heat transfer chamber can also cause several problems. Most of the height of the vertical wall which contained the boiling fluid was at the temperature of the pool. The bottom of the vertical wall was less than $0.5 \mathrm{~mm}$ from the heat transfer plate. Both superheated vapor and a solid thermal insulator existed between the plate and the vertical wall, and there was a large thermal gradient across this gap. This thermal gradient may have caused the vapor film to be unstable, and may have introduced some nucleate boiling around the inside bottom perimeter of the circular quartz tube. 


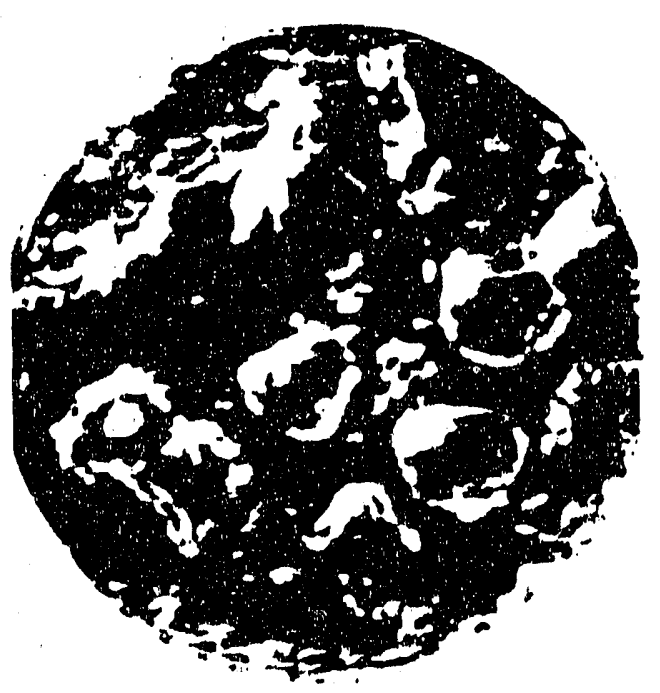

(a)

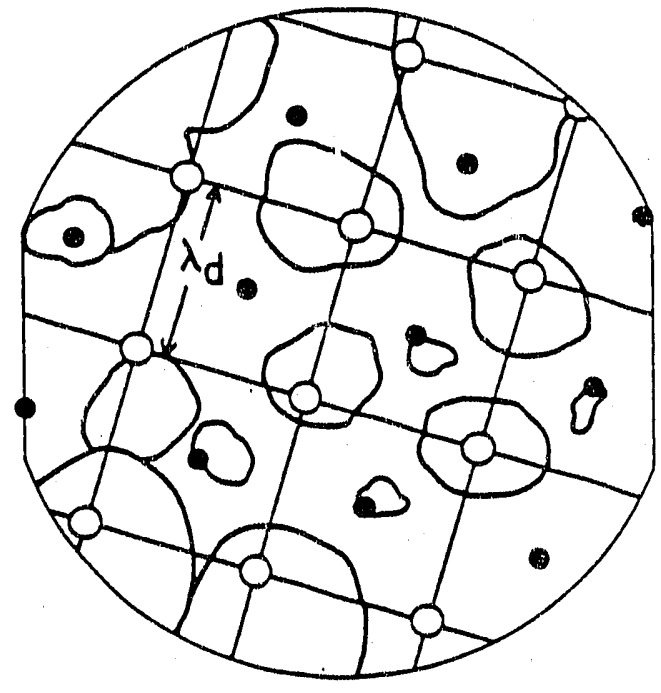

(b)

Figure V.l Single frame from the high-speed film of film boiling (Water at $1 \mathrm{~atm} ., \Delta \mathrm{T}_{\text {SAT }} \sim 362 \mathrm{~K}, \mathrm{q} \sim 67 \mathrm{~kW} / \mathrm{m}^{2}$ )

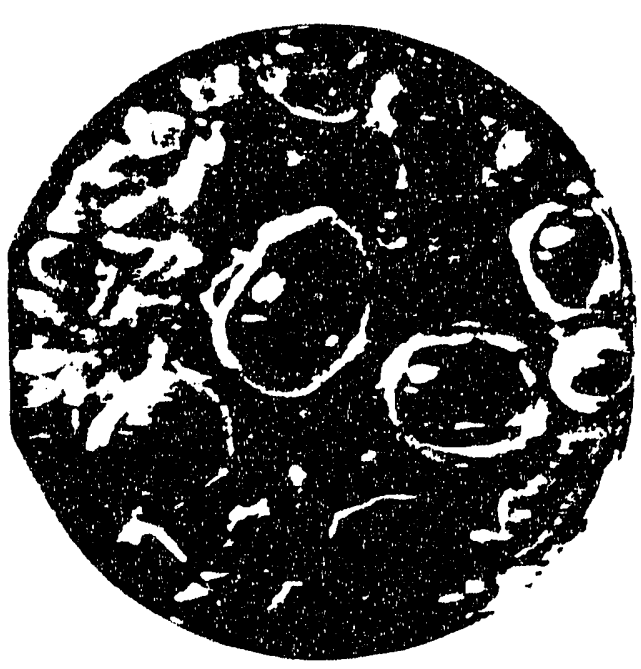

(a)

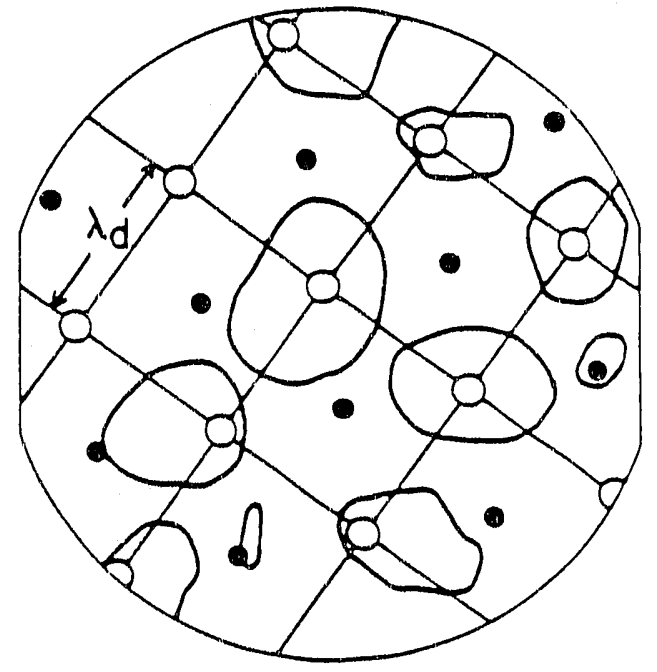

(b)

Figure V.2 Still photograph of film boiling (Water at $1 \mathrm{~atm} ., \Delta T_{\text {SAT }} \sim 319 \mathrm{~K}, \mathrm{q} \sim 63 \mathrm{~kW} / \mathrm{m}^{2}$ ) 
The high-speed films provided enough information to calculate the heat transfer during film boiling from measurements of the inter-bubble spacing, the dianeter of the bubble as it left the vapor-liquid interface, and the bubble's release period. These results are summarized below.

For the inter-bubble spacings, 52 spacings were measured from 45 different photographic frames. The average spacing was,

$$
\lambda_{\text {d,MEASUAED }}=27.9 \mathrm{~min}
$$

with a sample standard deviation of $3.9 \mathrm{~mm}$. This measurement is within $2.6 \%$ of the theoretical most dangerous wavelength, i.e.,

$$
\lambda_{d}=2 \pi\left[3 \sigma /\left(g\left(\rho_{l}-\rho_{f}\right)\right)\right]^{1 / 2}=27.2 \mathrm{~mm}
$$

From 68 observations the average diameter was $D_{b}=26.8 \mathrm{~mm}$, with a sample standard deviation of $2.3 \mathrm{~mm}$. The shallow pool was not sufficiently deep for bubbles to form and break off from the vapor $f i l m$, so they broke while still having a large hemispherical shape. To compare the volumes of hemispherical bubbles based on deep pool conditions, the hemispherical bubble volumes were equated to equivalent spherical volumes to obtain an equivalent spherical diameter, i.e.,

$$
D=D_{b} /(2)^{1 / 3}=21.3 \mathrm{~mm}
$$

Comparing this diameter to the most dangerous wavelength gives $D=\lambda_{d} / 1.28$, which is close to the result obtained by Hosler and Westwater (1962), i.e., $D=\lambda_{d} / 1.45$.

For the release period, 61 observations were made from the film which was optically marked at $100 \mathrm{~Hz}$. The average period measured was,

$$
r=0.27 \text { seconds }
$$

with a sample standard deviation of 0.04 seconds. This result is larger than the value of 0.20 seconds previously reported by Hosler and Westwater (1962) at the minimum film-boiling superheat. 
The measured values for the spacing, diameter, and release period of the bubbles were used to make an additional heat balance. This value was for comparison to the average heat flux of $67 \mathrm{~kW} / \mathrm{m}^{2}$ measured by conduction through the test plate and condensate collection, as previously described. The boiling lieat flux is given by,

$$
\begin{gathered}
q=\frac{\text { volume of vapor }}{\text { bubble }} \times \frac{\text { bubbles }}{\text { area }} \times \text { frequency } \times \text { density } \times\left(\begin{array}{l}
\text { effective heat } \\
\text { of vaporization }
\end{array}\right) \\
q=\left[(4 / 3) \pi(D / 2)^{3}\right]\left[2 /\left(\lambda_{\text {d,MEASUAED }}\right)^{2}\right][1 / \tau]\left[\rho_{f}\right]\left[h_{f g}+0.5 c_{p_{f}} \Delta T_{S A T}\right]
\end{gathered}
$$

Assuming an average film temperature of $554 \mathrm{~K}$, the heat flux calculated from the photographic parameters is $50.4 \mathrm{~kW} / \mathrm{m}^{2}$, which is within $25 \%$ of the average of the heat fluxes measured by conduction and condensation $\left(67 \mathrm{~kW} / \mathrm{m}^{2}\right)$.

\section{b. Film Boiling with No Gas Injection}

Film boiling with a non-condensible gas jet emerging from the heat transfer surface reaches an asymptote when the velocity of the jet goes to zero. That is, without a gas jet, there should remain only film boiling; therefore the heat transfer should be governed by the mechanisin of film boiling. Obtaining heat transfer data for only film boiling would not only be a baseline asymptote, by which to compare the heat transfer when the jet velocity is larger than zero, but it would be a means to compare to other film boiling models and data.

The film boiling model of Berenson (1961),

$$
q_{B E R}=h_{B E R} \Delta T_{S A T}=.425\left[k_{f}^{3} g \rho_{f}\left(\rho_{l}-\rho_{f}\right) h_{f g}{ }^{\prime} / \mu_{f} D_{l}\right]^{1 / 4} \Delta T_{S A T}^{3 / 4}
$$

was chosen for comparison because of its demonstrated accuracy for several fluids [better than $\pm 20 \%$ as shown by Berenson (1962), Hosler and Westwater (1962), Frederking et al. (1966), and Ramilison and Lienhard (1987)]. Data are scarce for water over large horizontal flat surfaces. Hosler and Hestwater (1962) showed filin boiling data for water, but only up to surface superheats of about $220 \mathrm{~K}$. Berenson (1961), who did not use water in his experiments, stated that while his model was developed for the conditions near the minimum film boiling point (MFB) it "...probably applies to temperature differences [surface superheats] as high as [ 556K] for some fluids." For this study, the maximum surface superheat attained was $\Delta T_{\text {SAT }}=567 \mathrm{~K}$ [Run $1,9 / 22 / 87$ in Table A5.1], so 
this should be a good test to see if his statement holds for water at atmospheric pressure. Higher superheats were not possible because nucleate boiling on the quartz container wall could not be suppressed.

Investigating for conditions near the minimum film boiling point Berenson (1961) did not have to be concerned with the radiation from the heat transfer surface because it was insignificant. At higher surface temperatures, the radiative contribution to the overall heat transfer increases to a point where it must be included for his model to remain accurate. At the highest measured surface temperature, $T_{\text {SUAF }}=\Delta T_{\text {SAT }}+T_{\text {SAT }}=567 \mathrm{~K}+373 \mathrm{~K}=940 \mathrm{~K}$, the heat transfer in the form of radiation is about $7.2 \%$ of the total. This value is based on a total normal emittance for the polished metal surface of 0.26 and 0.96 for the vapor-liquid interface. Note, the correct total emittance which should be used for the metal and water surfaces is hemispherical. Total hemispherical emittance data are scare, but Sparrow and Cess (1970) point out that the difference in magnitude between hemispherical and normal emittances is less than the measurement uncertainties of these quantities caused by differences in surface condition. Therefore, total normal emittance data are used whenever the total emittance is needed.

Figure V. 3 compares the experimental data to the Berenson mode1, presenting it in terms of the measured quantities $q$ and $\Delta T_{S A T}$, as opposed to the dimensionless form of Equation III.21 with $j_{f_{1}}=0$. Using the latter to present the data would include the uncertainties il the thermo-physical properties, shown in Appendix $A 6$, as well as in the measured quantities, shown in Appendix A4, Table A4.1

As mentioned, the radiative contribution must be taken into account at high surface temperatures. To make the comparison in Figure V.3, the quantity of heat transfer due to radiation was subtracted from the measured heat flux by using Equation 11.7 , i.e.,

$$
q_{\text {COND }}=q-3 / 4 q_{\text {RADIATION }}
$$

and from Equation II.8,

$$
q_{\text {RAD }}=h_{\text {RAD }} \Delta T_{S A T}=\sigma_{S B}\left[1 / \epsilon_{S S}+1 / \epsilon_{\ell}-1\right]^{-1}\left(T_{S U R F}{ }^{4}-T_{S A T}{ }^{4}\right)
$$




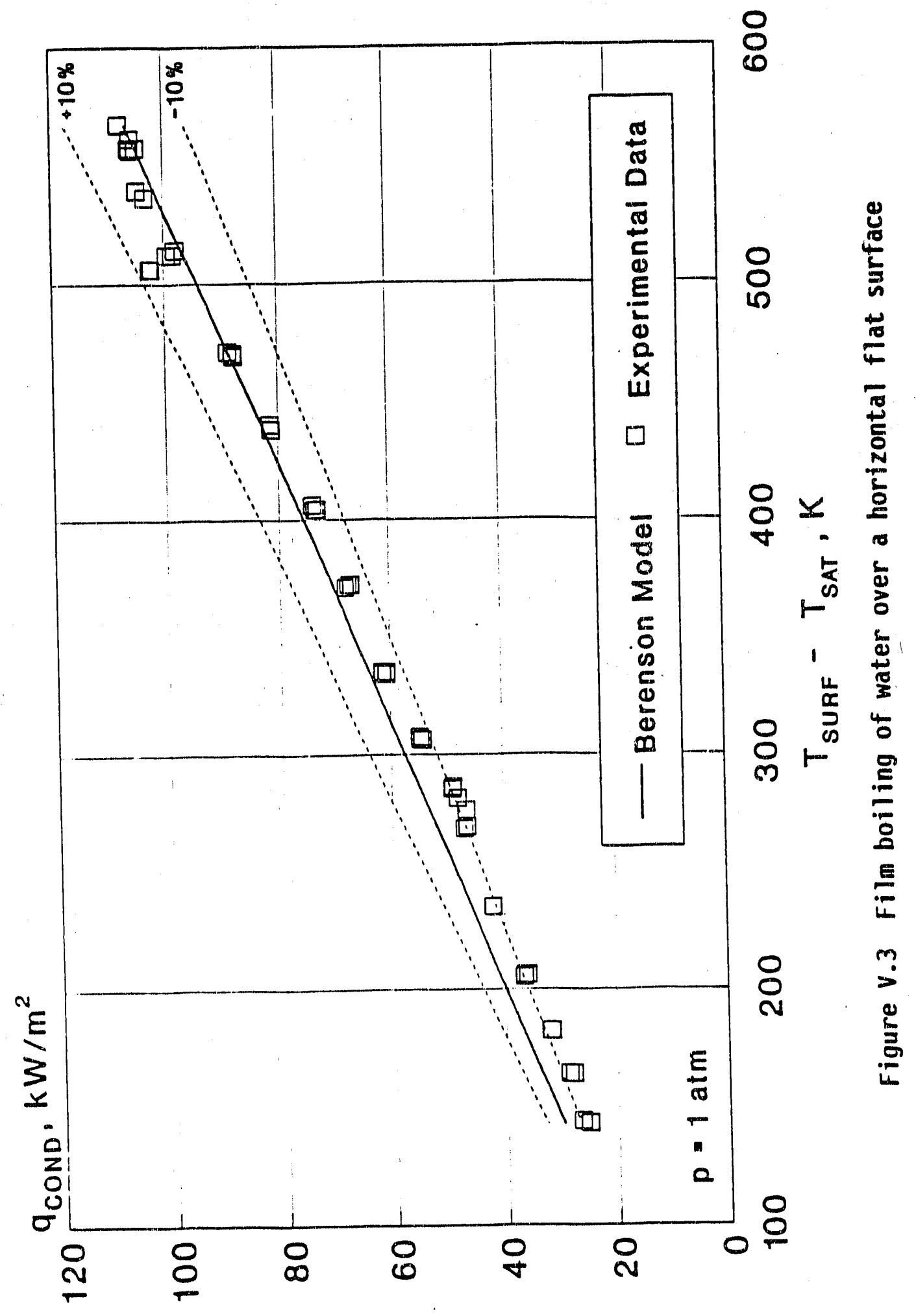


The total emittance, $\epsilon_{S S}$, is a function of temperature and its normal component can be found in Appendix A6. Note that the water vapor in the film is assumed to be radiatively non-participating, that is, the emission and absorption properties of the vapor are insignificant across the thickness of the vapor film. Sparrow (1964) states that for film boiling "...the emissivit" of steam at atmospheric pressure appears to be less than $0.01 \ldots$ " because of the thin vapor film and therefore, "...the effect of such an emissivity on the heat transfer is completely negligible."

Figure V. 3 srows that the film boiling model, Equation V.1, represents the data well, but at lower surface superheats the data are systematically lower than the model. On the average, the data differ by $6.8 \%$ from the model over the entire range of measured surface superheats and nowhere is the difference greater than $17 \%$. The data were also correlated to a best fit curve [by letting the coefficient, 0.425 , in Equation V.1, float] to determine if it could be improved for water. The coefficient obtained was 0.417 , with a standard deviation of 0.003 . At the $99 \%$ confidence level the range of the coefficient is $[0.409,0.425]$, therefore, the $2 \%$ difference between the two correlation coefficients is insignificant. The coefficient $\beta_{\| 1}^{1 / 4}=0.425$ will be used when correlating the data on gas-flux-enhanced film boiling to Equation III.21.

Another way of presenting the data, shown in Figure V.3, is in terms of the heat transfer coefficient, Figure V.4. The latter figure shows the relative constant value of the heat transfer coefficient, characteristic of stable film boiling.

\section{Gas Jetiing into an Overlying Liquid Pool}

Before presenting the data on gas-flux-enhanced film boiling it is interesting to look at the heat-transfer environment when discreetly located jets energe into an overlying pool of liquid with no boiling occurring. As shown in Section IV. Figure IV.3, there were nine gas jet holes in the heat transfer surface, separated sufficiently to be considered "sparsely" located, as explained in section II. The holes were arranged to coincide with the bubble release pattern, shown in Figures V.1b and V.2b. A detailed explanation of the experimental procedure and results are given in a recent paper (Duignan et al.. 1990) and will only be sumnarized here.

The data are presented in Tables A5.2a and A5.2b. The latter table was included to show that pool height had to be considered. The data were obtained by maintaining the superficial gas velocity $\left[j_{g}=6.4( \pm 0.8) \mathrm{cm} / \mathrm{s}\right]$ and the heat flux $\left[q=26.9( \pm 0.7) \mathrm{kW} / \mathrm{m}^{2}\right]$ constant, while the pool height was varied from $2.5 \mathrm{~cm}$ to $15 \mathrm{~cm}$. For heights below $6 \mathrm{~cm}$ the heat transfer coefficient decreased linearly with a decrease in ponl height. For pool heights of $6 \mathrm{~cm}$ and greater. 


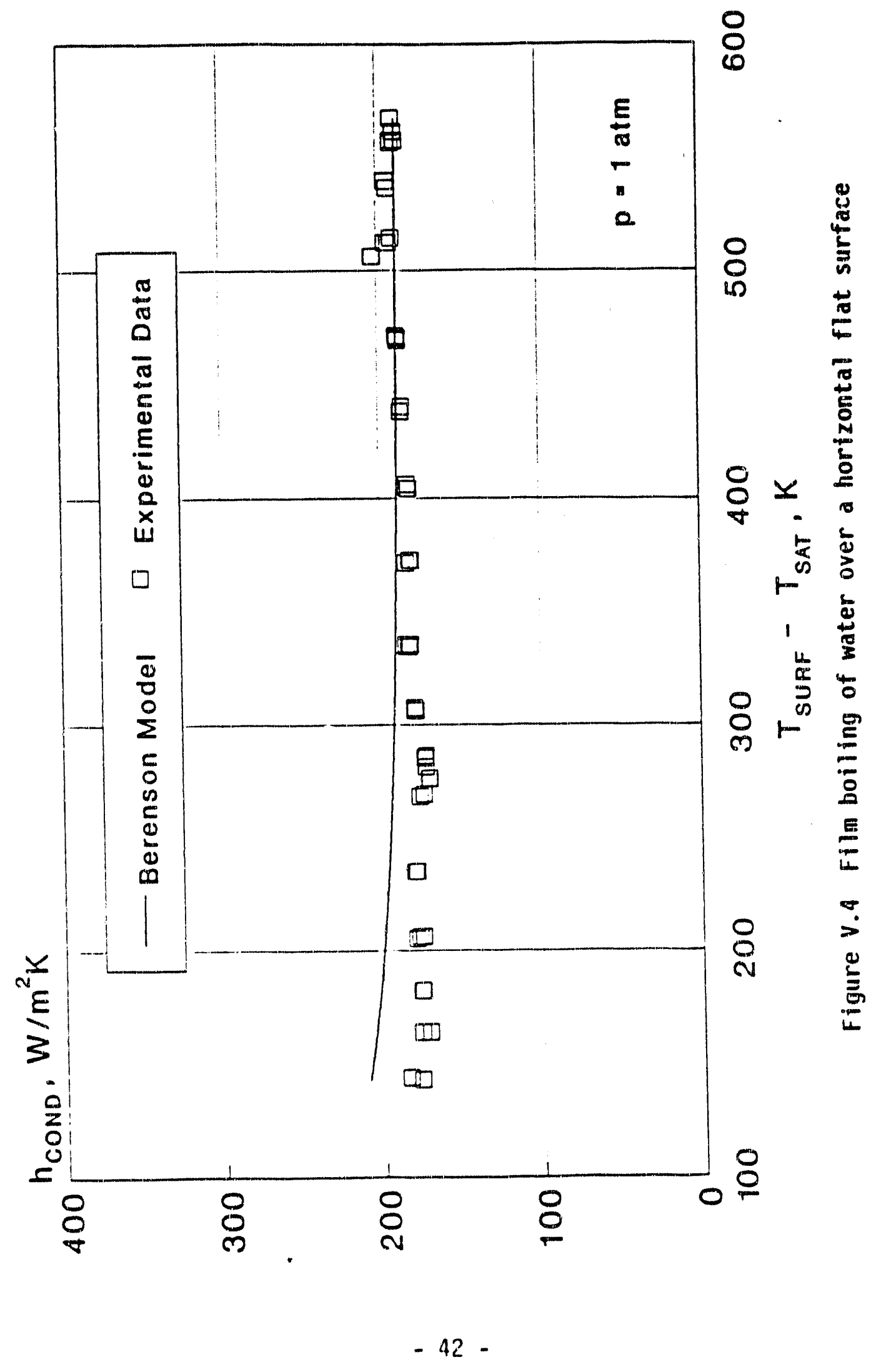


the heat transfer coefficient remained relatively constant $[h \sim 5400( \pm 200)$ $\left.\mathrm{W} / \mathrm{m}^{2} \mathrm{~K}\right]$. To eliminate the added complication of the effect of pool height on the heat transfer, the data shown in Figure $V .5$ are only for heights above $11 \mathrm{~cm}$, as shown in Table A5.2a. The mean values of data [i.e., for $q, h$, and $j_{g}$ ] are followed by a number in parentheses which is the standard deviation of the value, as shown above and in Figure V.5.

Included in Figure $V .5$ are the data of Kolbel et al. (1958) and the correlation of Fair et al. (1962). Even though these studies involved heat transfer surfaces that were neither flat, horizontal, nor the source of - the bubbling, as was the case in the present study, their data show reasonable agreement with the present measurements. Also shown in Figure $V .5$ is the Konsetor turbulent heat transfer model [Equation II.11] with the coefficient changed from 0.19 to 0.28 . This change in the coefficient causes the Konsetov model to be bounded by the present experimental data. [The water properties were extrapolated from the tabulated values given in Eckert and Drake (1972)]. This new correlation coefficient, 0.28 , was obtained by a least-squares fit to the present experimental data for $j_{g}>2 \mathrm{~cm} / \mathrm{s}$. The $47 \%$ increase in the magnitude of the coefficient for water over the original 0.19 , given by Konsetov, is consistent with the observation of Greene (1989) who found that, on the average, the measured bubbling heat transfer coefficient from a water pool to a vertical boundary exceeded the Konsetov model prediction by the same margin.

An interesting result shown in Figure $V .5$ is that for superficial gas velocities greater than $0.6 \mathrm{~cm} / \mathrm{s}$, the heat transfer from a solid surface to a liquid pool is neither dependent on the orientation of the heat transfer surface, horizontal or vertical, nor on the location of the bubbling source, that is, whether the bubbles pass through the heat transfer surface itself or come from some other, lower, surface. These observations support the following hypotheses: 1) the bubbles that are formed at and leaving the heat transfer surface contribute little to the local heat transfer when they are "sparsely" located, 2) the superficial gas velocity from the heat transfer surface is adequate to maintain the turbulence in the liquid pool, and 3) the pool is deep enough not to affect the steady-state turbulent structure in the pool. Hypotheses (2) and (3) will be discussed, although direct measurements of turbulence in the pool were not made during the course of this investigation.

With respect to the first hypothesis, it was previously discussed in Section II at what distance the bubbling holes must be placed in a horizontal surface to consider the inter-bubble effects negligible. The fact that these effects can be ignored for this investigation are substanciated by using a criterion that was developed by Kutateladze and Styrikovich, as found in Wallis (1969). They showed that when the gas leaving an orifice exceeds a certain velocity, it no longer forms bubbles at the orifice but forms a jet, which 


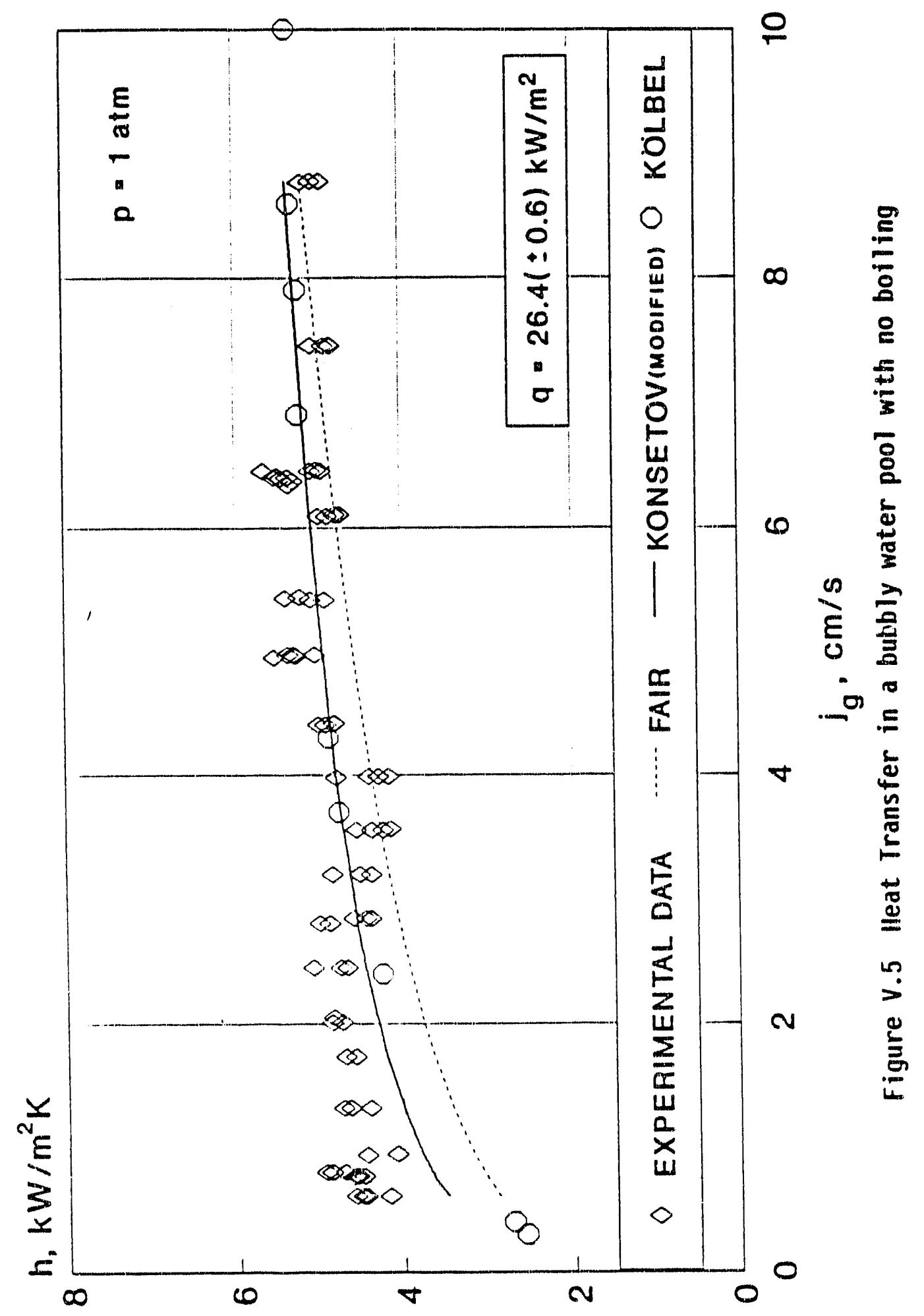


breaks into bubbles later in the pool. Applying the Kutateladze and Styrikovich criterion to the present tests, predicts that at a local jet velocity of greater than $32 \mathrm{~m} / \mathrm{s}$ the gas will leave the orifice as a jet, instead of as bubbles. This local gas velocity translates into a superficial gas velocity of approximately $2.8 \mathrm{~cm} / \mathrm{s}$ in the present apparatus. In Figure $V .5$ there is no discernible change in the heat transfer coefficient at that gas velocity, suggesting that the bubbles which form and break off from an orifice do not control the heat transfer from that surface when they are located far enough away from each other. If the forming of bubbles had a controlling effect, it would be observed the moment the bubbles could no longer form at the orifice, i.e., at $j_{\mathrm{g}}>2.8 \mathrm{~cm} / \mathrm{s}$ in this experiment. This cut-off velocity was substantiated by photographic observations.

The situation implied by the second hypothesis is attained once the heat transfer coefficient ceases to be strongly dependent upon the superficial gas velocity. That is, for $\mathrm{j}_{\mathrm{g}}>2 \mathrm{~cm} / \mathrm{s}$ the data are bounded by Konsetor's turbulent pool model which would suggest that the liquid pool was turbulent.

Finally, the third hypothesis was investigated by varying the pool height, Table A5.2b. The Konsetor model assumes that the characteristic length scale, the average size of a turbulent eddy, is a constant since he assumed it only to be a function of the inside diameter of the pool. His database came from two studies which used pool heights much greater than their inside diameter. For pool heights of greater than $6 \mathrm{~cm}$, which is $60 \%$ of the inside diameter $[10.16 \mathrm{~cm}]$ of the pool used, the heat transfer coefficient was found not to vary.

The functional relationship between the heat transfer in pool bubbling with "sparsely" located jets and the superficial gas velocity is of interest. From Equation II.11 it can be seen that $h$ or $q=f\left(j_{g}^{0.22}\right)$, and from Equation III.21 of the film boiling model, $h$ or $q=f\left(j_{g}{ }^{0.25}\right)$. This similarity may be $a$ coincidence or may mean that the increase in the heat transfer owing to the presence of a jet has similar causes. Assumed here is that the model leading to Equation III.21 is close to the true physical situation, a fact to be determined from the experimental data.

\section{Film Boiling and Gas Jetting Combined}

The primary goal was to develop a database for gas-flux-enhanced film boiling. To that end, this section presents most of the averaged data on heat flux and then the correlation of that data to the semi-empirical model, Equation 111.21. These results are for water pools greater than $10 \mathrm{~cm}$ in height, to avoid the shallow-pool effects discussed in the previous section. 


\section{a. Database On Gas-Flux-Enhanced Film Boiling}

Figure V.6 shows the actual measured heat flux as a function of the superficial gas velocity with surface superheat as the parameter [the superheat value shown is followed by a number in parentheses containing the standard deviation]. The figure depicts all of the averaged data from Table A5.3 with a few exceptions. The experimental runs $3 a, 3 b, 4 a$ and $4 b ; 10 / 26 / 88$ are for higher superficial gas velocities than shown in the figure, but they were for only one surface superheat, therefore there was no basis for comparison to other superheats. Also, the word "averaged" was used to describe the data shown. These data are listed in Table A5.3 under the title "Average Values" and are the averaged values of several experimental runs, made to observe their reproducibility. The complete set of data is shown in the columns to the left of the "Average Values" of Table A5.3.

The ranges of the data shown in Figure V.6 for both the surface superheat, $\Delta T_{S A T}$, and superficial gas velocity, $j_{g}$, were not arbitrarily chosen but were set by the physical limitations of the experimental apparatus and the phenomena being measured. For the lowest superheats, $159 \mathrm{~K}$ and $211 \mathrm{~K}$, the data do not extend over the entire range of $j_{g}$. At the lower superheats, care had to be taken not to fall out of film boiling because of the proximity to the minimum film boiling point (MFB). For water at atmospheric pressure, Hosler and Westwater (1962) measured the MFB to be at a surface superheat of $158 \mathrm{~K}$; this study observed $115 \mathrm{~K}$. One criterion (Poniewski, 1987) for film boiling postulates that when the surface temperature is below the liquid critical temperature and above that at the MFB, a small percentage of liquid still touches the heat transfer surface [for water: TCAITICAL $\sim 647 \mathrm{~K}$ or $\Delta \mathrm{T}_{\mathrm{SAT}} \sim 274$ $K]$. With the introduction of gas jets from the surface, the physical situation becomes more unstable and possibly leads to a higher percentage of liquid touching the surface. At a constant heat flux, increasing the amount of liquid solid contacts will eventually cause a spontaneous shift from film boiling to transition boiling and, finally, to nucleate boiling. In other words, it appears that the required surface superheat at the MFB increases with increasing $j_{g}$ (Duignan and Greene, 1988) because of the increased instability caused by the jet. For surface superheats of $159 \mathrm{~K}, 211 \mathrm{~K}$, and $271 \mathrm{~K}$ film boiling could not be maintained for approximately $j_{g}>1 \mathrm{~cm} / \mathrm{s}, j_{g}>4 \mathrm{~cm} / \mathrm{s}$ and $j_{g}>10.5 \mathrm{~cm} / \mathrm{s}$, respectively.

Another physical limitation was the surface superheat. Heat transfer measurements were made for surface superheats greater than those listed in Table A5.3 but were not included because of the presence of nucleate boiling on the boiling pool wall. As explained under Experimental Apparatus, care was taken to minimize any nucleate boiling but when the surface temperature of the heat transfer plate rose above approximately $650{ }^{\circ} \mathrm{C}$, its occurrence was unavoidable. Also of concern at high temperatures was the oxidation of the heat transfer 


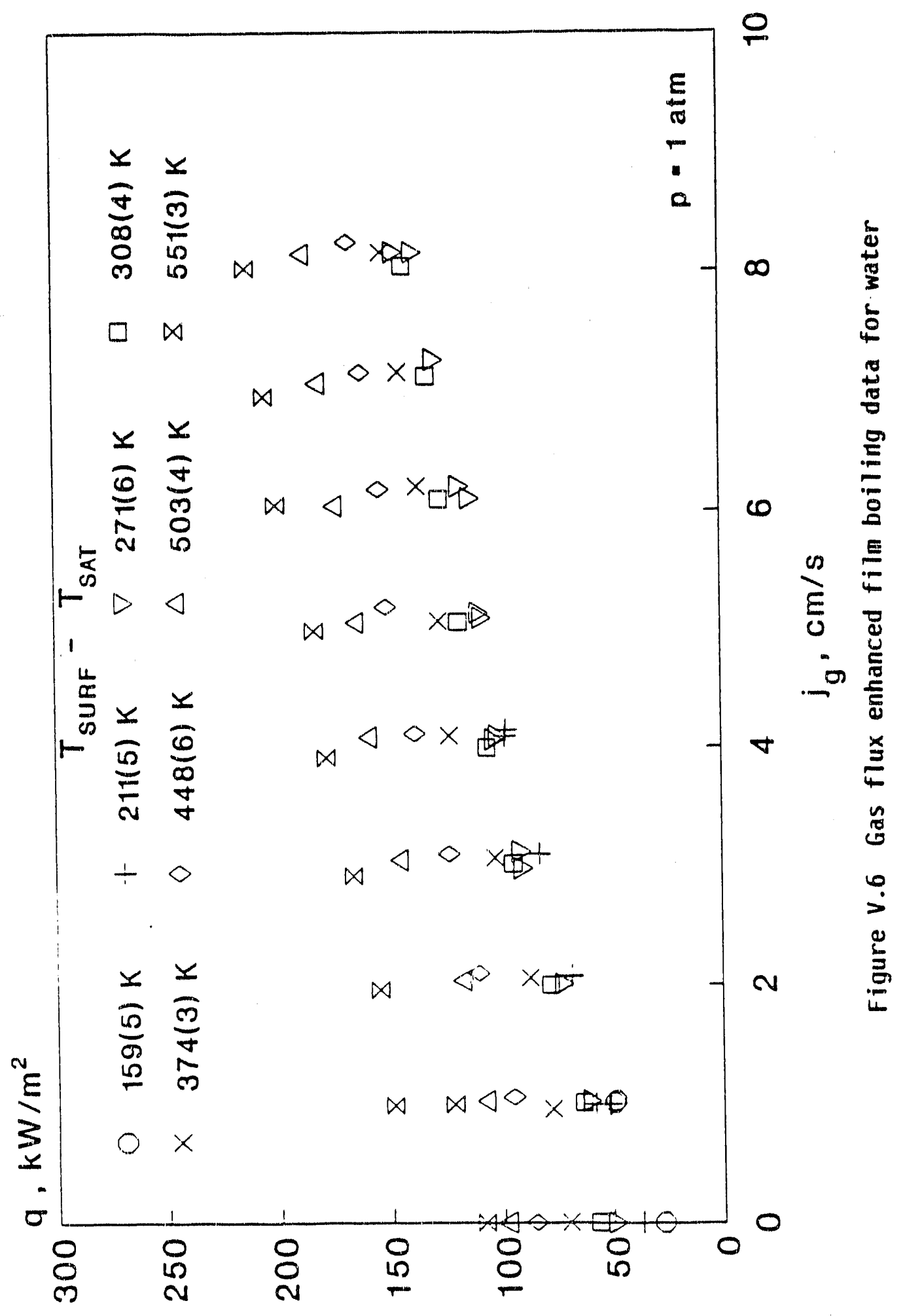


surface that occurred during the several hours needed for each experimental run. Below a surface temperature of about $650{ }^{\circ} \mathrm{C}$, the plate was minimally oxidized and could be cleaned off by the removal of a negligible amount of surface metal. This assured that the plate-to-thermocouple distances were negligibly affected; thus, accurate temperature extrapolations could be made.

The last limitation was for superficial gas velocities above $9 \mathrm{~cm} / \mathrm{s}$. At about $\mathrm{j}_{\mathrm{g}}=9$ or $10 \mathrm{~cm} / \mathrm{s}$, nitrogen flowed through the condensing system at a rate which caused droplets of water to be carried through the system with the gas, and consequently, were not captured in the collection system. To measure the data as accurately as possible, most measurements were made for superficial gas velocities under $\mathrm{j}_{\mathrm{g}} \sim 8.5 \mathrm{~cm} / \mathrm{s}$.

Figure V.6 also includes the measured values for the heat flux at $j_{\mathrm{g}}=0$. These values were obtained by interpolating between the values shown in Table A5.1. Heat flux measurements could not be made at $j_{g}=0$ in the gas-fluxenhanced phase of this study because at approximately $j_{\mathrm{g}}<0.6 \mathrm{~cm} / \mathrm{s}$ some of the jets stopped bubbling. A further reduction in gas flow would have caused backflooding into the gas plenum through the 1-mm-diameter jet holes.

Figure V.6 shows that the non-condensible gas enhances the heat flux from the heat-transfer surface, at all superheats. Unfortunately, the trend of this heat flux increase is not evident over the range of gas velocities measured. It appears that the slope of the data decreases with increasing $j_{g}$, leading to a possible conclusion that the heat flux reaches an asymptotic value at large gas velocities. The fact that the heat flux becomes a weak function of the superficial gas velocity is consistent with pool bubbling, as shown in Figure V.5. Even so, there is no basis for extrapolating the observed trend of the data in Figure $V .6$ beyond the range of gas velocities actually tested since a flow regime transition from bubbly flow to churn-turbulent flow is expected for a superficial gas velocity of approximately $10 \mathrm{~cm} / \mathrm{s}$.

\section{b. Correlation of Experimental Data to the Semi-Empirical Model}

Equation III.21 shows two free constants, i.e., $\beta_{1}$ and $\beta_{\| 1}$, but only one, $\beta_{1}$, needs to be determined. As mentioned in the Results, the coefficient $\beta_{11}^{1 / 4}$ equals 0.425 from the Berenson (1961) model. Also since $\beta_{11}$ is dimensionless then the remaining coefficient, $\beta_{1}$, has the reciprocal dimensions of $j_{g}$. Figure V.7 is dimensionless, so that any dimensional quantity can be used for $\beta_{1}$ and $j_{g}$. Moreover, as shown in Figures V.5 and V.6, the dimensions [cm/s] are used for $\mathrm{j}_{\mathrm{g}}$ because of its common use in the literature. The coefficient was determined by correlating the data so that the sum of the squared differences between the 


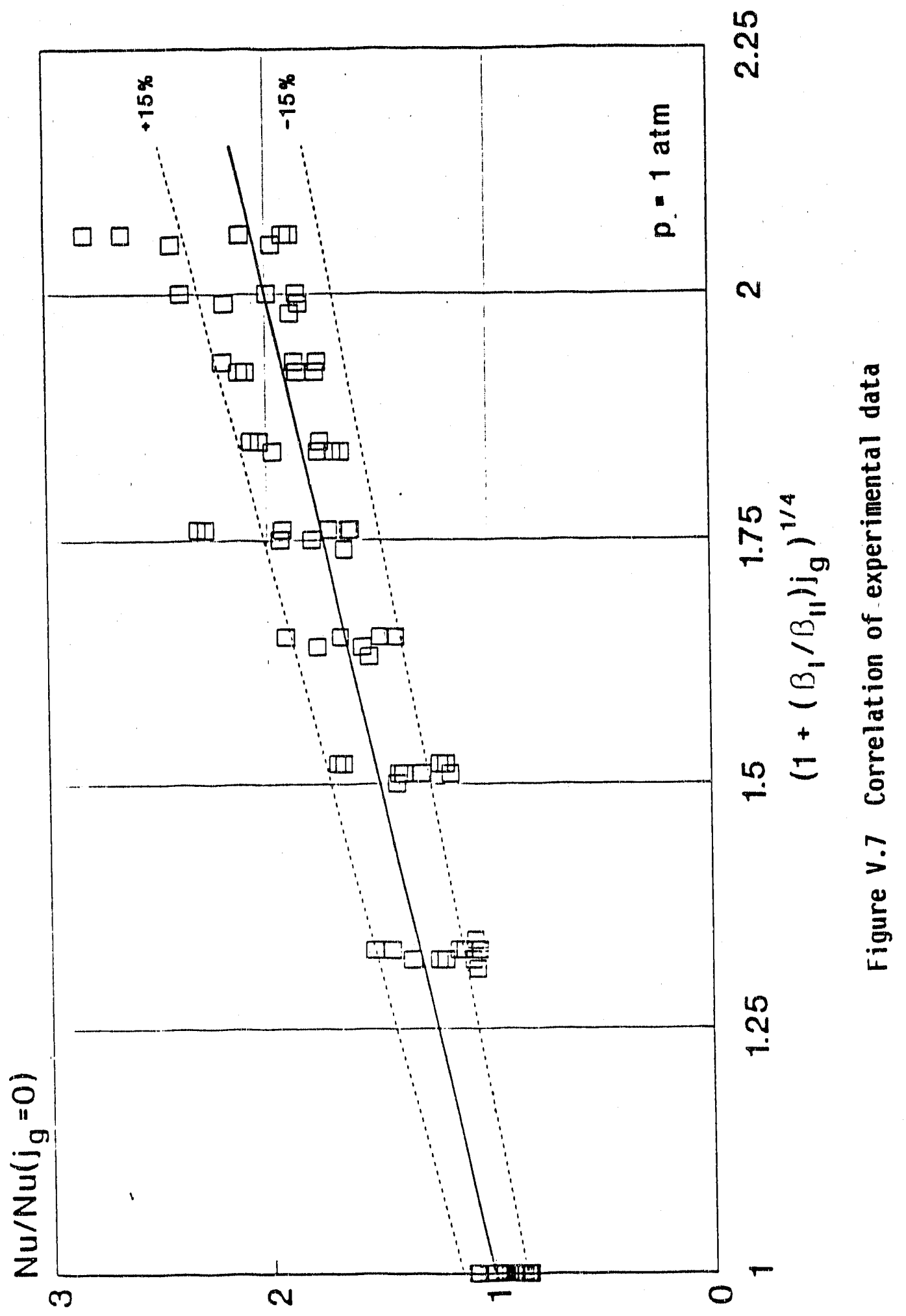


model and the data was minimized. The result is:

$$
\beta_{1}=0.068(\mathrm{~cm} / \mathrm{s})^{-1}
$$

and $\beta_{1}$ has a standard deviation of $0.005(\mathrm{~cm} / \mathrm{s})^{-1}$ and for a $99 \%$ confidence leve 1 has a range of $\left[0.053(\mathrm{~cm} / \mathrm{s})^{-1}, 0.083(\mathrm{~cm} / \mathrm{s})^{-1}\right]$. This correlation was based on all of the averaged data shown in Table $A 5.3$ after subtracting the radiation contribution to the total heat flux.

Superimposed on the correlated data in Figure $V .7$ are three lines. The solid line represents a perfect correlation to the model and the broken lines are $\pm 15 \%$ bounds, which encompass over $90 \%$ of the experimental data. The difference of the data from the correlation line cannot be explained by the measurement uncertainties, as seen in Appendix A4. Ruling out this possible source of error it is concluded that the observed differences must emanate from the inadequacies of the semi-empirical model, Equation III.21.

Based on the similar fluctuations of the heat flux data around $\mathrm{Nu} / \mathrm{Nu}\left(\mathrm{j}_{\mathrm{g}}=0\right)=1$ as seen in Figures $V .3, V .4$ and $V .7$ to the widely accepted Berenson (1961) model, Equation III.21 adequately represents the experimental data when radiation is negligible or when the component of the heat transfer, due to radiation, is removed from the total heat flux. Further comparisons between the experimental data and Equation III.21 can be found in Duignan (1989). 


\section{SUMMARY AND CONCLUSIONS}

This section again is broken down into the three major areas of investigations, i.e., stable film bofling, pool bubbling, and film bofling with gas-flux-enhancement.

\section{Stable Film Boiling}

1.) From visual observations of stable film boiling over a large horizontal flat surface bubbles are released in an orderly pattern which conforms to a square grid with a cell dimension of the most dangerous wavelength, $\lambda_{d}$.

2.) The heat flux in film boiling over a large horizontal flat surface at a single superheat can be estimated within $25 \%$ of the actual heat flux by measurements of: the most dangerous wavelength, $\lambda_{d}$, the bubble release diameter, $D$, and the bubble release period, $\tau$, assuming that two bubbles are released from a $\lambda_{d}^{2}$ area per period.

3.) On the average, the Berenson film boiling model, Equation V.1, represents within $7 \%$ the heat flux from a large horizontal flat surface, over which film boiling of water occurs. Further, the model is applicable near the minimum film boiling point and up to surface temperatures of, at least, $950 \mathrm{~K}$, as long as the radiation contribution to the heat flux is included in the form of Equation II. 6 .

\section{Pool Bubbling}

1.) For the pattern of gas jet holes in the heat-transfer surface, Figure IV.3, and for the inside pool diameter of $10.16 \mathrm{~cm}$ it was found that, at a constant superficial gas velocity, the heat transfer coefficient decreased when the pool height fell below $6 \mathrm{~cm}$, Table A5.2b. Moreover, above pool heights of $6 \mathrm{~cm}$ the heat transfer coefficient remained relatively constant [for $j_{\mathrm{g}}=6.4 \mathrm{~cm} / \mathrm{s}$, $\left.h \sim 5400 \mathrm{Wm}^{2} \mathrm{~K}\right]$. The bubbling pool was visually turbulent at all heights but was lese so at its lowest, $2.5 \mathrm{~cm}$. The reduction in the measured heat transfer coefficient was probably caused by a reduction in the turbulent eddy movement or a reduction in the turbulent eddy size itself. However, direct measurements of the eddies were not made.

2.) For pool heights greater than $6 \mathrm{~cm}$, the heat transfer coefficient is a weak function of the superficial gas velocity. The functional relationship of $h$ to $j_{g}$ may be similar to that shown in the Konsetor model represented by Equation I1.11, i.e., $h=f\left(j_{g}{ }^{0.22}\right)$. When the coefficient of that equation was determined 
to be $0.28(\mathrm{~m} / \mathrm{s})^{-0.22}$ for water [by correlation to the present data] instead of the $0.19(\mathrm{~m} / \mathrm{s})^{-0.22}$ as given by Konsetov, that model is bounded by all the experimental data. Further, it appears that the main function of the "sparsely" located jets is to maintain the pool turbulent and well mixed. Over the range measured, changes in the jet velocity did little to change the general level of agitation in the pool.

\section{Film Boiling with Gas-Flux-Enhancement}

1.) Over the range of superficial gas velocities used, the effect of the gas jetting on the filin boiling was to increase the surface heat transfer, at a constant surface superheat. The increase is approximately two-fold over heat transfer without gas jetting at $j_{\mathrm{g}} \sim 8.5 \mathrm{~cm} / \mathrm{s}$.

2.) The heat transfer is increased by gas jetting at all the surface superheats observed.

3.) When the surface superheat is close to the minimum film-boiling point, the introduction of the gas jets tends to cause the film to collapse to nucleate boiling, unless the surface temperature is increased. This finding suggests that the required minimum film boiling superheat may increase with an increase in $j_{g}$.

4.) The semi-empirical model, Equation III.21, rar.esents film boiling with gas jetting for water with an uncertainty of $\pm 15 \%$.

$A \pm 15 \%$ uncertainty in the model presented, Equation III.21, for gas-fluxenhanced heat transfer by $f i 1 \mathrm{~m}$ boiling was expected because it was based on a film-boiling model which already had an uncertainty of approximately $\pm 7 \%$, and had uncertainties from the simple assumptions made in the model development. The heat and mass transfer mechanisms of gas-flux-enhanced film boiling are complex, but the present model may be improved by improving on the assumptions which were made. For example, the pressure gradient in the vapor film, that causes vapor movement in film boiling, may not have the direct proportionality assumed to the pressure gradient set up in the vapor film near a gas jet. Also, it is not known where the jets lie with respect to the forming film boiling bubbles, whether inside or out. It seems logical that the bubbles would avoid crossing over the gas jets so they can form and break off; otherwise, they would be destroyed by these jets. It is also possible that partially formed bubbles are destroyed by the jets and the vapor, released from the bubbles, is entrained away from the heat transfer surface. Clearly, to improve on the present modeling a better knowledge of how the vapor is transported away from the film is necessary. 
A comprehensive understanding on how film boiling heat transfer is affected by gas jetting can only be obtained with more extensive experimentation to include variation of:

* the number of gas jet holes in the heat transfer plate.

* the type of liquid in the pool.

* the degree of pool subcooling.

* the pressure above the liquid pool.

* the type of non-condensible gas of the jets.

It is generally concluded that when there is a surface over which film boiling occurs and from which gas jets emerge, the actual heat transfer from that surface can only be accurately ascertained when including the effects of those jets. Equation III.21 is a useful approximation to the enhancement of film boiling heat transfer caused by jetting, as is illustrated in Appendix A7. 


\section{REFERENCES}

Bard, Y. and E. F. Leonard, "Heat Transfer in Simulated Boiling," Int. J. Heat Mass Transfer, 10, 1727 (1967).

Bellman, R. and R. H. Pennington, "Effects of Surface Tension and Viscosity on 'Taylor Instability," Quar. Appl. Math., 12, 151 (1954).

Benjanin, A. S., "Core-Concrete Interfacial Heat Transfer and Molten Pool Dynamics," Trans. Am. Nucl. Soc., 33, 527 (1979).

Berenson, P. J., "Film-Boiling Heat Transfer from a Horizontal Surface," J. Heat Transfer, 83, 351 (1961).

Berenson, P. J., "Experiments on Pool-Boiling Heat Transfer," Int. J. Heat Mass Transfer, 5, 985 (1962).

Blose, R. E., J. E. Gronager, A. J. Suo-Anttila, and J. E. Brockmann, "SWISS: Sustained Heated Metallic Melt/Concrete Interactions with Overlying Water Pools," NUREG/CR-4727 (1987).

Borishansky, V. M. "Heat Transfer to a Liquid Freely Flowing Over a Surface lleated to a Temperature Above the Boiling Point," in Problems of Heat Transfer During a Change of State, (S. S. Kutateladze, editor), AEC Report No. AEC-tr-3405 (1953).

Bradley, D. R., "Modelling of Heat Transfer between Core Debris and Concrete," Proc. ANS 1988 National Heat Transfer Conf., July 24-27. Houston, Texas, 3, 37 (1988) .

Bromley, L. A., "Heat Transfer in Stable Filı Boiling," PhD thesis, Department of Chemistry, University of California, Berkeley, California (1948).

Chang, Y. P., "Wave Theory of Heat Transfer in Film Boiling," J. Heat Transfer, 81,1 (1959).

Churchill, R. V., J. W. Brown, and R. F. Verhey, Complex Variables and Applications, McGraw-Hi11, New York, Pp. 253-256 (1976).

Currie, I. G., Fundamental Mechanics of Fluids, McGraw-Hill, New York, pp. 122125 (1974).

Dhir, V. K., J. N. Castle, and I. Catton, "Role of Taylor Instability on Sublimation of a Horizontal Slab of Dry Ice," J. Heat Transfer, 99, 411 (1977). 
Dhir, V. K. and J. H. Lienhard, "Laminar Film Condensation on Plane and Axisymmetric Bodies in Nonuniform Gravity," J. Heat Transfer, 93, 97 (1971).

Duignan, M. R., "Enhanced Convective and Film Boiling Heat Transfer by Surface Gas Injection," Pho thesis, Dept. of Mechanical Engineering, State University of New York at Stony Brook, New York (1989).

Duignan, M. R. and G. A. Greene, "Heat Transfer in Core-Concrete Interactions: Roiling from Submerged Porous Surfaces," NUREG/CR-2331, 8(4), Chap. 24 (1988).

Duignan, M. R., G. A. Greene, and T. F. Irvine, Jr., "Measurements of the Film Boiling Bubble Parameters on a Horizontal Plate," Int. Comm. Heat Mass Transfer, $16(3), 355$ (1989).

Duignan, M. R., G. A. Greene, and T. F. Irvine, Jr., "Heat Transfer from a. Horizontal Bubbling Surface to an Overlying Water Pool," Chem. Eng. Comm., 87, 185 (1990).

Eckert, E.R.G. and R. M. Drake, Jr., Analysis of Heat and Mass Transfer, McGrawHill, New York, pp. 74-78, 107-110 (1972).

Fair, J. R., A. J. Lambright, and J. W. Andersen, "Heat Transfer and Gas Holdup in a Sparged Contactor," I/EC Process Des. Dev., 1(1), 33 (1962).

Frederking, T, H., Y. C. Wu, and B. W. Clement, "Effects of Interfacial Instability on Filin Boiling of Saturated Liquid Helium I Above a Horizontal Surface," A.I.Ch.E. Journal, 12, 238 (1966).

Go:tfried, B. S., C. J. Lee, and K. J. Bell, "The Leidenfrost Phenomenon: Film Boiling of Liquid Droplets on a Flat Plate," Int. J. Heat Mass Transfer, 9, 1167 (1966).

Greene, G. A., "Heat Transfer from a Liquid Pool in the Bubbly Flow Regime to a Vertical Boundary," 1989 National Heat Transfer Conf., August 6-9, AIChE Symposium Series 269 Volume 85, Philadelphia, PA, (1989).

Hamill, T. O. and K. J. Baumeister, "Effect of Subcooling and Radiation on Filin Boiling Heat Transfer from a Flat Plate," NASA Report NO. TN D-3925 (1967).

Hosler E. R. and 3. W. Westwater, "Film Boiling on a Horizontal Plate," ARS Jourral, 32, 553 (1962).

Kesselring, R. C., P. H. Rosche, and S. G. Bankoff, "Transition and Filim Boiling from Horizontal Strips." A.I.Ch.E. Journal, 13, 669 (1967). 
Klimenkn, V. V., "Film Boiling on a Horizontal Plate - New Correlation," Int. J. Heat Mass Transfer, 24, 69 (1981).

Klimenko, V. V. and A. G. Shelepen, "Film Boiling on a Horizontal Plate - A Supplementary Communication," Int. J. Heat Mass Transfer, 25, 1611 (1982).

Konlbel, H., W. Siemes, R. Maas, and K. Müller. "Wärmeüberbergang an Blasensallen," Chemie-Ing.-Techn., 30(6), 400 (1958). [Also exists in English: Brookhaven National Laboratory Report No. BNL-tr-1074]

Konsetov, V. V., "Heat Transfer during Bubbling of Gas through Liquid," Int. J. Heat Mass Transfer, 9, 1103 (1966).

Kurihara, H. M. and J. E. Myers, "The Effects of Superheat and Surface Roughness on Boiling Coefficients," A.I.Ch.E. Journal, 6(1), 83 (1960).

Kutateladze, S. S. and I. G. Malenkov, "rluid-and Gasdynamical Aspects of Heat Transfer in the Injection Bubbling and Boiling of Liquids," High Temperature, 11. $703(1976)$.

Lao, Y. J., "A Study of Film Boiling on a Horizontal Plate," PhD thesis, University of Michigan, Michigan (1969).

Lewis, D. J., "The Instability of Liquid Surfaces When Accelerated in a Direction Perpendicular to The ir Planes," Proc. Roy. Soc., ser. 1 (London), 202, 81 (1950).

Lienhard, J. H., "A Semi-rational Nucleate Boiling Heat Flux Correlation," Int. J. Heat Mass Transfer, 6, 215 (1963).

Lienhard, J.H. and V. E. Schrock, "The Effect of Pressure, Geometry and the Equation of State Upon the Peak and Minimum Boiling Heat Flux," J. Heat Transfer, 85, 261 (1963).

Liemhard, J. H. and P. T. Y. Hong, "The Dominant Unstable Wavelength aind Min imuli Heat Flux During Film Boiling on a Horizontal Cylinder," J. Heat Transfer, 86, 220 (1964).

Mand:1, J., The Statistical Analys is of Experimental Data, Dover Publications, New York, pp. 72-75 (1984).

McAdams, W. H., Heat Trailsmission, McGraw-Hi11, New York, 3rd ed., pp. 368-389 (1954). 
Mnnrad, C. C. and W. L. Badger, "The Condensation of Vapors," Trans. Am. Inst. Chem. Engrs., 24, 84 (1930).

Nukiyama, S., "The Maximum and Minimum Values of the Heat Q Transmitted from Metal to Boiling Water Under Atmospheric Pressure," J. Japan Soc. Mech. Engrs., $37(207), 367$ (1934). [Also exists in English: Int. J. Heat Mass Transfer, 27(7), $959(1984)]$

Nusse1t, W., "Die Oberflachenkondensation des Wasserdanfes," Z. Ver. deut. Ing., $60,541,569$ (1916).

Poniewski, M., "Dissipative Model of Film Boiling Crisis," Int. J. Heat Mass Transfer, 30, 1847 (1987).

Rabinowicz, E., An Introduction to Experimentation, Addison-Wesley Publishing Cumpany, Massachusetts, p. 32 (1970).

Rallis, C. J. and H. H. Jawurek, "latent Heat Transport in Saturated Nucleate Boiling," Int. J. Heat Mass Transfer, 7. 1051 (1964).

Ramilison, J. M. and J. H. Lienhard, "Transition Boiling Heat Transfer and the Film Transition Regime," J. Heat Transfer, 109, 746 (1987).

Rankin, G. W., K. Sridhar, M. Arulraja, and K. R. Kumar, "An Experimental Investigation of Laminar Axisymmetric Subnerged Jets, " J. Fluid Mech., 133, 217 (1983).

Reimann, M. and H. Alsmeyer, "Hydrodynamics and Heat Transfer Processes of Dry Ice Slabs Suhlimating in Liquid Pools," Proc. Seventh Int. Heat Transfer Conf., Munich, Germany, 4, 167 (1982).

Ruckenstein, E., "rilin Boiling on a Horizontal Surface," Int. J. Heat Mass Transfer, 10, 911 (1967).

Schlichting, H., Boundary-Layer Theory, McGraw-Hill, New York, $7^{\text {th }}$ ed, p. 748 (1979).

Sernas, V., "Mininum Heat Flux in Film Boiling - A Three Dimensional Model," Proc. Second Can. Cong. App. Mech., Univ. of Waterloo, Canada, 19 (1969).

Sernas, V., J. II. Lienhard, and V. K. Dhir, "The Taylor Wave Configuration During Boiling from a Flat Plate," Int. U. Heat Mass Transfer, 16, 1820 (1973).

Sims, C. F. and P. 1. Duffield, "Comparison of Heat-transfer Coefficients in Pon! Bartontange and Saturated Pool Boiling," Trans. Can. Soc. Mech. Eng., Canada, $14(B-1), 1$ (1971). 
Sparrow, E. M., "The Effect of Radiation on Film boiling Heat Transfer," Int. J. Heat Mass Transfer, 7, 229 (1964).

Sparrow, E.M., "Error Estimates in Temperature Measurements," Measurements in Heat Transfer, (E.R.G. Eckert and R.J. Goldstein, eds.), Hemispliere Publishing Corp., Washington, pp. 1-23 (1976).

Sparrow, E. M. and R. D. Cess, Radiation Heat Transfer, Brooks/Cole Publishing Company, California, revised ed., p.49 (1970).

Taylor, G. I., "The Instability of Liquid Surfaces When Accelerated in a Direction Perpendicular to Their Plane," Proc. Roy. Soc., ser. A (London), 201, 192 (1950).

Tien, C. L., "A Hydrodynamic Model for Nucleate Pool Boiling," Int. J. Heat Mass Transfer, 5, 533 (1962).

Touloukian, Y. S., R. W. Powell, C. Y. Ho, and P. G. Klemens, Thermo-physical Properties of Matter: Thermal Conductivity(Metallic Elements and Alloys), IFI/PLENUM, New York, 1, pp. 1160-1173 (1970).

Wallis, G. B., One-dimensional Two-phase Flow, McGraw-Hill, New York, p. 245 (1969).

Westwater, J. W. and J. G. Santangelo, "Photographic Study of Boiling," Ind. Eng. Chem., $47(8), 1605$ (1955).

Zuber, N., "llydrodynamic Aspects of Boiling lleat Transfer," AEC Report No. AECU-4439, Physics and Mathematics, (1959).

Zuber, N. and M. Tribus, "Further Remarks on the Stability of Boiling Heat Transfer," UCLA Report No. 58-5 (1958), also AEC Report No. AECU-3631, Physics and Mathematics (1958). 


\section{APPENDIX A1: ANALYTICAL MODEL TO STABLE FILM BOILING}

Presented here is an order of magnitude comparison of the terms in the radial component of the momentum equation. The purpose is to justify the general differential equation used as the starting point for the analytical modeling of stable film boiling (Bromley, 1948; Berenson, 1961) and for the current problem. Also, it is shown that when two different choices of the boundary condition at $y=\delta$ are made, the governing equation takes the same general form; a fact used in the model development.

Figures II.1d and III.1a show the idealized physical model and the assumptions are:

1) The vapor flows only radially into a bubble, i.e., $v_{r} i v_{\theta}=v_{y}=0$.

2) The inertial forces in the vapor film are negligible in comparison with the viscous forces, i.e., $\operatorname{Re}_{f}=\bar{v}_{r} \delta / \nu_{f}<1$.

3) From (2) the vapor flow is laminar.

4) The change in height of the vapor-liquid boundary between bubbles is negligible compared to the average height of the bubble above the interface, i.e., $\Delta \delta / \ell \ll 1$.

From assumption one,

$$
v_{r}(r, y)=\text { vapor velocity in the film }
$$

and $v_{\theta}=v_{y}=0$ everywhere in the vapor $f i l$ in between $r_{1}$ and $r_{2}$. These conditions give the momentum equation the following form,

$$
v_{r} \partial v_{r} / \partial r=-1 / \rho_{f} \partial p / \partial r+\nu_{f}\left[\partial^{2} v_{r} / \partial r^{2}+1 / r \partial v_{r} / \partial r+\partial^{2} v_{r} / \partial y^{2}-v_{r} / r^{2}\right]
$$

and the continuity equation results in,

$$
\partial v_{r} / \partial r+v_{p} / r=0
$$

When applying Equation A1.2 to Equation Al.1 the sum of the first, second and fourth terms in the brackets is identically zero. Therefore, the equation of Newton's second law applied along a radius takes the form, 


$$
v_{r} \partial v_{r} / \partial r=-1 / \rho \partial p / \partial r+\nu_{p} \partial^{2} v_{r} / \partial y^{2}
$$

The inertial and viscous terms are compared by an order of magnitude analysis, i. e.,

$$
v_{r} \partial v_{r} / \partial r \sim \bar{v}_{r}^{2} / r_{1} \text { and } \quad \nu_{p} \partial^{2} v_{r} / \partial y^{2} \sim \nu_{f} \bar{v}_{r} / \delta^{2}
$$

Here, $r_{1}$ is the radius of the bubble while $\bar{v}_{r}$ and $\delta$ are the average vapor velocity and the height of the vapor film, respectively. Their magnitudes are assumed,

$$
\begin{aligned}
& r_{1} \sim \lambda_{d} / 4=0.0272 \mathrm{~m} / 4=6.8 \times 10^{-3} \mathrm{~m} \\
& \delta \sim 30 \mu \mathrm{m} \text { (Berenson, 1961) }
\end{aligned}
$$

Taking the heat transfer results from a typical experimental run, the magnitudes of the vapor velocity and the kinematic viscosity can be obtained,

$$
\begin{aligned}
& \text { Run No.1, 9/22/87 (Table A5.1) } \\
& q=116.3 \mathrm{~kW} / \mathrm{m}^{2} ; T_{\text {SUPFACE }}=667^{\circ} \mathrm{C}
\end{aligned}
$$

therefore $T_{\text {film }} \sim 657 \mathrm{~K}$, making the properties of water vapor at 1 atm

$$
\nu_{f} \sim 6 \times 10^{-5} \mathrm{~m}^{2} / \mathrm{s} \text { and } \rho_{\mathrm{f}} \sim 0.53 \mathrm{~kg} / \mathrm{m}^{3}
$$


and assuming that all the heat goes into making vapor,

$$
\bar{v}_{r} \sim q /\left(\rho_{f} h_{f g}\right)=116.3 /(0.53 \times 2257)=0.097 \mathrm{~m} / \mathrm{s}
$$

The terms can now be compared,

inertial: $v_{r} \partial v_{r} / \partial r \sim \bar{v}_{r}^{2} / r_{1}=(0.097)^{2} /\left(6.8 \times 10^{-3}\right)=1.4 \mathrm{~m} / \mathrm{s}^{2}$

viscous: $\nu_{f} \partial^{2} v_{r} / \partial y^{2} \sim \nu_{\uparrow} \bar{v}_{r} / \delta^{2}=\left(6 \times 10^{-5}\right)(0.097) /\left(3 \times 10^{-5}\right)^{2}=6.5 \times 10^{3} \mathrm{~m} / \mathrm{s}^{2}$

The assumption of negligible inertial forces seems to be valid based on the comparison of terms.

Since the pressure gradient term in Equation Al.3 cannot be small compared to the viscous term because it is from this pressure difference that the vapor in the film has movement, then the resulting governing equation is,

$$
0=-d p / d r+\mu_{f} d^{2} v_{r} / d y^{2}
$$

Equation A1.4 assumes that $\partial p / \partial r$ is independent of $y$ from $r=r_{1}$ to $r=r_{2}$, therefore the vapor velocity has the form,

$$
v_{r}=1 /\left(2 \mu_{f}\right) d p / d r y^{2}+C_{1} y+C_{2}
$$

and the constants $C_{1}, C_{2}$ can be determined from the following boundary conditions:

$$
\text { b.c. 1: } v_{r}=0 \text { at } y=0 ; \text { b.c. } 2: v_{r}=v_{r \delta} \text { at } y=\delta
$$


therefore,

$$
v_{r}=1 /\left(2 \mu_{f}\right) d p / d r \delta^{2}(y / \delta)^{2}+\left[v_{r \delta}-1 /\left(2 \mu_{f}\right) d p / d r \delta^{2}\right](y / \delta)
$$

and in terms of the mean velocity: $\quad \bar{v}_{r}=1 / \delta \int_{0}^{\delta} v_{r} d y$

$$
\text { i.e., } \quad \bar{v}_{r}=1 / 2 v_{r \delta}-1 /\left(12 \mu_{f}\right) d p / d r \delta^{2}
$$

The actual velocity of the boundary at $y=\delta$ is not known but the general form of Equation A1.6 was shown by Bromley (1948) to be,

$$
\bar{v}_{r}=1 /\left(\beta \mu_{f}\right) d p / d r \delta^{2}
$$

If the boundary at $y=\delta$ is chosen to be stationary, i.e., it acts as a fixed wall, then b.c.2 becomes $v_{r \delta}=0$ which makes $\beta=12$ from Equation Al.6. Moreover, if the boundary at $y=\delta$ is chosen such that no shear stress exists between the vapor and liquid, then b.c.2 is actually $d v_{r} / d y l_{y=\delta}=0$ which forces the vapor velocity to be $v_{r \delta}=-1 /\left(2 \mu_{f}\right) d p / d r \delta^{2}$, from Equation A1.5. Substituting this $v_{r \delta}$ into Equation $A 1.6$ makes the constant $\beta=3$. As stated, the true boundary movement is not known but from Berenson's (1961) correlation of his film boiling heat transfer data $\beta \sim 7.3$, which is close to the arithmetic average of the aforementioned constants.

The form of Equation A1.6 shows that the vapor velocity at $y=\delta, v_{r} \delta^{\prime}$ is a linear addition to the average vapor velocity, $\bar{v}_{r}$, in the vapor film, resulting in an equation having the form of Equation A1.7. This aspect of Equation A1.7 will be used to develop a model for the current problem. 


\section{APPENDIX A2: CALIBRATION OF THE HEAT TRANSFER PLATE THERMOCOUPLES}

Calibrations of the thermocouples used in both heat transfer plates, i.e., with and without gas injection holes, were done separately. It was assumed initially that the same set of thermocouples was to be used for both phases of the experiment, therefore a second set would not have been necessary. However, when it was determined that a second set would be necessary, the experience in using the first set was carried over to the second, as is explained below. As can be seen from Tables $A 2.1$ and $A 2.2$ the first calibration was far more extensive than the second.

It was found during the first calibration that the temperature readings obtained from type $K$ micro-thermocouples, based on standard millivolt versus temperature tables issued by the National Bureau of Standards, did not vary more than $1.5 \mathrm{~K}$ from the Platinum Resistance Thermometer standard used for calibration. On the average, those thermocouple readings varied approximately $0.75 \mathrm{~K}$ from the temperature standard over the entire range measured, from $25^{\circ} \mathrm{C}$ to $570^{\circ} \mathrm{C}$. The important temperature range for this experiment was for film boiling where the temperature of the heat transfer plate was not lower than $200^{\circ} \mathrm{C}$. This means that the relative temperature uncertainty would be less than $1 \%$ if the standard temperature tables were used to determine the thermocouple temperatures. With this knowledge, the second set of thermocouples was not calibrated as extensively as the first. The second set was just checked at three temperature points to make sure that they were as accurate and precise as the first set, after which the standard thermocouple tables were used to determine the temperature.

It should be noted that the calibration for the first set of thermocouples was very carefully done over a three week period but the procedure will not be included because of its length and detail. The averages and standard deviations shown in Table A2.1 may not be determinable from the thermocouple temperatures listed since the results were rounded off and truncated; temperatures were not needed to the accuracy obtained from the calibration so they were only listed to the significant figures which have absolute certainty. 
Table A2.1 Thermocouple calibration for heat transfer plate without gas holes

\begin{tabular}{|c|c|c|c|c|c|c|c|}
\hline \multirow{2}{*}{$\begin{array}{c}\text { Temperature* } \\
\text { RTD } \\
\text { Standard }\end{array}$} & \multicolumn{7}{|c|}{$\begin{array}{l}\text { Thermocoup le Temperature Readings" } \\
\left({ }^{\circ} \mathrm{C}\right)\end{array}$} \\
\hline & $\mathrm{TC} 1$ & TC2 & $\mathrm{TC} 3$ & TC4 & TC5 & TC6 & $\mathrm{TC7}$ \\
\hline 25.05 & 25.2 & 25.2 & 25.2 & 25.2 & 25.2 & 25.2 & 25.2 \\
\hline 76.03 & 76.8 & 76.9 & 76.8 & 76.7 & 76.8 & 76.7 & 76.9 \\
\hline+100.02 & 101.1 & 101.3 & 101.1 & 101.1 & 101.1 & 101.1 & 101.2 \\
\hline 224.47 & 226.0 & 225.7 & 226.1 & 226.0 & 226.2 & 226.0 & 225.6 \\
\hline 281.38 & 283.0 & 282.4 & 283.0 & 282.9 & 283.1 & 282.9 & 282.3 \\
\hline 323.92 & 323.3 & 323.3 & 323.4 & 323.4 & 323.5 & 323.4 & 323.2 \\
\hline 338.88 & 340.2 & 339.4 & 340.2 & 340.1 & 340.3 & 340.1 & 339.3 \\
\hline 359.64 & 358.9 & 358.7 & 359.0 & 358.9 & 359.1 & 359.0 & 358.6 \\
\hline 402.45 & 403.8 & 402.9 & 403.9 & 403.8 & 403.9 & 403.7 & 402.7 \\
\hline 404.91 & 406.3 & 405.3 & 406.3 & 406.2 & 406.3 & 406.2 & 405.1 \\
\hline 434.77 & 436.0 & 435.0 & 436.0 & 436.0 & 436.0 & 435.9 & 434.8 \\
\hline 468.18 & 468.5 & 467.2 & 468.6 & 468.6 & 468.5 & 468.3 & 467.2 \\
\hline 489.11 & 490.1 & 489.1 & 490.3 & 490.2 & 490.2 & 490.0 & 488.9 \\
\hline 509.30 & 510.2 & 509.1 & 510.3 & 510.3 & 510.3 & 510.1 & 509.0 \\
\hline 569.12 & 569.6 & 568.4 & 569.8 & 569.7 & 569.6 & 569.4 & 568.2 \\
\hline
\end{tabular}


Table A2.1 (continued)

\begin{tabular}{lrrrrrrr}
\hline $\begin{array}{l}\text { Temperature } \\
\text { RTD } \\
\text { Standard }\end{array}$ & TC8 & TC9 & TC10 & TC11 & Average \\
(A11) & $\begin{array}{c}\text { Std. Dev. } \\
(\text { A11) }\end{array}$ & $\left(T_{\text {AVG }}-T_{\text {ATD }}\right)$ \\
\hline 25.05 & 25.2 & 25.2 & 25.2 & 25.2 & 25.2 & 0.0 & 0.2 \\
76.03 & 76.8 & 76.9 & 76.9 & 76.8 & 76.8 & 0.1 & 0.8 \\
100.02 & 101.1 & 101.3 & 101.2 & 101.2 & 101.2 & 0.1 & 1.1 \\
224.47 & 226.0 & 225.8 & 225.7 & 226.1 & 225.9 & 0.2 & 1.5 \\
281.38 & 282.9 & 282.5 & 282.3 & 283.0 & 282.7 & 0.3 & 1.4 \\
323.92 & 323.3 & 323.3 & 323.2 & 323.4 & 323.3 & 0.1 & -0.6 \\
338.88 & 340.1 & 339.6 & 339.3 & 340.3 & 339.9 & 0.4 & 1.0 \\
359.64 & 358.8 & 358.7 & 358.6 & 359.0 & 358.8 & 0.2 & -0.8 \\
402.45 & 403.7 & 403.0 & 402.7 & 403.8 & 403.4 & 0.5 & 1.0 \\
404.91 & 406.1 & 405.5 & 405.1 & 406.3 & 405.9 & 0.5 & 1.0 \\
434.77 & 435.9 & 435.1 & 434.8 & 436.1 & 435.6 & 0.5 & 0.8 \\
468.18 & 468.3 & 467.3 & 467.0 & 468.4 & 468.0 & 0.7 & -0.2 \\
489.11 & 490.0 & 489.1 & 488.8 & 490.2 & 489.7 & 0.6 & 0.6 \\
509.30 & 510.1 & 509.3 & 509.0 & 510.4 & 509.8 & 0.6 & 0.5 \\
569.12 & 569.5 & 568.6 & 568.1 & 569.7 & 569.1 & 0.7 & 0.0 \\
& & & & & & &
\end{tabular}

* The temperature standard used was a Leeds and Northrup plat inum Resistance Thermometer(RTD) calibrated against the National Bureau of Standard's certified master standard.

** TC's $1,3,4,5,6,8$ and 11 were chosen to be placed in the heat transfer plate because they had the best precision among the eleven tested:

+ A hypsometer was used for a saturation point measurement at room temperature as an extra check on accuracy of measurement. Its reading was: $T=100.015^{\circ} \mathrm{C} \otimes p=760.4 \mathrm{mmHg}$ and the actual $\mathrm{RTD}$ reading was $T=100.017^{\circ} \mathrm{C}$. 
Table A2.2 Thermocouple calibration for heat transfer plate with gas holes

\begin{tabular}{rrrrrrrrr}
\hline & \multicolumn{8}{c}{ Thermocouple Temperature Readings $\left({ }^{\circ} \mathrm{C}\right)$} \\
$\begin{array}{c}\text { Temperature } \\
\text { Standard }\end{array}$ & TC1 & TC2 & TC3 & TC4 & TC5 & TC6 & TC7 & TC8 \\
\hline 0.0 & 0.1 & 0.2 & 0.2 & 0.2 & 0.2 & 0.2 & 0.2 & 0.2 \\
99.6 & 100.1 & 100.2 & 100.2 & 100.2 & 100.2 & 100.2 & 100.2 & 100.2 \\
203.1 & 204.4 & 204.4 & 204.5 & 204.3 & 204.3 & 204.5 & 204.5 & 204.4 \\
\hline
\end{tabular}

Table A2.2 (continued)

\begin{tabular}{l}
$\begin{array}{c}\text { Temperature } \\
\text { Standard }\end{array}$ TC9 \\
\hline
\end{tabular}




\section{APPENDIX A3: LIST OF MEASURING DEVICES USED AND THEIR UNCERTAINTY}

\section{Temperature Measurement}

Micro-thermocouple, type $K$

Digital Voltmeter, HP $3455 \mathrm{~A}$

Reference Junction, REF-CEL 200

Scanner, HP 3495A

Hewlett-Packard Minicomputer, 21MX Series $\pm 0.15^{\circ} \mathrm{C}$

$\pm 5 \mu \mathrm{V}$

$\pm 0.10^{\circ} \mathrm{C}$

Gas Flow Measurements

$$
\begin{array}{ll}
\text { In-line Thermocouples, type K } & \pm 0.15{ }^{\circ} \mathrm{C} \\
\text { In-line Pressure Gauge, Weiss }(0-10) \text { psi) } & \pm 1 \text { psi } \\
\text { Rotameter, SGP FM } 150 \text { PAFV }(0-15 \mathrm{~cm}) & \pm 1 \% \text { of F.S. } \\
\quad+\text { Flow Tube, FT 6-B05 } & \\
+ \text { Glass Float } &
\end{array}
$$

\section{Condensation Measurements}

Chronometer, Micronta 63-5009A

Mass Balance, Sartorius 3862 MP8-1 \pm 0.1 jeconds

\pm 0.05 grams

\section{System Power}

Power Stat, Superior Elec.Comp. (0-100 W) $\pm 1 \%$ of F.S. watt Meter, Weston 310 (0-250 W) $\pm 0.25 \%$ of F.S. $(0-500 \mathrm{~W})$ $(0-1000 \mathrm{~W})$ $(0-2000 \mathrm{~W})$

Coil Heater, Aerorod BXX-09B-53-4T 


\section{APPENDIX A4: ERROR ANALYSIS}

\section{Estimate of the Measurement Uncertainties}

Using the Law of Propagation of Errors (Mande1, 1984) the measurement uncertainties are determined for the fundamental quantities: Heat Transfer Plate Thermocouple Temperatures, Heat Flux, Heat Transfer Surface Temperature, Heat Transfer Coefficient, Superficial Gas Velocity. The resulting uncertainties for the those quantities are listed below in Table A4.1.

Table A4.1 Measurement uncertainties

\begin{tabular}{lllll} 
& Low: $T_{\text {SURF }}$ and $j_{g}$ & High: $T_{\text {SURF }}$ and $j_{g}$ \\
Quantity & Absolute Relative & Absolute Relative \\
\hline & & & & \\
$T_{\text {tc }}$ & $1.0 \mathrm{~K}$ & $0.2 \%$ & $1.0 \mathrm{~K}$ & $0.1 \%$ \\
$T_{\text {SURF }}$ & $1.0 \mathrm{~K}$ & $0.2 \%$ & $1.0 \mathrm{~K}$ & $0.1 \%$ \\
$\mathrm{q}$ & $0.3 \mathrm{~kW} / \mathrm{m}^{2}$ & $0.5 \%$ & $1.1 \mathrm{~kW} / \mathrm{m}^{2}$ & $0.5 \%$ \\
$\mathrm{j}_{\mathrm{g}}$ & $2.6 \mathrm{~W} / \mathrm{m}^{2} \mathrm{~K}$ & $0.8 \%$ & $2.0 \mathrm{~W} / \mathrm{m}^{2} \mathrm{~K}$ & $0.5 \%$ \\
\hline
\end{tabular}

The general method used to obtain the values in Table A4.1 is highlighted below [as shown by Rabinowicz (1970)], after which each individual quantity will be treated to show from where the uncertainties propagate. The results in Table A4.1 were determined by using the experimental data for two experimental runs to illustrate the extreme values, i.e., at a high and a low heat transfer plate temperature and superficial gas velocity. Those data, along with their respective absolute uncertainties, are listed in Table A4.2 


\section{General Outline}

If a measured quantity, $y$, includes errors from a combination of sources, then one way to estimate the overall uncertainty is as follows:

Let $y=y\left(n_{1}, n_{2}, \ldots, n_{N}\right)$, where $n_{i}=i^{\text {th }}$ quantity containing uncertainty

and

$$
d y=\sum_{i=1}^{N}\left(\partial y / \partial n_{i}\right) d n_{i}
$$

If the variation in $y$ is produced by the uncertainties in the quantities, $n_{i}$, and the magnitude of these uncertainties are $e_{n_{1}}$, therefore,

$$
e_{y}=\sum_{i=1}^{N}\left(\partial y / \partial n_{i}\right) e_{n_{1}}
$$

This equation implies that $e_{n_{i}}$ is small compared to $n_{i}$ [a good approximation when $e_{n_{1}} / n_{i} \leq 0.1$ (Mandel, 1984)].

Since it is not known if the terms, $e_{n_{i}}$ will be positive or negative, the uncertainties should be evaluated by r.m.s. of $e_{y}$, i.e.,

$$
e_{y}^{2}=\sum_{i, 1}^{N}\left(\partial y / \partial n_{i}\right)^{2} e_{n_{1}}+\sum_{i, 1,1}^{n}\left(\partial y / \partial n_{i}\right)\left(\partial y / \partial n_{j}\right) e_{n_{1}} e_{n_{1}} \quad \text { where } i \neq j
$$

Assuming that the error components, $e_{n}$, are both indep indent and symmetrical then the expected valua of the second term of the RHS of sie preceding equation is zero. Therefore.

$$
e_{y}^{2}=\sum_{i}^{N}\left(\partial y / \partial n_{1}\right)^{2} e_{n_{i}}
$$

Equation A4.1 is the most probable error due to the uncertainties in the components $n_{i}$. 


\section{Specific Measurement Uncertainties}

To obtain the magnitude of the measurement uncertainty for each fundamental quantity Equation $A 4.1$ is applied in order to determine which quantities propagate the uncertainties. The resulting magnitudes are listed in Table A4.1, which were obtained by substituting the appropriate quantities from Table A4.2 into the following equations.

a. Heat Transfer Plate Thermocouple Temperature

Equation A4.1 gives the absolute uncertainty to be:

$$
e_{T_{10}}=\left[e_{1}^{2}+e_{2}^{2}+e_{3}^{2}+e_{4}^{2}\right]^{1 / 2}
$$

b. Heat Flux: $q=(m / t) h_{f g} / A_{p}=(m / t) h_{f g} /\left(\pi R^{2}\right)$

From Equation A4.1 the absolute uncertainty is:

$$
e_{q}=\left[(\partial q / \partial m)^{2} e_{m}{ }^{2}+(\partial q / \partial t)^{2} e_{t}{ }^{2}+\left(\partial q / \partial h_{f g}\right)^{2} e_{h_{t g}}{ }^{2}+(\partial q / \partial R)^{2} e_{h}{ }^{2}\right]^{1 / 2}
$$

This equation can be simplified if put in the form of the relative error,

$$
e_{q} / q=\left[\left(e_{m} / m\right)^{2}+\left(e_{t} / t\right)^{2}+\left(e_{h_{1 g}} / h_{f g}\right)^{2}+4\left(e_{R} / R\right)^{2}\right]^{1 / 2}
$$

C. Heat Transfer Surface Temperature: $T_{\text {SUAF }}=T_{\text {tc }}-(q / k) \Delta y$

From Equation A4.1 the absolute uncertainty is:

$$
\begin{aligned}
& e_{T_{\text {SUAF }}}=\left[\left(\partial T_{\text {SUAF }} / \partial T_{\text {TC }}\right)^{2} e_{T_{\text {IC }}}^{2}+\left(\partial T_{\text {SUAF }} / \partial O\right)^{2} e_{q}^{2}+\left(\partial T_{\text {SUAF }} / \partial K\right)^{2} e_{k}^{2}+\right. \\
& \left.\left(\partial T_{\text {SUAF }} / \partial(\Delta y)\right)^{2} e_{\Delta y}{ }^{2}\right]^{1 / 2}
\end{aligned}
$$

which results in,

$$
e_{T_{\text {SUPF }}}=\left[e_{T_{1 c}}{ }^{2}+(\Delta y / k)^{2} e_{q}{ }^{2}+\left(q \Delta y / k^{2}\right)^{2} e_{k}{ }^{2}+(q / k)^{2} e_{\Delta y}{ }^{2}\right]^{1 / 2}
$$


d. Heat Transfer Coefficient: $\quad h=q /\left(T_{\text {SURF }}-T_{\text {SAT }}\right)=q / \Delta T_{\text {SURF }}$

From Equation A4.1 the absolute uncertainty is:

$$
e_{h}=\left[(\partial h / \partial q)^{2} e_{q}^{2}+\left(\partial h / \partial\left(\Delta T_{\text {SUPF }}\right)\right)^{2} e_{\Delta T_{\text {SUPF }}}{ }^{2}\right]^{1 / 2}
$$

and in the form of the relative uncertainty,

$$
e_{h} / h=\left[\left(e_{q} / q\right)^{2}+\left(e_{\Delta T_{\text {SURF }}} / \Delta T_{\text {SURF }}\right)^{2}\right]^{1 / 2}
$$

e. Superficial Gas Velocity: $j_{g}$

$$
j_{g}=\left(R_{g} / R_{F S}\right) V_{F S}\left[\left(M_{A I R} / M_{N_{2}}\right)\left(P_{g} / P_{S T D}\right)\left(T_{S T D} / T_{g}\right)\right]^{1 / 2}\left(T_{\text {SUPF }} / T_{g}\right) / A_{p}
$$

as before $A_{p}=\pi R^{2}$

From Equation A4.1 the absolute uncertainty is:

$$
\begin{array}{r}
e_{i_{g}}=\left[\left(\partial j_{g} / \partial R_{g}\right)^{2} e_{R_{g}}{ }^{2}+\left(\partial j_{g} / \partial P_{g}\right)^{2} e_{P_{g}}{ }^{2}+\underset{g}{\left(\partial j_{g} / \partial T_{g}\right)^{2} e_{T_{g}}{ }^{2}+}\right. \\
\left.\left(\partial j_{g} / \partial T_{\text {SUPF }}\right)^{2} e_{T_{\text {BUPF }}}{ }^{2}+\left(\partial j_{g} / \partial R\right)^{2} e_{R}{ }^{2}\right]^{1 / 2}
\end{array}
$$

and in terms of the relative uncertainty,

$$
\begin{aligned}
& e_{J_{g}} / j_{g}=\left[\left(e_{R_{g}} / R_{g}\right)^{2}+(1 / 4)\left(e_{P_{g}} / P_{g}\right)^{2}+(g / 4)\left(e_{T_{g}} / T_{g}\right)^{2}+\left(e_{T_{\text {SUPF }}} / T_{\text {SURF }}\right)^{2}+\right. \\
& \left.4\left(e_{R} / R\right)^{2}\right]^{1 / 2}
\end{aligned}
$$

To repeat, the measured quantities listed in Table A4.2 were substituted into the preceding equations to obtain the measurement uncertainty for each fundamental quantity. The resulting uncertainties for a high and a low heat transfer plate temperature and superficial gas velocity are listed in rable A4.1. 
Table A4.2 Film boiling data to determine errors

Low: TSURF, $j_{g}$ High: TSURF, $j_{g}$ Quantity Run 1a,9/19/88 Run 8b,10/19/88 Uncertainty Units

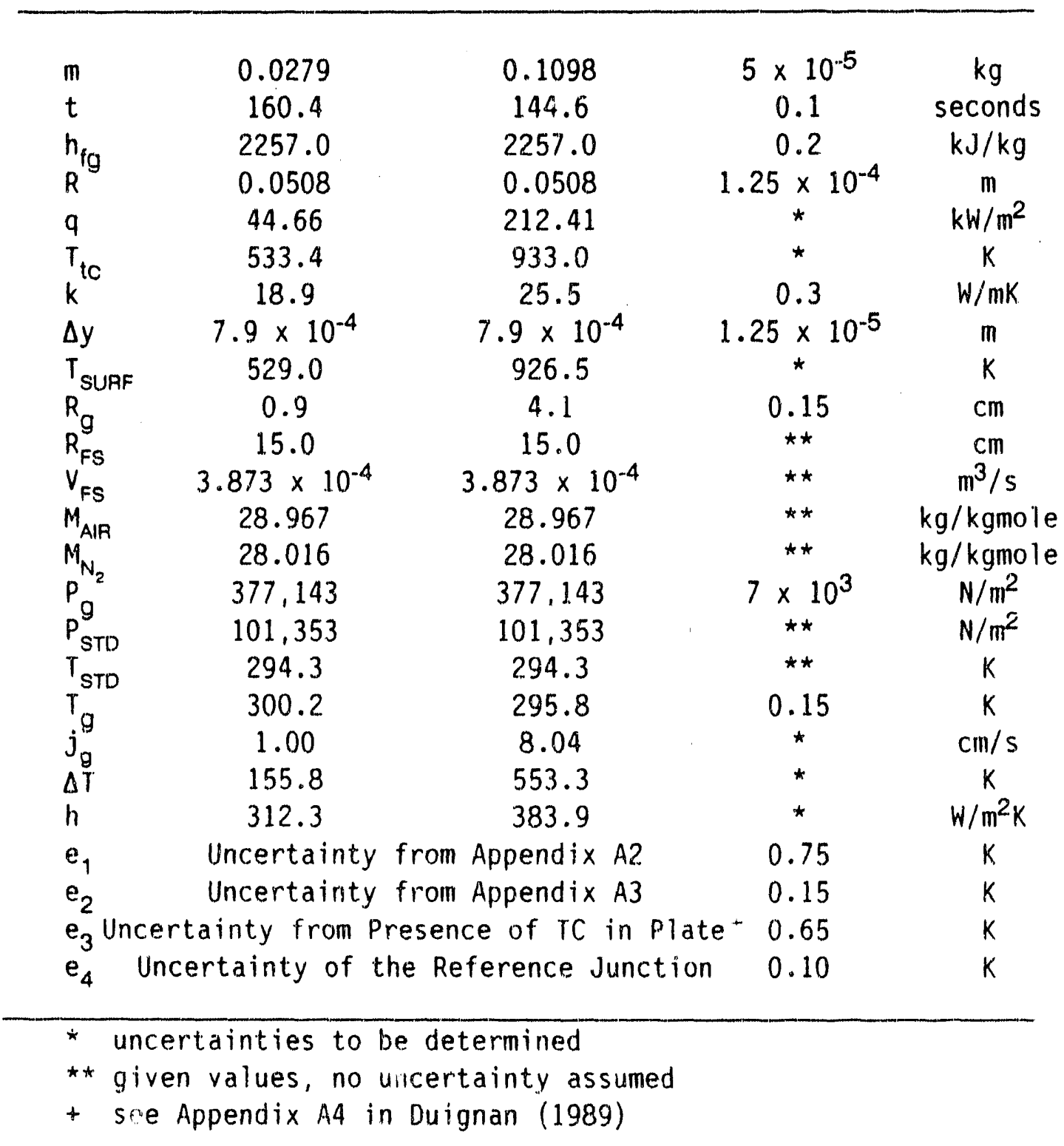




\section{APPENDIX A5: TABULAR DATA}

The following tables contain all of the experimental data for this present investigation. All quantities listed were experimentally measured except the heat transfer coefficient which is simply $q /\left(T_{\text {SUAF }}-T_{\text {SAT }}\right)$ or $q /\left(T_{\text {SUAF }}-T_{\text {POOL }}\right)$. For clarity of the tabular presentation, the measurement uncertainties of the individual quantities have not been presented but typical values are given in Appendix A4.

Table A5.1 is of the stable film boiling measurements (i.e., no noncondensible gas flux). Two columns of the heat flux are shown since two methods were used for measurement, viz., by heat conduction through the heat transfer plate and by condensation of the water vapor leaving the boiling chamber.

Tables A5.2a and A5.2b are for the pool bubbling measurements (i.e. no film boiling). Only one heat flux column is listed because most of the heat was transferred to the overlying pool of water in the form of sensible heat, therefore, the condensation method was not utilized. Table A5.2 was broken into two tables, (a) and (b), to highlight the respective parameters held constant. While in Table A5.2a the pool height was held relatively constant, in Table A5.2b the superficial gas velocity was kept constant. Note, measured quantities having a pool height of $11.5 \mathrm{~cm}$ and greater in Table $A 5.2 \mathrm{~b}$ are also listed in Table A5.2a.

Table A5.3 is of the film boiling heat transfer in the presence of a noncondensible gas. The measured quantities are displayed in columns 3, 4, and 5 . As a measure of the experimental reproducibility and the random errors in the measurements, several runs were taken at similar surface superheats ( $T_{\text {SUAF }}$ $\left.T_{S A T}\right)$. An average value is given of repeated runs in columns 7,8 , and 9 which are the values used in the Results section of this study. As for stable filin boiling the heat flux was measured by the conduction and condensation inethod. Unfortunately, the conduction method became very unstable during this last set of experiments, and several of the thermocouples, near the heating coil, failed. only the heat flux measurements by the condensation method are listed. 
Table A5.1 Film boiling with no gas injection

\begin{tabular}{|c|c|c|c|c|c|c|}
\hline \multirow[b]{3}{*}{$\begin{array}{l}\text { Run } \\
\text { No. }\end{array}$} & \multirow[b]{3}{*}{$\begin{array}{l}\text { Run } \\
\text { Date }\end{array}$} & \multirow[b]{3}{*}{$T_{\text {SUPF }}-T_{\text {SAT }}$} & \multirow{2}{*}{\multicolumn{4}{|c|}{$\begin{array}{l}\text { Determined by: } \\
\text { Conduction } \\
\text { Condensation }\end{array}$}} \\
\hline & & & & & & \\
\hline & & & $\left(\mathrm{kW} / \mathrm{m}^{2}\right)$ & $\frac{h}{\left(W / m^{2} \cdot K\right)}$ & $\frac{\mathrm{q}}{\left.\mathrm{q} W / \mathrm{m}^{2}\right)}$ & $\frac{h}{\left(W / m^{2} K\right)}$ \\
\hline 1 & $8 / 05 / 87$ & 276 & 50.7 & 184 & 45.0 & 163 \\
\hline 2 & $8 / 05 / 87$ & 276 & 50.7 & 184 & 44.8 & 162 \\
\hline 3 & $8 / 05 / 87$ & 281 & 51.6 & 184 & 46.9 & 167 \\
\hline 4 & $8 / 05 / 87$ & 281 & 52.0 & 185 & 46.8 & 167 \\
\hline 5 & $8 / 05 / 87$ & 285 & 52.5 & 184 & 48.1 & 169 \\
\hline 6 & $8 / 05 / 87$ & 286 & 51.9 & 181 & 48.4 & 169 \\
\hline 7 & $8 / 05 / 87$ & 404 & 78.5 & 194 & 73.5 & 182 \\
\hline 8 & $8 / 05 / 87$ & 404 & 79.4 & 197 & 73.5 & 182 \\
\hline 9 & $8 / 05 / 87$ & 406 & 79.7 & 196 & 74.1 & 183 \\
\hline 10 & $8 / 05 / 87$ & 469 & 94.7 & 202 & 90.1 & 192 \\
\hline 11 & $8 / 05 / 87$ & 470 & 95.7 & 204 & 89.3 & 190 \\
\hline 12 & $8 / 05 / 87$ & 471 & 95.4 & 203 & 91.2 & 194 \\
\hline 1 & $8 / 12 / 87$ & 334 & 64.2 & 192 & 61.7 & 185 \\
\hline 2 & $8 / 12 / 87$ & 335 & 64.4 & 192 & 61.9 & 185 \\
\hline 3 & $8 / 12 / 87$ & 334 & 64.7 & 194 & 60.0 & 180 \\
\hline 4 & $8 / 12 / 87$ & 335 & 64.3 & 192 & 60.2 & 180 \\
\hline 5 & $8 / 12 / 87$ & 306 & 57.9 & 189 & 53.4 & 175 \\
\hline 6 & $8 / 12 / 87$ & 306 & 57.4 & 188 & 54.6 & 178 \\
\hline 7 & $8 / 12 / 87$ & 307 & 57.9 & 189 & 54.4 & 177 \\
\hline 8 & $8 / 12 / 87$ & 268 & 49.6 & 185 & 46.6 & 174 \\
\hline 9 & $8 / 12 / 87$ & 269 & 49,1 & 183 & 46.1 & 171 \\
\hline 10 & $8 / 12 / 87$ & 206 & 39.1 & 1.90 & 34.7 & 168 \\
\hline 11 & $8 / 12 / 87$ & 205 & 39.4 & 192 & 34.9 & 170 \\
\hline 12 & $8 / 12 / 87$ & 206 & 38.9 & 189 & 33.9 & 165 \\
\hline
\end{tabular}


Table A5.1 (continued)

\begin{tabular}{|c|c|c|c|c|c|c|}
\hline \multirow[b]{3}{*}{$\begin{array}{l}\text { Run } \\
\text { No. }\end{array}$} & \multirow[b]{3}{*}{$\begin{array}{l}\text { Run } \\
\text { Date }\end{array}$} & \multirow[b]{3}{*}{ 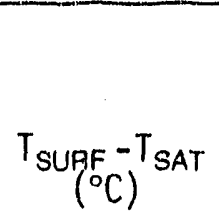 } & \multicolumn{4}{|c|}{ Determined by: } \\
\hline & & & \multicolumn{2}{|c|}{ Conduction } & \multicolumn{2}{|c|}{ Condensation } \\
\hline & & & $\begin{array}{c}q \\
\left(\mathrm{~kW} / \mathrm{m}^{2}\right)\end{array}$ & $\frac{h}{\left(W / m^{2} K\right)}$ & $\begin{array}{c}q \\
\left(\mathrm{~kW} / \mathrm{m}^{2}\right)\end{array}$ & $\begin{array}{c}h \\
\left(W / m^{2} K\right)\end{array}$ \\
\hline 1 & $8 / 14 / 87$ & 235 & 45.1 & 192 & 40.0 & 170 \\
\hline 2 & $8 / 14 / 87$ & 235 & 45.1 & 192 & 40.5 & 172 \\
\hline 3 & $8 / 14 / 87$ & 182 & 34.0 & 187 & 30.5 & 168 \\
\hline 4 & $8 / 14 / 87$ & 182 & 34.0 & 187 & 30.8 & 169 \\
\hline 5 & $8 / 14 / 87$ & 182 & 33.9 & 186 & 30.5 & 168 \\
\hline 6 & $8 / 14 / 87$ & 164 & 30.6 & 187 & 27.7 & 169 \\
\hline 7 & $8 / 14 / 87$ & 164 & 28.6 & 174 & 28.1 & 171 \\
\hline 8 & $8 / 14 / 87$ & 144 & 27.2 & 189 & 26.2 & 182 \\
\hline 9 & $8 / 14 / 87$ & 143 & 26.7 & 187 & 24.3 & 170 \\
\hline 10 & $8 / 14 / 87$ & 143 & 27.1 & 190 & 23.8 & 166 \\
\hline 1 & $8 / 19 / 87$ & 371 & 72.8 & 196 & 67.6 & 182 \\
\hline 2 & $8 / 19 / 87$ & 372 & 71.8 & 193 & 67.5 & 181. \\
\hline 3 & $8 / 19 / 87$ & 372 & 71.5 & 192 & 66.9 & 180 \\
\hline 4 & $8 / 19 / 87$ & 438 & 88.2 & 201 & 81.7 & 187 \\
\hline 5 & $8 / 19 / 87$ & 438 & 88.2 & 201 & 81.8 & 187 \\
\hline 6 & $8 / 19 / 87$ & 440 & 88.4 & 201 & 82.0 & 186 \\
\hline 7 & $8 / 19 / 87$ & 512 & 103.8 & 203 & 104.9 & 205 \\
\hline 8 & $8 / 19 / 87$ & 512 & 103.7 & 203 & 107.1 & 209 \\
\hline 9 & $8 / 19 / 87$ & 514 & 103.1 & 201 & 104.8 & 204 \\
\hline 1 & $8 / 21 / 87$ & 506 & 108.0 & 213 & & \\
\hline 2 & $8 / 21 / 87$ & 506 & 108.3 & 214 & & \\
\hline 3 & $8 / 21 / 87$ & 536 & 110.3 & 206 & & \\
\hline 4 & $8 / 21 / 87$ & 539 & 111.8 & 207 & & \\
\hline 1 & $9 / 22 / 87$ & 567 & 116.3 & 205 & & \\
\hline 2 & $9 / 22 / 87$ & 561 & 114.0 & 203 & & \\
\hline 3 & $9 / 22 / 87$ & 557 & 114.1 & 205 & & \\
\hline 4 & $9 / 22 / 87$ & 556 & 113.8 & 205 & & \\
\hline 5 & $9 / 22 / 87$ & 557 & 112.7 & 202 & & \\
\hline
\end{tabular}


Table A5.2a Bubbling data, no film boiling: constant pool height

\begin{tabular}{|c|c|c|c|c|c|}
\hline$\left(\mathrm{cm}_{\mathrm{g}} \mathrm{s}_{\mathrm{s}}\right)$ & $\begin{array}{l}\text { pool height } \\
(\mathrm{cm})\end{array}$ & $\left(w^{q} / m^{2}\right)$ & $T_{\text {SURF }}\left({ }^{\circ} \mathrm{C}\right)$ & $\begin{array}{c}T_{P O O L} \\
\left({ }^{\circ} \mathrm{C}\right)\end{array}$ & $\begin{array}{c}h \\
\left(W / m^{2} K\right)\end{array}$ \\
\hline 0.61 & 12.0 & 25668 & 89.6 & 84.0 & 4608 \\
\hline 0.61 & 12.0 & 25032 & 90.0 & 84.0 & 4172 \\
\hline 0.61 & 12.0 & 25564 & 90.1 & 84.4 & 4485 \\
\hline 0.61 & 12.0 & 25673 & 90.1 & 84.4 & 4504 \\
\hline 0.61 & 12.0 & 25916 & 89.7 & 84.1 & 4628 \\
\hline 0.61 & 12.0 & 25687 & 89.8 & 84.2 & 4587 \\
\hline 0.61 & 12.0 & 25364 & 90.3 & 84.4 & 4299 \\
\hline 0.61 & 12.0 & 25886 & 90.2 & 84.4 & 4463 \\
\hline 0.77 & 12.0 & 26049 & 89.1 & 83.3 & 4491 \\
\hline 0.77 & 12.0 & 26073 & 89.1 & 83.3 & 4495 \\
\hline 0.77 & 12.0 & 26192 & 89.2 & 83.5 & 4595 \\
\hline 0.77 & 12.0 & 26477 & 89.4 & 83.5 & 4488 \\
\hline 0.77 & 12.0 & 26467 & 89.2 & 83.4 & 4563 \\
\hline 0.80 & 12.0 & 26141 & 88.2 & 82.7 & 4753 \\
\hline 0.80 & 12.0 & 26212 & 88.1 & 82.8 & 4946 \\
\hline 0.80 & 12.0 & 26500 & 87.9 & 82.5 & 4907 \\
\hline 0.94 & 12.0 & 25781 & 87.4 & 81.6 & 4445 \\
\hline 0.95 & 12.0 & 25309 & 87.7 & 81.5 & 4082 \\
\hline 1.32 & 12.0 & 25986 & 84.7 & 79.1 & 4640 \\
\hline 1.32 & 12.0 & 25514 & 84.3 & 78.5 & 4399 \\
\hline 1.32 & 12.0 & 26031 & 84.5 & 79.0 & 4733 \\
\hline 1.73 & 12.0 & 26317 & 82.1 & 76.5 & 4699 \\
\hline 1.73 & 12.0 & 26532 & 82.5 & 76.7 & 4574 \\
\hline 2.01 & 12.0 & 26055 & 80.4 & 74.9 & 4737 \\
\hline 2.01 & 12.0 & 26231 & 80.3 & 74.9 & 4858 \\
\hline 2.05 & 12.0 & 26128 & 80.5 & 75.1 & 48.39 \\
\hline 2.45 & 12.0 & 26145 & 78.9 & 73.3 & 4669 \\
\hline 2.45 & 12.0 & 26962 & 78.8 & 73.5 & 5087 \\
\hline 2.45 & 12.0 & 27079 & 79.4 & 73.7 & 4751 \\
\hline 2.81 & 12.0 & 27342 & 77.7 & 72.1 & 4883 \\
\hline 2.81 & 12.0 & 26856 & 77.7 & 72.2 & 4883 \\
\hline 2.81 & 12.0 & 27032 & 77.2 & 71.8 & 5006 \\
\hline 2.85 & 12.0 & 27089 & 77.1 & 71.2 & 4591 \\
\hline 2.85 & 12.0 & 26162 & 77.2 & 71.3 & 4434 \\
\hline 2.85 & 12.0 & 26663 & 77.0 & 70.9 & 4371 \\
\hline
\end{tabular}


Table A5.2a (continued)

\begin{tabular}{|c|c|c|c|c|c|}
\hline$\underset{(\mathrm{cm} / \mathrm{s})}{\mathrm{j}_{\mathrm{g}}}$ & $\begin{array}{c}\text { pool height } \\
(\mathrm{cm})\end{array}$ & $\left(W^{q} / m^{2}\right)$ & TSUPF & ${ }^{T}{ }^{\mathrm{POO}}$ & $\stackrel{h}{\left(W / m^{2} K\right)}$ \\
\hline $\begin{array}{l}3.20 \\
3.20 \\
3.20 \\
3.56 \\
3.56 \\
3.56 \\
3.57 \\
3.98 \\
3.99 \\
3.99 \\
3.99 \\
4.41 \\
4.41 \\
4.42 \\
4.42 \\
4.95 \\
4.96 \\
4.97 \\
4.97 \\
4.97 \\
4.97 \\
5.42 \\
5.42 \\
5.43 \\
5.44 \\
6.09 \\
6.09 \\
6.10 \\
6.10 \\
6.34 \\
6.34 \\
6.34 \\
6.37 \\
6.37 \\
6.38\end{array}$ & $\begin{array}{l}12.0 \\
12.0 \\
12.0 \\
12.0 \\
12.0 \\
12.0 \\
12.0 \\
12.0 \\
12.0 \\
12.0 \\
12.0 \\
12.0 \\
12.0 \\
12.0 \\
12.0 \\
12.0 \\
12.0 \\
12.0 \\
12.0 \\
12.0 \\
12.0 \\
12.0 \\
12.0 \\
12.0 \\
12.0 \\
12.0 \\
12.0 \\
12.0 \\
12.0 \\
15.0 \\
15.0 \\
15.0 \\
15.0 \\
15.0 \\
15.0\end{array}$ & $\begin{array}{l}26642 \\
26607 \\
26633 \\
26825 \\
26128 \\
27007 \\
26402 \\
26842 \\
26344 \\
26488 \\
26546 \\
26546 \\
26522 \\
26464 \\
26431 \\
26561 \\
26389 \\
27003 \\
26724 \\
27349 \\
27531 \\
26483 \\
26593 \\
26425 \\
26093 \\
25945 \\
25881 \\
25831 \\
26032 \\
27246 \\
27313 \\
27285 \\
27436 \\
27534 \\
27265\end{array}$ & $\begin{array}{l}75.1 \\
75.3 \\
75.3 \\
73.9 \\
74.4 \\
74.4 \\
74.3 \\
74.4 \\
72.7 \\
72.9 \\
72.9 \\
73.1 \\
73 \\
70.8 \\
70.6 \\
71.1 \\
71.1 \\
68.7 \\
68.8 \\
69.0 \\
69 \\
69.2 \\
69.4 \\
69.7 \\
6\end{array}$ & $\begin{array}{l}69.6 \\
69.4 \\
69.2 \\
68.0 \\
68.2 \\
68.1 \\
68.0 \\
67.1 \\
66.9 \\
66.7 \\
66.7 \\
65.4 \\
65.3 \\
65.6 \\
65.6 \\
63.9 \\
63.8 \\
63.9 \\
63.9 \\
64.3 \\
64.5 \\
62.4 \\
62.6 \\
62.3 \\
62 \\
62.4 \\
60.4 \\
60.4 \\
60.5 \\
60 \\
60 \\
60.4 \\
60 \\
60.0 \\
60.1 \\
61 \\
61.6 \\
61.6 \\
61.7\end{array}$ & $\begin{array}{l}4844 \\
4510 \\
4366 \\
4547 \\
4214 \\
4356 \\
4125 \\
4793 \\
4391 \\
4272 \\
4148 \\
4916 \\
5004 \\
4812 \\
4806 \\
5534 \\
5278 \\
5295 \\
5042 \\
5363 \\
5294 \\
5093 \\
4925 \\
5393 \\
5219 \\
4989 \\
4883 \\
4784 \\
4733 \\
5342 \\
5253 \\
5350 \\
5380 \\
5295 \\
5243\end{array}$ \\
\hline
\end{tabular}


Table A5.2a (continued)

\begin{tabular}{|c|c|c|c|c|c|}
\hline$\left(\mathrm{cm}_{\mathrm{g}} \mathrm{s}_{\mathrm{s}}\right)$ & $\begin{array}{l}\text { pool height } \\
(\mathrm{cm})\end{array}$ & $\left(w / m^{2}\right)$ & ${ }^{T}$ SURF & $\begin{array}{c}T_{\text {pool }} \\
\left({ }^{\circ} \mathrm{C}\right)\end{array}$ & $\begin{array}{c}h \\
\left(W / m^{2} K\right)\end{array}$ \\
\hline $\begin{array}{l}6.38 \\
6.39 \\
6.39 \\
6.45 \\
6.45 \\
6.45 \\
6.45 \\
6.45 \\
6.46 \\
6.46 \\
6.46 \\
6.46 \\
6.47 \\
7.45 \\
7.45 \\
7.45 \\
7.46 \\
8.77 \\
8.77 \\
8.78 \\
8.78\end{array}$ & $\begin{array}{l}13.0 \\
13.0 \\
13.0 \\
12.0 \\
12.0 \\
12.0 \\
12.0 \\
14.0 \\
14.0 \\
14.0 \\
11.5 \\
11.5 \\
11.5 \\
12.0 \\
12.0 \\
12.0 \\
12.0 \\
12.0 \\
12.0 \\
12.0 \\
12.0\end{array}$ & $\begin{array}{l}27039 \\
27149 \\
27242 \\
25927 \\
25779 \\
25821 \\
25754 \\
26573 \\
26533 \\
26457 \\
26060 \\
26735 \\
26365 \\
25630 \\
25854 \\
25575 \\
25702 \\
25914 \\
25851 \\
25803 \\
25717\end{array}$ & $\begin{array}{l}66.7 \\
66.8 \\
66.9 \\
64.1 \\
64.2 \\
64.2 \\
64.2 \\
64.6 \\
64.7 \\
64.8 \\
65.0 \\
64.8 \\
65.1 \\
62.1 \\
61.9 \\
62.0 \\
62.1 \\
59.2 \\
59.2 \\
59.5 \\
59.5\end{array}$ & $\begin{array}{l}61.7 \\
61.8 \\
61.7 \\
59.0 \\
59.0 \\
59.0 \\
59.0 \\
59.9 \\
59.6 \\
59.6 \\
59.8 \\
59.8 \\
59.8 \\
56.8 \\
56.8 \\
56.8 \\
56.8 \\
54.2 \\
54.2 \\
54.4 \\
54.3\end{array}$ & $\begin{array}{l}5408 \\
5430 \\
5239 \\
5084 \\
4958 \\
4966 \\
4953 \\
5654 \\
5203 \\
5088 \\
5012 \\
5347 \\
4975 \\
4836 \\
5069 \\
4918 \\
4849 \\
5183 \\
5170 \\
5059 \\
4946\end{array}$ \\
\hline
\end{tabular}


Table A5.2b Bubbling data, no film boiling: constant $j_{g}$

\begin{tabular}{|c|c|c|c|c|c|}
\hline $\begin{array}{l}\text { pool height } \\
(\mathrm{cm})\end{array}$ & $\underset{(\mathrm{cm} / \mathrm{s})}{\mathrm{j}_{\mathrm{g}}}$ & $\left(w^{q} / m^{2}\right)$ & $\mathrm{T}_{\text {SuRF }}$ & $\begin{array}{l}T_{\text {POOL }} \\
\left({ }^{\circ} \mathrm{C}\right)\end{array}$ & $\stackrel{h}{\left.h / m^{2} K\right)}$ \\
\hline $\begin{array}{l}2.5 \\
2.5 \\
2.5 \\
3.0 \\
3.0 \\
3.0 \\
3.0 \\
3.0 \\
3.0 \\
3.0 \\
3.5 \\
3.5 \\
3.5 \\
4.0 \\
4.0 \\
4.0 \\
4.0 \\
4.0 \\
4.0 \\
4.0 \\
4 \\
4.0 \\
4.0 \\
5\end{array}$ & $\begin{array}{l}6.47 \\
6.47 \\
6.47 \\
6.46 \\
6.46 \\
6.46 \\
6.50 \\
6.51 \\
6.51 \\
6.44 \\
6.43 \\
6.43 \\
6.46 \\
6.46 \\
6.46 \\
6.43 \\
6.42 \\
6.42 \\
6.43 \\
6.43 \\
6.43 \\
6.48 \\
6.48 \\
6.48 \\
6.48 \\
6.42 \\
6.42 \\
6.41 \\
6.49 \\
6.49 \\
6.49 \\
6.47 \\
6.47 \\
6.47 \\
6.45 \\
6.45\end{array}$ & $\begin{array}{l}27106 \\
26671 \\
26753 \\
27377 \\
27761 \\
27683 \\
27340 \\
27588 \\
27520 \\
27177 \\
27510 \\
27802 \\
26824 \\
26977 \\
27085 \\
27466 \\
27571 \\
27368 \\
28002 \\
27905 \\
27883 \\
27015 \\
26761 \\
26796 \\
26856 \\
26598 \\
26260 \\
26129 \\
27435 \\
27559 \\
27617 \\
27792 \\
27733 \\
27793 \\
28005 \\
27865\end{array}$ & $\begin{array}{l}70.4 \\
70.4 \\
70.4 \\
70.5 \\
70.2 \\
70.3 \\
70.1 \\
70.2 \\
70.2 \\
69.9 \\
69.8 \\
69.8 \\
67.4 \\
67.5 \\
67.6 \\
68.3 \\
68.2 \\
68.3 \\
68.7 \\
68.7 \\
68.7 \\
65.9 \\
66.0 \\
65.9 \\
66.1 \\
65.9 \\
65.7 \\
65.6 \\
66.5 \\
66.5 \\
66.7 \\
66.8 \\
66.9 \\
67.0 \\
66.3 \\
66.4\end{array}$ & $\begin{array}{l}62.8 \\
62.7 \\
62.7 \\
62.8 \\
62.8 \\
62.8 \\
62.1 \\
62.2 \\
62.2 \\
62.3 \\
62.3 \\
62.3 \\
61.2 \\
61.3 \\
61.3 \\
61.8 \\
61.7 \\
61.8 \\
62.9 \\
62.9 \\
62.8 \\
60.6 \\
60.5 \\
60.5 \\
60.5 \\
60.8 \\
60.7 \\
60.6 \\
60.9 \\
60.9 \\
61.0 \\
61.1 \\
61.2 \\
61.2 \\
61.4 \\
61.5\end{array}$ & $\begin{array}{l}3567 \\
3464 \\
3474 \\
3555 \\
3751 \\
3691 \\
3418 \\
3449 \\
3440 \\
3576 \\
3668 \\
3707 \\
4326 \\
4351 \\
4299 \\
4226 \\
4242 \\
4210 \\
4828 \\
4811 \\
4726 \\
5097 \\
4866 \\
4962 \\
4796 \\
5215 \\
5252 \\
5226 \\
4899 \\
4921 \\
4845 \\
4876 \\
4865 \\
4792 \\
5715 \\
5687\end{array}$ \\
\hline
\end{tabular}


Table A5.2b (continued)

\begin{tabular}{|c|c|c|c|c|c|}
\hline $\begin{array}{l}\text { pool height } \\
(\mathrm{cm})\end{array}$ & $\left(\mathrm{cm}_{\mathrm{g}} \mathrm{s}_{\mathrm{s}}\right)$ & $\begin{array}{c}q \\
\left(W / m^{2}\right)\end{array}$ & $T_{\text {SURF }}$ & ${ }^{\mathrm{T} P O O L}$ & $\begin{array}{c}h \\
\left(W / m^{2} K\right)\end{array}$ \\
\hline $\begin{array}{r}6.5 \\
6.5 \\
6.5 \\
7.0 \\
7.0 \\
7.0 \\
7.0 \\
7.0 \\
7.0 \\
8.0 \\
8.0 \\
8.0 \\
8.0 \\
8.0 \\
8.0 \\
8.0 \\
8.0 \\
8.0 \\
9.0 \\
9.0 \\
9.0 \\
10.0 \\
10.0 \\
10.0 \\
10.0 \\
10.0 \\
11.0 \\
11.0 \\
11.0 \\
11.5 \\
11.5 \\
11.5 \\
12.0 \\
12.0 \\
12.0 \\
12.0\end{array}$ & $\begin{array}{l}6.39 \\
6.38 \\
6.38 \\
6.40 \\
6.40 \\
6.40 \\
6.39 \\
6.39 \\
6.38 \\
6.45 \\
6.45 \\
6.45 \\
6.41 \\
6.40 \\
6.40 \\
6.39 \\
6.39 \\
6.39 \\
6.41 \\
6.41 \\
6.41 \\
6.42 \\
6.41 \\
6.41 \\
6.45 \\
6.46 \\
6.40 \\
6.40 \\
6.40 \\
6.46 \\
6.46 \\
6.47 \\
6.09 \\
6.09 \\
6.10 \\
6.10\end{array}$ & $\begin{array}{l}27151 \\
27111 \\
26780 \\
26366 \\
26199 \\
26196 \\
27305 \\
27341 \\
27454 \\
27436 \\
27066 \\
27297 \\
27308 \\
27583 \\
27378 \\
26989 \\
27156 \\
27132 \\
26283 \\
26419 \\
26393 \\
25669 \\
25921 \\
25940 \\
26303 \\
26054 \\
24907 \\
25281 \\
26222 \\
26060 \\
26735 \\
26365 \\
25945 \\
25881 \\
25831 \\
26032\end{array}$ & $\begin{array}{l}66.7 \\
66.6 \\
66.6 \\
65.4 \\
65.3 \\
65.3 \\
66.8 \\
66.9 \\
66.8 \\
65.9 \\
65.9 \\
65.9 \\
67.1 \\
66.8 \\
66.9 \\
66.8 \\
66.8 \\
66.8 \\
64.6 \\
64.7 \\
64.8 \\
64.7 \\
64.5 \\
64.3 \\
65.0 \\
65.4 \\
63.6 \\
63.5 \\
63.7 \\
65.0 \\
64.8 \\
65.1 \\
65.6 \\
65.7 \\
65.9 \\
65.9\end{array}$ & $\begin{array}{l}62.0 \\
61.8 \\
61.9 \\
60.6 \\
60.5 \\
60.5 \\
62.0 \\
62.0 \\
61.9 \\
60.9 \\
60.8 \\
60.8 \\
61.8 \\
61.8 \\
61.7 \\
61.6 \\
61.8 \\
61.8 \\
59.8 \\
59.9 \\
60.0 \\
59.8 \\
59.8 \\
59.6 \\
60.0 \\
60.2 . \\
58.8 \\
58.7 \\
58.8 \\
59.8 \\
59.8 \\
59.8 \\
60.4 \\
60.4 \\
60.5 \\
60.4\end{array}$ & $\begin{array}{l}5777 \\
5648 \\
5698 \\
5493 \\
5458 \\
5458 \\
5689 \\
5580 \\
5603 \\
5487 \\
5307 \\
5352 \\
5152 \\
5517 \\
5265 \\
5190 \\
5431 \\
5426 \\
5476 \\
5504 \\
5499 \\
5239 \\
5515 \\
5519 \\
5261 \\
5010 \\
5189 \\
5267 \\
5351 \\
5012 \\
5347 \\
4975 \\
4989 \\
4883 \\
4784 \\
4733\end{array}$ \\
\hline
\end{tabular}


Table A5.2b (continued)

\begin{tabular}{|c|c|c|c|c|c|}
\hline $\begin{array}{l}\text { pool height } \\
(\mathrm{cm})\end{array}$ & $\left(\mathrm{cm}_{\mathrm{g}} / \mathrm{s}\right)$ & $\left(W^{q} / m^{2}\right)$ & ${ }^{T}\left({ }^{\circ} \mathrm{C}\right)$ & $\begin{array}{l}T_{P O O L} \\
\left({ }^{\circ} \mathrm{C}\right)\end{array}$ & $\stackrel{h}{\left(w / m^{2} K\right)}$ \\
\hline $\begin{array}{l}12.0 \\
12.0 \\
12.0 \\
12.0 \\
13.0 \\
13.0 \\
13.0 \\
14.0 \\
14.0 \\
14.0 \\
15.0 \\
15.0 \\
15.0 \\
15.0 \\
15.0 \\
15.0\end{array}$ & $\begin{array}{l}6.45 \\
6.45 \\
6.45 \\
6.45 \\
6.39 \\
6.39 \\
6.38 \\
6.45 \\
6.46 \\
6.46 \\
6.34 \\
6.34 \\
6.34 \\
6.37 \\
6.37 \\
6.38\end{array}$ & $\begin{array}{l}25927 \\
25779 \\
25821 \\
25754 \\
27149 \\
27242 \\
27039 \\
26573 \\
26533 \\
26457 \\
27246 \\
27313 \\
27285 \\
27436 \\
27534 \\
27265\end{array}$ & $\begin{array}{l}64.1 \\
64.2 \\
64.2 \\
64.2 \\
66.8 \\
66.9 \\
66.7 \\
64.6 \\
64.7 \\
64.8 \\
65.3 \\
65.2 \\
65.2 \\
66.7 \\
66.8 \\
66.9\end{array}$ & $\begin{array}{l}59.0 \\
59.0 \\
59.0 \\
59.0 \\
61.8 \\
61.7 \\
61.7 \\
59.9 \\
59.6 \\
59.6 \\
60.2 \\
60.0 \\
60.1 \\
61.6 \\
61.6 \\
61.7\end{array}$ & $\begin{array}{l}5084 \\
4958 \\
4966 \\
4953 \\
5430 \\
5239 \\
5408 \\
5654 \\
5203 \\
5088 \\
5342 \\
5253 \\
5350 \\
5380 \\
5295 \\
5243\end{array}$ \\
\hline
\end{tabular}


Table A5.3 Film bolling with gas injection database

\section{Average values}

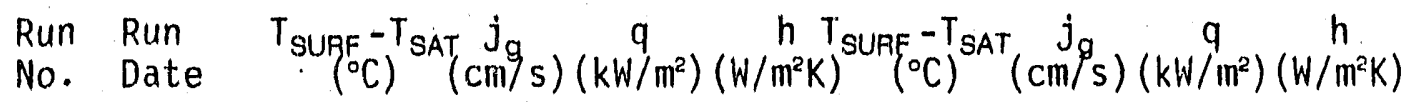

\begin{tabular}{|c|c|c|c|c|c|c|c|c|c|}
\hline d & $8 / 02 / 88$ & 272.9 & 1.02 & 57.6 & 211.1 & & & & \\
\hline & & 272.5 & 1.02 & 62.1 & 227 & & & & \\
\hline & $8 / 02 / 88$ & 272.7 & 1.02 & 61.0 & 223.7 & 272.7 & 1.02 & 60.2 & 220.9 \\
\hline & $8 / 02 / 88$ & 266.4 & 2.01 & 72.4 & 271.8 & & & & \\
\hline d & $8 / 02 / \varepsilon$ & 266 & 2.01 & 73.2 & 275.2 & 266.2 & 2.01 & 72.8 & 273.5 \\
\hline & & 30 & 2.99 & 91.1 & 346.4 & & & & \\
\hline & $8 / 02 / 88$ & & 2.97 & 91.1 & 351.1 & 261.3 & 2.98 & 91.1 & 348.8 \\
\hline & $8 / 02$ & 274.0 & 4.06 & 103.2 & 376.6 & & & & \\
\hline & $8 / 02$ & 274.4 & 4.06 & 105.1 & 383 & & & & \\
\hline & $8 / 05$ & 270 . & 4.05 & 104.0 & 38 & & & & \\
\hline d & & & 4.06 & 101.6 & 374 & 272.6 & 4.06 & 103.5 & 379.6 \\
\hline & $8 / 0$ & & 5.08 & 110 & & & & & \\
\hline & & 274 & 5.0 & 106.8 & & 274.3 & 5.09 & 108.4 & 395.3 \\
\hline & & & 6.1 & & & & & & \\
\hline & & 274 & 6.10 & 113.2 & 412 & 274.6 & 6.10 & 113.4 & 413.0 \\
\hline & & 211 & 0.99 & 58 & 274 & & & & \\
\hline & & & 0. & & & 211.9 & 0.99 & 57.8 & 272 \\
\hline & & & 2.07 & 68.3 & & & & & \\
\hline & & & 2.0 & & & 206.2 & 2.07 & 68.5 & 332.5 \\
\hline & & & 3 . & & & & & & \\
\hline & & 217 & 3. & 83.9 & & 217.2 & 3.10 & 83.1 & 382.4 \\
\hline & & & & & & & & & \\
\hline & & & & & & 213.2 & 4.09 & 98.2 & 460.6 \\
\hline$a$ & & & & 72 & & & & & \\
\hline & & & & & & & & & \\
\hline & & & 2. & & & 261.1 & 2.01 & 72.6 & 278.2 \\
\hline & & 279 & & 92 & & & & & \\
\hline & & & & & & & & & \\
\hline & & & 3. & 91 & & 281.4 & 3.12 & 91.7 & 325.9 \\
\hline 3 & & & & 101 & & & & & \\
\hline & & & & & & & & & \\
\hline & & & 4. & 102 & & 270.0 & 4.09 & 101.6 & 376.2 \\
\hline$a=$ & & 270 & & 109 & & & & & \\
\hline & & & & & & & & & \\
\hline
\end{tabular}


Table A5.3 (continued)

Average values

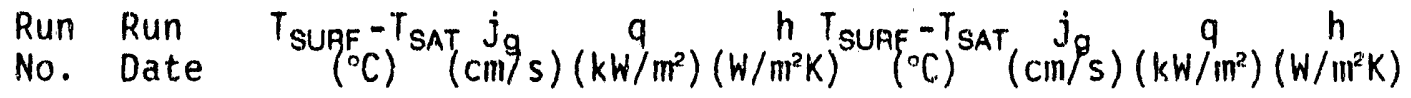

\begin{tabular}{rrrrrrrrrrr}
\hline $4 c$ & $8 / 30 / 88$ & 272.2 & 5.14 & 108.8 & 400.0 & 271.3 & 5.13 & 109.7 & 404.3 \\
$5 \mathrm{a}$ & $8 / 30 / 88$ & 275.8 & 6.19 & 120.0 & 435.1 & & & & \\
$5 \mathrm{~b}$ & $8 / 30 / 88$ & 276.6 & 6.20 & 116.8 & 422.3 & & & & \\
$5 \mathrm{c}$ & $8 / 30 / 88$ & 277.2 & 6.20 & 117.3 & 423.2 & 276.5 & 6.20 & 118.0 & 426.9 \\
$6 \mathrm{a}$ & $8 / 30 / 88$ & 276.4 & 7.24 & 127.6 & 461.6 & & & & \\
$6 \mathrm{~b}$ & $8 / 30 / 88$ & 276.8 & 7.25 & 129.3 & 467.1 & & & & \\
$6 \mathrm{c}$ & $8 / 30 / 88$ & 279.4 & 7.27 & 129.4 & 463.1 & 277.5 & 7.25 & 128.8 & 463.9 \\
$7 \mathrm{a}$ & $8 / 30 / 88$ & 269.3 & 8.18 & 138.4 & 513.9 & & & & \\
$7 \mathrm{~b}$ & $8 / 30 / 88$ & 267.3 & 8.16 & 138.7 & 518.9 & & & & \\
$7 \mathrm{c}$ & $8 / 30 / 88$ & 265.0 & 8.13 & 136.8 & 516.2 & 267.2 & 8.15 & 138.0 & 516.3 \\
$1 \mathrm{a}$ & $9 / 08 / 88$ & 307.2 & 1.01 & 63.0 & 205.1 & & & & \\
$1 \mathrm{~b}$ & $9 / 08 / 88$ & 306.8 & 1.00 & 63.5 & 207.0 & & & & \\
$1 \mathrm{c}$ & $9 / 08 / 88$ & 307.1 & 1.00 & 63.7 & 207.4 & 307.0 & 1.00 & 63.4 & 206.5 \\
$2 \mathrm{a}$ & $9 / 08 / 88$ & 303.8 & 2.00 & 79.3 & 261.0 & & & & \\
$2 \mathrm{~b}$ & $9 / 08 / 88$ & 304.9 & 2.00 & 77.9 & 255.5 & & & & \\
$2 \mathrm{c}$ & $9 / 08 / 88$ & 307.5 & 2.01 & 77.5 & 252.0 & 305.4 & 2.00 & 78.2 & 256.2 \\
$3 \mathrm{~b}$ & $9 / 08 / 88$ & 310.3 & 3.02 & 93.2 & 300.4 & & & & \\
$3 \mathrm{c}$ & $9 / 08 / 88$ & 308.8 & 3.02 & 95.9 & 310.6 & & & & \\
$3 \mathrm{~d}$ & $9 / 08 / 88$ & 308.6 & 3.02 & 94.4 & 305.9 & 309.2 & 3.02 & 94.5 & 305.6 \\
$4 \mathrm{a}$ & $9 / 08 / 88$ & 303.7 & 4.00 & 105.1 & 346.1 & & & & \\
$4 \mathrm{~b}$ & $9 / 08 / 88$ & 302.2 & 3.99 & 106.5 & 352.4 & & & & \\
$4 \mathrm{c}$ & $9 / 08 / 88$ & 302.9 & 3.99 & 106.2 & 350.6 & 302.9 & 3.99 & 105.9 & 349.7 \\
$5 \mathrm{a}$ & $9 / 08 / 88$ & 308.1 & 5.05 & 119.1 & 386.6 & & & & \\
$5 \mathrm{~b}$ & $9 / 08 / 88$ & 308.4 & 5.05 & 117.4 & 380.7 & & & & \\
$5 \mathrm{c}$ & $9 / 08 / 88$ & 310.1 & 5.06 & 117.9 & 380.2 & 308.9 & 5.05 & 118.1 & 382.5 \\
$6 \mathrm{a}$ & $9 / 08 / 88$ & 310.0 & 6.07 & 125.6 & 405.2 & & & & \\
$6 \mathrm{~b}$ & $9 / 08 / 88$ & 312.9 & 6.10 & 126.3 & 403.6 & & & & \\
$6 \mathrm{c}$ & $9 / 08 / 88$ & 313.6 & 6.10 & 126.9 & 404.7 & 312.2 & 6.09 & 126.3 & 404.5 \\
$7 \mathrm{a}$ & $9 / 08 / 88$ & 311.8 & 7.11 & 131.5 & 421.7 & & & & \\
$7 \mathrm{~b}$ & $9 / 08 / 88$ & 311.9 & 7.11 & 133.3 & 427.4 & & & & \\
$7 \mathrm{c}$ & $9 / 08 / 88$ & 313.3 & 7.12 & 130.7 & 417.2 & 312.3 & 7.11 & 131.8 & 422.1 \\
$8 \mathrm{a}$ & $9 / 08 / 88$ & 303.6 & 8.03 & 140.7 & 463.4 & & & & \\
$8 \mathrm{~b}$ & $9 / 08 / 88$ & 304.8 & 8.05 & 142.3 & 466.9 & & & & \\
$8 \mathrm{c}$ & $9 / 08 / 88$ & 302.8 & 8.02 & 143.3 & 473.3 & 303.7 & 8.03 & 142.1 & 467.9
\end{tabular}


Table A5.3 (continued)

\section{Average values}

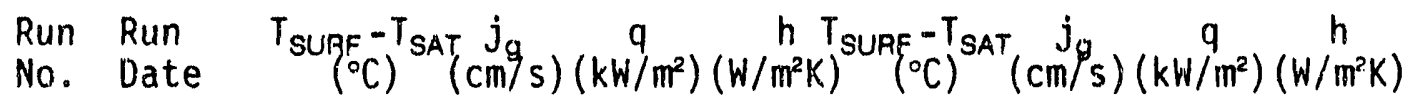

\begin{tabular}{lrrrrrrrrrr}
\hline la & $9 / 19 / 88$ & 155.8 & 1.00 & 48.7 & 312.3 & & & & \\
$1 b$ & $9 / 19 / 88$ & 155.7 & 1.00 & 48.8 & 313.3 & & & & \\
$1 \mathrm{c}$ & $9 / 19 / 88$ & 154.5 & 1.00 & 50.3 & 325.3 & 155.3 & 1.00 & 49.3 & 317.0 \\
$1 \mathrm{a}$ & $9 / 22 / 88$ & 376.4 & 0.95 & 76.5 & 203.2 & & & & \\
$1 \mathrm{~b}$ & $9 / 22 / 88$ & 376.6 & 0.95 & 79.4 & 210.8 & & & & \\
$1 \mathrm{c}$ & $9 / 22 / 88$ & 377.2 & 0.95 & 77.4 & 205.2 & 376.7 & 0.95 & 77.8 & 206.4 \\
$2 \mathrm{a}$ & $9 / 22 / 88$ & 376.5 & 2.06 & 88.2 & 234.3 & & & & \\
$2 \mathrm{~b}$ & $9 / 22 / 88$ & 377.5 & 2.07 & 88.7 & 235.0 & & & & \\
$2 \mathrm{c}$ & $9 / 22 / 88$ & 376.5 & 2.06 & 36.4 & 229.5 & 376.8 & 2.06 & 87.8 & 232.9 \\
$3 \mathrm{a}$ & $9 / 22 / 88$ & 371.6 & 3.08 & 101.6 & 273.4 & & & & \\
$3 \mathrm{~b}$ & $9 / 22 / 88$ & 370.6 & 3.07 & 103.0 & 278.5 & & & & \\
$3 \mathrm{c}$ & $9 / 22 / 88$ & 369.8 & 3.07 & 103.7 & 280.4 & 371.0 & 3.07 & 102.8 & 277.4 \\
$4 \mathrm{a}$ & $9 / 22 / 88$ & 369.0 & 4.09 & 122.8 & 322.8 & & & & \\
$4 \mathrm{~b}$ & $9 / 22 / 88$ & 369.8 & 4.09 & 123.1 & 332.9 & & & & \\
$4 \mathrm{c}$ & $9 / 22 / 88$ & 368.5 & 4.08 & 122.4 & 332.2 & 369.1 & 4.09 & 122.8 & 329.3 \\
$5 \mathrm{a}$ & $9 / 22 / 88$ & 375.7 & 5.08 & 126.4 & 336.4 & & & & \\
$5 \mathrm{~b}$ & $9 / 22 / 88$ & 371.7 & 5.05 & 128.7 & 346.3 & & & & \\
$5 \mathrm{c}$ & $9 / 22 / 88$ & 371.0 & 5.04 & 125.8 & 339.1 & 372.8 & 5.06 & 127.0 & 340.6 \\
$6 \mathrm{a}$ & $9 / 22 / 88$ & 375.6 & 6.19 & 136.9 & 364.5 & & & & \\
$6 \mathrm{~b}$ & $9 / 22 / 88$ & 377.9 & 6.21 & 136.6 & 361.5 & & & & \\
$6 \mathrm{c}$ & $9 / 22 / 88$ & 378.6 & 6.21 & 135.5 & 357.9 & 377.4 & 6.20 & 136.3 & 361.3 \\
$7 \mathrm{a}$ & $9 / 22 / 88$ & 377.4 & 7.16 & 145.4 & 385.3 & & & & \\
$7 \mathrm{~b}$ & $9 / 22 / 88$ & 376.5 & 7.15 & 144.9 & 384.9 & & & & \\
$7 \mathrm{c}$ & $9 / 22 / 88$ & 375.7 & 7.14 & 142.8 & 380.1 & 376.5 & 7.15 & 144.4 & 383.4 \\
$8 \mathrm{a}$ & $9 / 22 / 88$ & 374.8 & 8.17 & 151.8 & 405.0 & & & & \\
$8 \mathrm{~b}$ & $9 / 22 / 88$ & 372.4 & 8.14 & 152.0 & 408.2 & & & & \\
$8 \mathrm{c}$ & $9 / 22 / 88$ & 371.1 & 8.13 & 151.3 & 407.7 & 372.8 & 8.15 & 151.7 & 407.0 \\
$1 \mathrm{a}$ & $9 / 28 / 88$ & 455.0 & 1.05 & 92.5 & 203.3 & & & & \\
$1 \mathrm{~b}$ & $9 / 28 / 88$ & 453.6 & 1.05 & 96.0 & 211.6 & & & & \\
$1 \mathrm{c}$ & $9 / 28 / 88$ & 452.0 & 1.05 & 97.1 & 214.8 & & & & \\
$1 \mathrm{~d}$ & $9 / 28 / 88$ & 448.8 & 1.04 & 93.3 & 207.9 & & & & \\
$1 \mathrm{e}$ & $9 / 28 / 88$ & 447.2 & 1.04 & 97.6 & 218.2 & 451.3 & 1.05 & 95.3 & 211.2 \\
$2 \mathrm{a}$ & $9 / 28 / 88$ & 457.5 & 2.10 & 107.8 & 235.7 & & & & \\
$2 \mathrm{~b}$ & $9 / 28 / 88$ & 457.7 & 2.10 & 112.2 & 245.2 & & & & \\
& & & & & & & & &
\end{tabular}


Table A5.3 (continued)

Average values

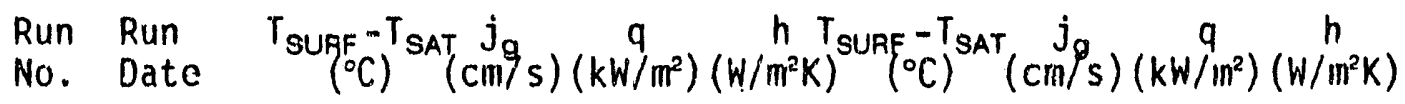

\begin{tabular}{|c|c|c|c|c|c|c|c|c|c|}
\hline $\begin{array}{l}2 c \\
3 a\end{array}$ & $\begin{array}{l}9 / 28 / 88 \\
9 / 28 / 88\end{array}$ & $\begin{array}{l}457.3 \\
447.3\end{array}$ & $\begin{array}{l}2.10 \\
3.11\end{array}$ & $\begin{array}{l}111.4 \\
122.8\end{array}$ & $\begin{array}{l}243.6 \\
274.5\end{array}$ & 457.5 & 2.10 & 110.5 & 241.5 \\
\hline $3 b$ & $9 / 28 / 88$ & 444.7 & 3.10 & 122.2 & 274.8 & & & & \\
\hline $3 c$ & $9 / 28 / 88$ & 443.9 & 3.10 & 124.9 & 281.4 & 445.3 & 3.10 & 123.3 & 276.9 \\
\hline $4 a$ & $9 / 28 / 88$ & 439.2 & 4.11 & 138.2 & 314.7 & & & & \\
\hline $4 b$ & $9 / 28 / 88$ & 438.9 & 4.11 & 139.1 & 316.9 & & & & \\
\hline $4 c$ & $9 / 28 / 88$ & 438.6 & 4.11 & 137.1 & 312.6 & 438.9 & 4.11 & 138.3 & 314.7 \\
\hline $5 a$ & $9 / 28 / 88$ & 442.2 & 5.17 & 151.1 & 341.7 & & & & \\
\hline $5 b$ & $9 / 28 / 88$ & 443.0 & 5.18 & 150.0 & 338.6 & & & & \\
\hline 5 & $9 / 28 / 88$ & 443.3 & 5.18 & 151.8 & 342.5 & 442.8 & 5.18 & 151.0 & 340.9 \\
\hline $6 a$ & $9 / 28 / 88$ & 447.6 & 6.17 & 154.6 & 345.4 & & & & \\
\hline $6 b$ & $9 / 28 / 88$ & 448.2 & 6.17 & 154.3 & 344.3 & & & & \\
\hline & $9 / 28 / 88$ & 452.5 & 6.21 & 152.8 & 337.7 & 449.4 & 6.18 & 153.9 & 342.5 \\
\hline $7 a$ & $9 / 28 / 88$ & 446.8 & 7.14 & 161.5 & 361.4 & & & & \\
\hline $7 b$ & $9 / 28 / 88$ & 448.4 & 7.15 & 161.5 & 360.2 & & & & \\
\hline 7c & $9 / 28 / 88$ & 450.1 & 7.17 & 161.8 & 359.5 & 448.4 & 7.15 & 161.6 & 360.4 \\
\hline $8 a$ & $9 / 28 / 88$ & 452.2 & 8.24 & 166.0 & 367.1 & & & & \\
\hline $8 b$ & $9 / 28 / 88$ & 452.2 & 8.24 & & & & & & \\
\hline $8 c$ & $9 / 28 / 88$ & 451.8 & 8.24 & 167.8 & 371.4 & 452.1 & 8.24 & 167.3 & 370.1 \\
\hline $1 \mathrm{a}$ & $10 / 05 / 88$ & 202.5 & 2.08 & 67.8 & 334.8 & & & & \\
\hline $1 \mathrm{~b}$ & $10 / 05 / 88$ & 202.0 & 2.08 & 67.2 & 332.5 & & & & \\
\hline 1c & $10 / 05 / 88$ & 201.0 & 2.08 & 70.9 & 352.7 & 201.8 & 2.08 & 68.7 & 340.0 \\
\hline $2 a$ & $10 / 05 / 88$ & 210.0 & 0.99 & 51.2 & & & & & \\
\hline 28 & $10 / 05 / 88$ & 211.2 & 0.99 & 50.2 & 237.6 & & & & \\
\hline 2 & $10 /($ & 210.7 & 0.99 & 51.7 & & 210.6 & 0.99 & 51.0 & 212.4 \\
\hline 3 & 101 & 216.6 & 4.14 & 98.1 & 452.8 & & & & \\
\hline $3 b$ & $10 /($ & 216 & 4.14 & & & & & & \\
\hline $3 c$ & $10 / 0$ & 214.7 & 4.13 & 96.5 & 449.3 & 215.8 & 4.14 & 97.6 & 452.2 \\
\hline 1 & $10 / 10$ & 208.1 & 0.99 & 52.6 & 252.8 & & & & \\
\hline ib & & 208.0 & 0.99 & & & & & & \\
\hline 1c & $10 / 10 / 88$ & 208.7 & 0.99 & 52.8 & 252.9 & 208.3 & 0.99 & 51.9 & 219.2 \\
\hline 1 & & 161.7 & 1.02 & 48 & 299.9 & 161.7 & 1.02 & 48.5 & 299.9 \\
\hline & & 504. & 1.02 & 105 & & & & & \\
\hline & & 506. & 1.02 & 108. & 213. & & & & \\
\hline
\end{tabular}


Table A5.3 (continued)

Average values

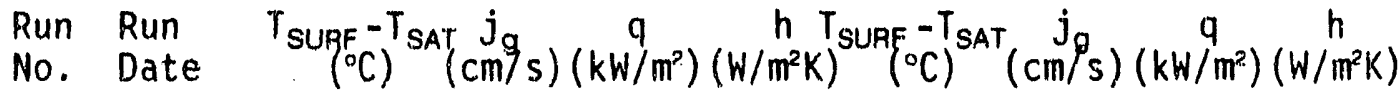

le $10 / 13 / 88$

2a $10 / 13 / 88$

2b $10 / 13 / 88$

2c $10 / 13 / 88$

3c $10 / 13 / 88$

3d $10 / 13 / 88$

3e $10 / 13 / 88$

4a $10 / 13 / 88$

4 b $10 / 13 / 88$

4c $10 / 13 / 88$

5a $10 / 13 / 88$

5b $10 / 13 / 88$

5c $10 / 13 / 88$

6a $10 / 13 / 88$

6b $10 / 13 / 88$

6c $10 / 13 / 88$

7 a $10 / 13 / 88$

7 b $10 / 13 / 88$

7c $10 / 13 / 88$

8a $10 / 13 / 88$

8c $10 / 13 / 88$

8d $10 / 13 / 88$

$1 \quad 10 / 19 / 88$

la $10 / 19 / 88$

ib $10 / 19 / 88$

ic $10 / 19 / 88$

2a $10 / 19 / 88$

2b $10 / 19 / 88$

2c $10 / 19 / 88$

3a $10 / 19 / 88$

3b $10 / 19 / 88$

3c $10 / 19 / 88$

4a $10 / 19 / 88$

4b $10 / 19 / 88$

$\begin{array}{llllllll}506.5 & 1.02 & 108.3 & 213.8 & 505.9 & 1.02 & 107.1 & 211.7 \\ 503.5 & 2.04 & 117.4 & 233.2 & & & & \\ 501.5 & 2.04 & 116.4 & 232.1 & & & & \\ 499.2 & 2.03 & 117.6 & 235.6 & 501.4 & 2.04 & 117.1 & 233.6 \\ 497.2 & 3.05 & 144.4 & 290.4 & & & & \\ 498.3 & 3.05 & 144.1 & 289.2 & & & & \\ 496.2 & 3.05 & 146.6 & 295.5 & 497.2 & 3.05 & 145.0 & 291.7 \\ 500.3 & 4.08 & 158.8 & 317.4 & & & & \\ 500.8 & 4.08 & 158.5 & 316.5 & & & & \\ 502.0 & 4.09 & 158.5 & 315.7 & 501.0 & 4.08 & 158.6 & 316.5 \\ 506.8 & 5.05 & 163.4 & 322.4 & & & & \\ 506.0 & 5.04 & 163.1 & 322.3 & & & & \\ 507.6 & 5.05 & 165.7 & 326.4 & 506.8 & 5.05 & 164.1 & 323.7 \\ 504.6 & 6.06 & 172.5 & 341.9 & & & & \\ 502.3 & 6.04 & 174.5 & 347.4 & & & & \\ 499.0 & 6.02 & 173.8 & 348.3 & 502.0 & 6.04 & 173.6 & 345.9 \\ 505.5 & 7.09 & 182.8 & 361.6 & & & & \\ 499.8 & 7.04 & 180.4 & 360.9 & & & & \\ 499.6 & 7.04 & 179.3 & 358.9 & 501.6 & 7.06 & 180.8 & 360.5 \\ 508.0 & 8.14 & 187.4 & 368.9 & & & & \\ 508.4 & 8.14 & 188.0 & 369.8 & & & & \\ 507.7 & 8.13 & 185.7 & 365.8 & 508.0 & 8.14 & 187.0 & 368.2 \\ 557.1 & 0.99 & 121.7 & 218.5 & 557.1 & 0.99 & 121.7 & 218.5 \\ 546.0 & 0.98 & 149.3 & 273.4 & & & & \\ 544.8 & 0.98 & 149.5 & 274.4 & & & & \\ 544.6 & 0.98 & 146.9 & 269.7 & 551.1 & 0.98 & 148.6 & 272.5 \\ 547.9 & 1.96 & 153.0 & 279.3 & & & & \\ 549.1 & 1.96 & 155.4 & 283.0 & & & & \\ 550.4 & 1.96 & 156.3 & 284.0 & 549.1 & 1.96 & 154.9 & 282.1 \\ 547.8 & 2.92 & 166.6 & 304.1 & & & & \\ 547.3 & 2.92 & 167.2 & 305.5 & & & & \\ 546.9 & 2.92 & 165.3 & 302.3 & 547.3 & 2.92 & 166.4 & 304.0 \\ 549.6 & 3.91 & 178.7 & 324.2 & & & & \\ 550.4 & 3.91 & 178.2 & 323.8 & & & & \end{array}$


Table A5.3 (continued)

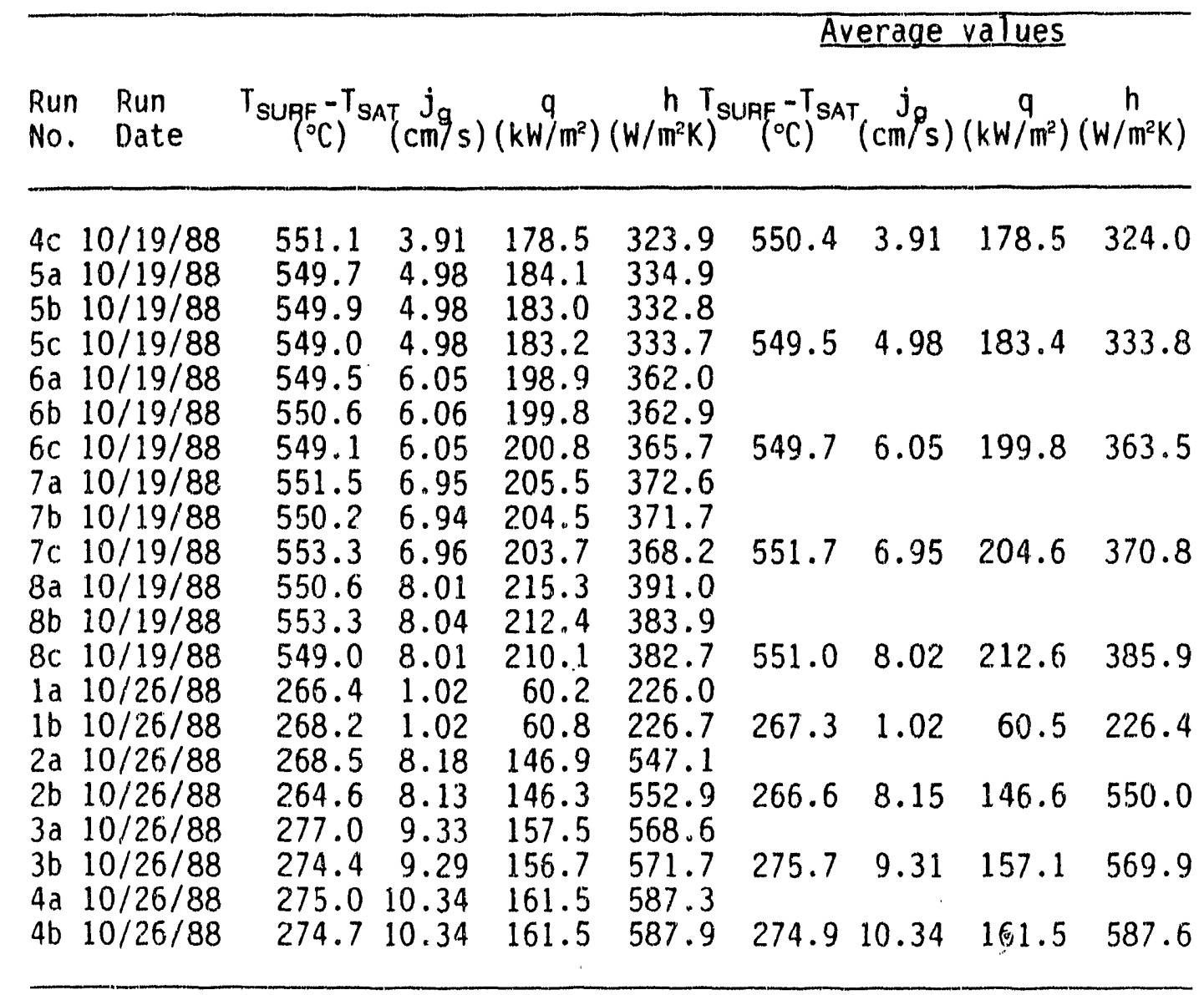




\section{APPENDIX A6: PHYSICAL PROPERTIES OF IMPORTANCE}

The properties used in this study were determined from the following relations. The relations shown were either developed specifically for this work, from existing data [or correlations of data], or developed by the source of the original data. The data sources follow the relations. All values are given at standard pressure, i.e., 1 atmosphere.

\section{Properties of $\mathrm{H}_{2} \mathrm{O}$}

Surface Tension, Liquid and its Vapor

$\sigma=58.91 \times 10^{-3}, \mathrm{~N} / \mathrm{m}$

[Range: $T=373.15 \mathrm{~K}$ ]

[Source: 10]

Density, Liquid at Saturation

$\rho_{\ell}=958.31, \mathrm{~kg} / \mathrm{m}^{3}$

[Range: $T=373.15 \mathrm{~K}$ ]

[Sources: $1,2,3,10$ ]

Comment: This is an average value from the available sources where the values vary less that $.04 \%$ among themselves.

Latent Heat of Vaporization

$h_{f g}=2257, \mathrm{~kJ} / \mathrm{kg}$

[Range: $T=373.15 \mathrm{~K}$ ]

[Sources: $1,2,3,9$ ]

Comnent: This is an average value from the available sources where values vary less than $0.01 \%$ among themselves.

Density, Vapor

$\rho_{f}=241.9 T_{f}^{-1.0145}, \mathrm{~kg} / \mathrm{m}^{3}$

[Range: $393.15 \mathrm{~K} \leq \mathrm{T}_{\mathrm{f}} \leq 1033.15 \mathrm{~K}$ ]

[Sources: $2,3,9$ ]

Comment: This is a relation based on three sources which have a maximum difference of approximately $0.5 \%$ among their data. The average relative difference of the given relation to the data is approximately $0.17 \%$.

Specific Heat, Vapor

$$
\begin{aligned}
& { }^{C} p_{f}=8142.69-37.369 T_{f}+7.4874 \times 10^{-2} T_{f}^{2}-4.959 \times 10^{-5} T_{f}^{3}{ }^{3} \mathrm{~J} / \mathrm{kgK} \\
& \text { [Range: } 377.59 \mathrm{~K} \leq T_{1} \leq 533.15 \mathrm{~K} \text { ] }
\end{aligned}
$$

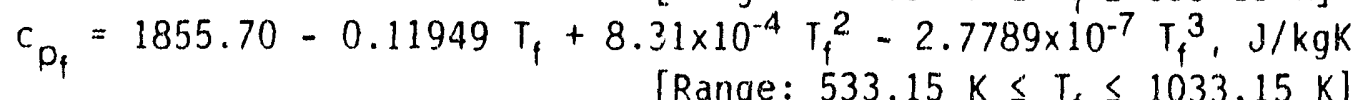


Comment: These relations are based on an average database which is tabulated in the given data source, from ten different data sources. The variation among the ten data sources has a relative difference of $0.46 \%$ and the relations given here differ from that average database by a relative difference of less than $0.1 \%$.

Thermal Conductivity, Vapor

$k_{f}=7.6255 \times 10^{-3}-1.050131 \times 10^{-5} T_{f}+1.78623 \times 10^{-7} T_{f}^{2}-8.90 \times 10^{-11} T_{f}^{3}, \mathrm{~W} / \mathrm{m} \cdot \mathrm{K}$

[Range: $280 \mathrm{~K} \leq \mathrm{T}_{f} \leq 900 \mathrm{~K}$ ]

[Source: 5]

Comment: This relation is based on an average database from ten data sources. Touloukian (1970) estimates the accuracy of the database to be within $2 \%$ for the range, $320 \mathrm{~K} \leq T \leq 700 \mathrm{~K}$, and within $5 \%$ for the ranges, $280 \mathrm{~K} \leq \mathrm{T} \leq 310 \mathrm{~K}$ and $710 \mathrm{~K} \leq T \leq 900 \mathrm{~K}$, of the true values. Pressure effects must be taken into account for better accuracies. The average relative difference between the value produced by the given relation and the database is $0.35 \%$.

Dynamic Viscosity, Vapor

$\mu_{f}=\left(-30.8+0.407 \mathrm{~T}_{f}\right) \times 10^{-7}, \mathrm{Ns} / \mathrm{sn}^{2}$

[Range: $280 \mathrm{~K} \leq \mathrm{T}_{\mathrm{f}} \leq 1000 \mathrm{~K}$ ]

[Source: 6]

Comment: This equation was recommended by a panel charged by the Sixth International Conference on the Properties of Steam to produce new tables on transport properties. The equation's accuracy is given to be: $\pm 1 \%$ in the range $373 \mathrm{~K} \leq T \leq 573 \mathrm{~K}$, and $\pm 3 \%$ in the range $573 \mathrm{~K} \leq \mathrm{T} \leq 973 \mathrm{~K}$.

\section{Properties of Stainless Stee1}

Normal Total Emittance, Types 304 and 321 Stainless Steel

$\begin{array}{ll}\epsilon_{\text {ss }}=1.5 \times 10^{-5} \mathrm{~T}_{\mathrm{ss}}^{1.427} & \text { [Range: } 400 \mathrm{~K} \leq \mathrm{T}_{\mathrm{ss}} \leq 1000 \mathrm{~K} \text { ] } \\ & \text { [Source: 7] }\end{array}$

Comment: This relation is based on four databases, two each on type 304 and 321 stainless steels, given in the source. Type 321 stainless steel was added to the databases because of the small amount data for type 304 and its very similar chemical and thermal characteristics. The databases were for cleaned, polished to machined surfaces as is the case for this study. Even so, for surface temperatures above $1000 \mathrm{~K}$ oxidation was suspected, although precautions were taken to minimize that possibility. The scatter in the data is large and the average relative difference between values produced by the given relation and the data is $30 \%$. 
Thermal Conductivity. Type 304 Stainless Steel

$\mathrm{k}_{\mathrm{sS}}=11.371+.01422 \mathrm{~T}_{\text {ss }} \mathrm{W} / \mathrm{mK}$

[Range: $373.2 \mathrm{~K} \leq \mathrm{T}_{\mathrm{ss}} \leq 1008.0 \mathrm{~K}$ ]

[Source: 8]

Comment: This is a relation based on five databases showr in the source for stainless steel. The average relative difference between the values produced by this relation and the data is $0.5 \%$.

\section{Data Sources for the Properties}

1. Dorsey, N. E., Properties of Ordinary WATER-SUBSTANCE, Hafner Publ. Company, New York, p.612 (1968).

2. Keenan, J. H., F. G. Keyes, P. G. Hill, and J. G. Moore, Steam Tables, Wiley, New York (1969).

3. Raznjevic, K., Handbook of Thermodynamic Tables and Charts, Hemisphere Publ. Corp., Washington, p.156 (1976).

4. Touloukian, Y.S. and T. Makita, Thermophysical Properties of Matter, Volume 6: Specific Heat - Nonmetallic Liquids and Gases, IP/Plenum, New York, p.105 (1970).

5. Touloukian, Y. S., P. E. Liley, and S. C. Saxena, Thermophysical Properties of Matter, Volume 3: Thermal Conductivity - Nonmatallic Liquids and Gases, IP/Plenum, New York, p.125 (1970).

6. Touloukian, Y. S., S. C. Saxena, and P. Hestermans, Thermophysical Properties of Matter, Volume 11: Viscosity, IP/Plenum, New York, p.96 (1975).

7. Touloukian, Y. S. and D. P. DeWitt, Thermophysical Properties of Matter, Volume 7: Thermal Radiative Properties - Metallic Elements and Alloys, IP/Plenum, New York, p.1210 (1970).

8. Touloukian, Y. S., Thermophysical Properties of Matter, Volume 1: Thermal Conductivity - Metallic Elements and Alloys, IP/Plenum, New York, p.1161 (1970).

9. Thermodynamic and Transport Properties of Steam, $3^{\text {rd }}$ ed., The American Society of Mechanical Engineers, New York (1977).

10. Vargaftik, N. B., Thermophysical Properties of Liquids and Gases (in Normal and Dissociated States), 2nd. ed., Hemisphere Publ. Company, Washington, p.43 (1975) . 


\section{APPENDIX A7: FILM BOILING WITH AND WITHOUT GAS FLUX ENHANCEMENT}

Shown here is an example of why it is important to take into account the enhancement to the heat flux in film boiling by gas jetting from the surface. A recent study (Blose et al., 1987) was made to better understand the simultaneous interactions of multen stainless steel with concrete and with an overlying water pool. The effect of the molten pool on the concrete was to liberate quantities of non-condensible gases, locked within the concrete, which then bubbled through the molten steel pool to the overlying water pool. From measurements taken, over the approximate 40 minute duration of the experimental run with water present, the heat flux to the water pool was approximately 800 $\mathrm{kW} / \mathrm{m}^{2}$ and the superficial gas velocity was approximately $20 \mathrm{~cm} / \mathrm{s}$. The superficial gas velocity is based on the surface area of the molten steel pool, i.e., $366.4 \mathrm{~cm}^{2}$. Furthermore, an inspection after the experiment determined that a thick porous solid crust of steel was present between the molten steel pool and the water during the run. For future phenomenological modeling the experimenters needed to know what heat transfer mechanisil, nucleate or filin boiling, existed between the steel and the water pool.

The high temperatures of the steel pool $\left[T_{\text {pool }}>1700 \mathrm{~K}\right.$; the approximate melting temperature of 304 stainless steel] prevented temperature measurements within the molten pool itself. Not knowing the surface temperature of the stainless steel crust forced the experimenters to deterinine the heat transfer mechanisin indirectly by backtracking through various nucleate and filin boiling models. They neglected both the effects of the gas jetting and subcooling [the water pool was approximately $50 \mathrm{~K}$ below the saturation temperature at approximately atinospheric pressure] and arrived at the following result for film boiling:

with

$$
q_{\text {TOTAL }}=\left(q^{4} \text { CONDUCtION } / q_{\text {TOTAL }}\right)^{1 / 3}+q_{\text {RADIATION }}
$$

where

$$
q_{\text {COND }}=h_{\text {BERENSON }} \Delta T_{\text {SAT }}=.425\left[k_{f}^{3} g \rho_{f}\left(\rho_{\ell}-\rho_{f}\right) h_{f g}{ }^{\prime} / \mu_{f} D_{\ell}\right]^{1: 4} \Delta T_{S A T}^{3 / 4}
$$


and

$$
\begin{gathered}
q_{R A D}=h_{R A D} \Delta T_{S A T}=\sigma_{S B}\left[1 / \epsilon_{S S}+1 / \epsilon_{\ell}-1\right]^{-1}\left(T_{S U R F}{ }^{4}-T_{S A T}{ }^{4}\right) \\
{\left[\sigma_{S B}=5.6697 \times 10^{-8} \mathrm{~W} / \mathrm{m}^{2} \mathrm{~K}^{4} ; \text { the Stefan-Boltzmann constant }\right]}
\end{gathered}
$$

then using the measured heat flux: qTOTAL $\sim 800 \mathrm{~kW} / \mathrm{m}^{2}$

results in,

$$
T_{\text {SURF }} \sim 1810 \mathrm{~K}
$$

[The properties at $T_{\text {FILM }}=\left(T_{\text {SUAF }}+T_{\text {SAT }}\right) / 2 \sim 1092 \mathrm{~K}$ are: $k_{f} \sim 0.093 \mathrm{~W} / \mathrm{mK}$, $\sigma \sim 5.89 \times 10^{-2} \mathrm{~N} / \mathrm{m}, \quad \rho_{f} \sim 0.20 \mathrm{~kg} / \mathrm{m}^{3}, \quad \rho_{\ell} \sim 958.3 \mathrm{~kg} / \mathrm{m}^{3}, \quad h_{\mathrm{fg}} \sim 2257 \mathrm{~kJ} / \mathrm{kg}$, $c_{p_{f}} \sim 2.35 \mathrm{~kJ} / \mathrm{kgK}, \mu_{f} \sim 4.14 \times 10^{-5} \mathrm{~kg} / \mathrm{ms}$, further Blose et al. (1987) assumed $\epsilon_{S S}$ $=1$ and $\left.\epsilon_{\ell}=1.\right]$

Since the calculated TSURF was above the melting temperature of stainless steel, i.e., $1700 \mathrm{~K}$, the solid steel crust observed by Blose et al. (1987) would not have been possible in the presence of film boiling. They concluded that nucleate boiling was occurring at the steel water interface during the experiment.

From the results of the present study another conclusion is possible if the effect of the gas flux enirancement to heat transfer in film boiling is taken into account. The following calculation shows what the steel crust surface temperature would be when including the gas flux enhancement effect.

Froin Equation III.22,

$$
q_{\text {COND }}=\left(1+\beta_{i} j_{g} / \beta_{11}\right)^{1 / 4} q_{C O N D}\left(j_{g}=0\right)
$$

where $\beta_{\|}=(.425)^{4}$ and $\beta_{1}=0.068(\mathrm{~cm} / \mathrm{s})^{-1}$ [from the Results section] 
Substituting $q_{\text {COND }}$ of Equation A7.2 for the $q_{\text {COND }}$ in Equation A7.1 then for $j_{g}=20 \mathrm{~cm} / \mathrm{s}$ the resulting surface temperature is:

$$
T_{\text {SURF }} \sim 1515 \mathrm{~K}
$$

[The properties at $T_{\text {FILM }}=\left(T_{\text {SUPF }}+T_{\text {SAT }}\right) / 2 \sim 945 \mathrm{~K}$ are: $\mathrm{k}_{f} \sim 0.082 \mathrm{~W} / \mathrm{mK}_{1}, \rho_{f} \sim 0.23$ $\mathrm{kg} / \mathrm{m}^{3}, c_{p_{f}} \sim 2.25 \mathrm{~kJ} / \mathrm{kgK}, \mu_{\mathrm{f}} \sim 3.54 \times 10^{-5} \mathrm{~kg} / \mathrm{ms}$, while $\sigma, \rho_{\ell}, h_{\mathrm{fg}}, \epsilon_{\mathrm{Ss}}$ and $\epsilon_{\ell}$ remain the same as before.]

This new surface temperature is approximately $200 \mathrm{~K}$ less than the melting temperature of stainless steel, therefore, a solid crust between the molten steel pool and the overlying pool of water would have been possible. From this result it can be concluded that film boiling could have occurred over the steel crust. Moreover, if the heat transfer caused by the $50 \mathrm{~K}$ subcooling were included into the above analysis the crust surface temperature would have to be even lower than $1515 \mathrm{~K}$, giving further evidence that film boiling probably was present on the crust surface.

It must be noted that the present investigation was made for superficial gas velocities up to a maximum of $10 \mathrm{~cm} / \mathrm{s}$. Therefore, using the results of this investigation to determine $T_{\text {SUPF }}$ at $j_{g}=20 \mathrm{~cm} / \mathrm{s}$ may not be valid. 

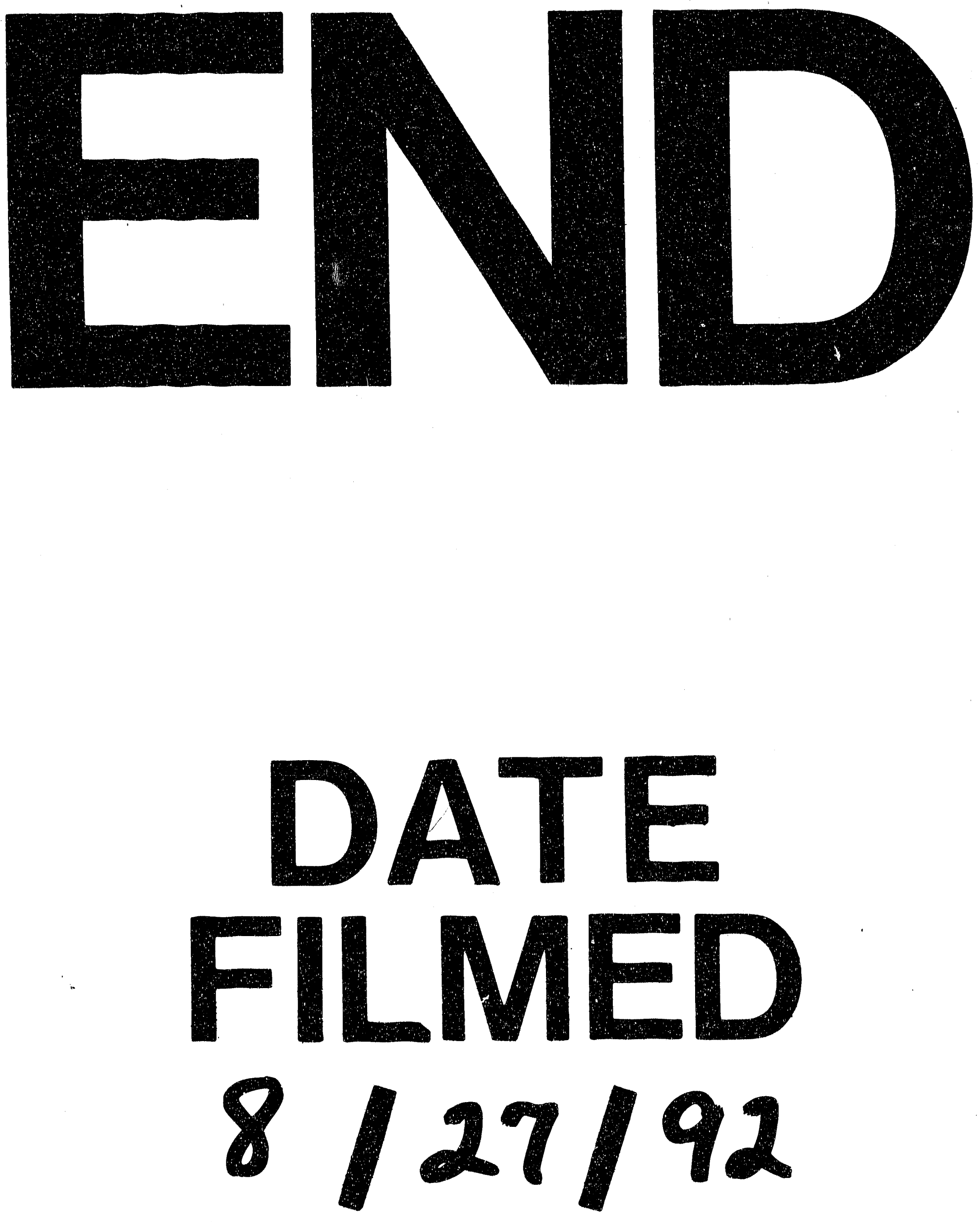